\title{
Living ROMP Syntheses and Redox Properties of Triblock Metallocopolymer \\ Redox Cascades
}

\author{
Haibin Gu, ${ }^{[\mathrm{a}, \mathrm{b}]}$ Roberto Ciganda, ${ }^{[\mathrm{b}]}$ Patricia Castel, ${ }^{[\mathrm{b}]}$ Jaime Ruiz, $^{[\mathrm{b}]}$ Didier Astruc ${ }^{[\mathrm{b}]}{ }_{*}$ \\ ${ }^{\mathrm{a}}$ Key Laboratory of Leather Chemistry and Engineering of Ministry of Education, Sichuan \\ University, Chengdu 610065, P. R. China \\ bISM, UMR CNRS $\mathrm{N}^{\mathrm{o}}$ 5255, Univ. Bordeaux, 33405 Talence Cedex, France. Email : \\ d.astruc@ism.u-bordeauxl.fr
}

\section{Supplementary information}

1. General data

2. Synthesis and kinetic study of the ROMP of monomer $\mathbf{2}$

Synthesis

Kinetic study of the ROMP of 2

${ }^{1} \mathrm{H}$ NMR spectrum of 2 in $\mathrm{CDCl}_{3}$ (Figure S1)

${ }^{13} \mathrm{C}$ NMR spectrum of 2 in $\mathrm{CDCl}_{3}$ (Figure S2)

ESI mass spectrum of 2 (Figure S3)

IR spectrum of 2 (Figure S4)

${ }^{1} \mathrm{H}$ NMR spectrum of homopolymer of $\mathbf{2}$ in $\mathrm{CD}_{2} \mathrm{Cl}_{2}$ (Figure S5) S9

${ }^{1} \mathrm{H}$ NMR spectrum of homopolymer of 2 in DMSO- $d_{6}$ (Figure S6) S9

${ }^{1} \mathrm{H}$ NMR spectrum in $\mathrm{CDCl}_{3}$ of the ROMP reaction mixture of 2 after 10 minutes $\mathrm{S} 10$ stirring (Figure S7)

${ }^{1} \mathrm{H}$ NMR spectrum in $\mathrm{CDCl}_{3}$ of the precipitate from the ROMP reaction mixture $\mathrm{S} 10$ of 2 after 10 minutes stirring (Figure S8)

${ }^{1} \mathrm{H}$ NMR spectrum in $\mathrm{CDCl}_{3}$ of products in filtrate and washing-liquors from the $\mathrm{S} 11$

ROMP reaction mixture of 2 after 10 minutes stirring (Figure S9)

3. Synthesis and kinetic study of the ROMP of monomer $\mathbf{3}$

Synthesis

Kinetic study of the ROMP of 3

${ }^{1} \mathrm{H}$ NMR spectrum of $\mathbf{3}$ in $\mathrm{CDCl}_{3}$ (Figure $\mathrm{S} 10$ )

${ }^{1} \mathrm{H}$ NMR spectrum of 3 in $\mathrm{CD}_{2} \mathrm{Cl}_{2}$ (Figure $\mathrm{S} 11$ )

${ }^{13} \mathrm{C}$ NMR spectrum of 3 in $\mathrm{CDCl}_{3}$ (Figure $\mathrm{S} 12$ )

ESI mass spectrum of $\mathbf{3}$ (Figure S13)

IR spectrum of $\mathbf{3}$ (Figure S14)

${ }^{1} \mathrm{H}$ NMR spectrum of homopolymer of $\mathbf{3}$ in $\mathrm{CD}_{2} \mathrm{Cl}_{2}$ (Figure S15) $\mathrm{S} 15$

${ }^{1} \mathrm{H}$ NMR spectrum of homopolymer of $\mathbf{3}$ in DMSO- $d_{6}$ (Figure S16) S16

${ }^{1} \mathrm{H}$ NMR spectrum in $\mathrm{CDCl}_{3}$ of the ROMP reaction mixture of $\mathbf{3}$ after 5 minutes $\mathrm{S} 16$ stirring (Figure S17)

${ }^{1} \mathrm{H}$ NMR spectrum in $\mathrm{CDCl}_{3}$ of the precipitate from the ROMP reaction mixture 
of monomer 3 after 5 minutes stirring (Figure S18)

${ }^{1} \mathrm{H}$ NMR spectrum in $\mathrm{CDCl}_{3}$ of products in filtrate and washing-liquors from the $\mathrm{S} 17$ ROMP reaction mixture of monomer 3 after 5 minutes stirring (Figure S19)

${ }^{1} \mathrm{H}$ NMR spectrum in $\mathrm{CDCl}_{3}$ of the ROMP reaction mixture of monomer 3 after $\mathrm{S} 18$ 10 minutes stirring (Figure S20)

${ }^{1} \mathrm{H}$ NMR spectrum in $\mathrm{CDCl}_{3}$ of the products in filtrate and washing liquors from the ROMP reaction mixture of monomer 3 after 15 minutes stirring (Figure S21)

4. Synthesis and kinetic study of the ROMP of monomer 4

Synthesis

Kinetic study of the ROMP of 4

$\begin{array}{lr}{ }^{1} \mathrm{H} \text { NMR spectrum of } \mathbf{4} \text { in acetone- } d_{6} \text { (Figure S22) S20 } & \text { S20 }\end{array}$

${ }^{1} \mathrm{H}$ NMR spectrum of $\mathbf{4}$ in $\mathrm{CD}_{2} \mathrm{Cl}_{2}$ (Figure S23) $\quad$ S20

${ }^{13} \mathrm{C}$ NMR spectrum of $\mathbf{4}$ in acetone- $d_{6}$ (Figure S24) $\quad$ S21

$\begin{array}{ll}\text { ESI mass spectrum of } \mathbf{4} \text { (Figure S25) } & \text { S21 }\end{array}$

$\begin{array}{ll}\text { IR spectrum of } 4 \text { (Figure S26) } & \text { S22 }\end{array}$

${ }^{1} \mathrm{H}$ NMR spectrum in acetone- $d_{6}$ of products in filtrate and washing-liquors from $\quad$ S22 the ROMP reaction mixture of monomer 4 after 10 minutes stirring (Figure S27) ${ }^{1} \mathrm{H}$ NMR spectrum in acetone- $d_{6}$ of products in filtrate and washing-liquors from the ROMP reaction mixture of monomer 4 after 20 minutes stirring (Figure S28) ${ }^{1} \mathrm{H}$ NMR spectrum in acetone- $d_{6}$ of products in filtrate and washing-liquors from the ROMP reaction mixture of monomer 4 after 30 minutes stirring (Figure S29)

5. Diblock copolymer 6

Synthesis

Kinetic study

$\begin{array}{lr}{ }^{1} \mathrm{H} \text { NMR spectrum of } 6 \text { in DMSO- } d_{6} \text { (Figure S30) } & \text { S25 }\end{array}$

$\begin{array}{ll}{ }^{1} \mathrm{H} \text { NMR spectrum of } \mathbf{6} \text { in } \mathrm{CD}_{2} \mathrm{Cl}_{2} \text { (Figure S31) } & \mathrm{S} 25\end{array}$

${ }^{13} \mathrm{C}$ NMR spectrum of 6 in $\mathrm{CD}_{2} \mathrm{Cl}_{2}$ (Figure S32) $\quad$ S26

$\begin{array}{ll}\text { IR spectrum of } 6 \text { (Figure S33) } & \text { S26 }\end{array}$

$\begin{array}{ll}\text { UV-Vis spectrum of } \mathbf{6} \text { in } \mathrm{CH}_{2} \mathrm{Cl}_{2} \text { (Figure S34) } & \mathrm{S} 27\end{array}$

$\begin{array}{ll}\text { MALDI-TOF MS spectrum of } 6 \text { (Figure S35) } & \text { S27 }\end{array}$

${ }^{1} \mathrm{H}$ NMR spectrum in $\mathrm{CD}_{2} \mathrm{Cl}_{2}$ of the precipitate from the ROMP reaction mixture $\mathrm{S} 28$

for the synthesis of $\mathbf{6}$ after the addition of monomer $\mathbf{4}$ with 20 minutes stirring (Figure S36)

${ }^{1} \mathrm{H}$ NMR spectrum in acetone- $d_{6}$ of the products in washing liquors and filtrate $\quad$ S28 from the ROMP reaction mixture for the synthesis of $\mathbf{6}$ after the addition of monomer 4 with 20 minutes stirring (Figure S37)

$n_{\mathrm{p} 2}$ of the first $\mathrm{Fc}^{*}$ block using the ${ }^{1} \mathrm{H}$ NMR spectrum in $\mathrm{CD}_{2} \mathrm{Cl}_{2}$ of homopolymer of 2 (Table S1)

$\begin{array}{lr}\text { Polymer degree of the second CcX block of } 6 \text { (Table S2) } & \text { S29 }\end{array}$

$\begin{array}{ll}\text { Redox potentials and reversibility data of } 6 \text { (Table S3) } & \text { S30 }\end{array}$

Calculation of $n_{\mathrm{p} 3}$ by Bard-Anson's method of 6 (Table S4) S30

6. Triblock copolymer 7

$\begin{array}{ll}\text { Synthesis } & \text { S32 }\end{array}$

$\begin{array}{ll}\text { Kinetic study } & \text { S32 }\end{array}$ 
${ }^{1} \mathrm{H}$ NMR spectrum of 7 in DMSO- $d_{6}$ (Figure S38) $\quad$ S33

$\begin{array}{ll}{ }^{1} \mathrm{H} \text { NMR spectrum of } 7 \text { in } \mathrm{CD}_{2} \mathrm{Cl}_{2} \text { (Figure S39) } & \text { S33 }\end{array}$

$\begin{array}{lr}\left.{ }^{13} \mathrm{C} \text { NMR spectrum of } 7 \text { in } \mathrm{CD}_{2} \mathrm{Cl}_{2} \text { (Figure } \mathrm{S} 40\right) & \mathrm{S} 34\end{array}$

$\begin{array}{ll}\text { IR spectrum of } 7 \text { (Figure S41) } & \text { S34 }\end{array}$

MALDI-TOF MS spectrum of 7 (Figure S42) $\quad$ S35

${ }^{1} \mathrm{H}$ NMR spectrum in $\mathrm{CD}_{2} \mathrm{Cl}_{2}$ of the precipitate from the ROMP reaction mixture $\quad \mathrm{S} 36$ for the synthesis of 7 after the addition of monomer 3 with 2 hrs stirring (Figure S43)

${ }^{1} \mathrm{H}$ NMR spectrum in $\mathrm{CDCl}_{3}$ of the products in washing liquors and filtrate from $\mathrm{S} 36$ the ROMP reaction mixture for the synthesis of 7 after the addition of monomer 3 with 2 hrs stirring (Figure S44)

$n_{\mathrm{p} 2}$ of the the second CcX block using the ${ }^{1} \mathrm{H}$ NMR spectrum in DMSO- $d_{6}$ of homopolymer of 7 (Table S5)

$n_{\mathrm{p} 2}$ of the the third Fc block using the ${ }^{1} \mathrm{H}$ NMR spectrum in DMSO- $d_{6}$ of

homopolymer of 7 (Table S6)

Redox potentials and reversibility data of 7 (Table S7)

S38

Calculation of $n_{\mathrm{p} 3}$ by Bard-Anson's method of 7 (Table S8)

7. Diblock copolymer 8

Synthesis

Kinetic study

S40

${ }^{1} \mathrm{H}$ NMR spectrum of 8 in $\mathrm{CDCl}_{3}$ (Figure $\mathrm{S} 45$ )

S41

${ }^{1} \mathrm{H}$ NMR spectrum of 8 in $\mathrm{CD}_{2} \mathrm{Cl}_{2}$ (Figure S46)

${ }^{13} \mathrm{C}$ NMR spectrum of 8 in $\mathrm{CDCl}_{3}$ (Figure S47) $\quad \mathrm{S} 42$

IR spectrum of 8 (Figure S48) $\quad$ S42

$\mathrm{UV}$-Vis spectrum of $\mathbf{8}$ in $\mathrm{CH}_{2} \mathrm{Cl}_{2}$ (Figure S49) $\quad \mathrm{S} 43$

SEC curve of 8 (Figure S50) $\quad$ S43

MALDI-TOF MS spectrum of 8 (Figure S51) S44

${ }^{1} \mathrm{H}$ NMR spectrum in $\mathrm{CDCl}_{3}$ of the ROMP reaction mixture for the synthesis of $\quad \mathrm{S} 45$

8 after the addition of monomer 3 with 15 minutes stirring (Figure S52)

$n_{\mathrm{p} 2}$ of the second Fc block using the ${ }^{1} \mathrm{H}$ NMR spectrum in $\mathrm{CD}_{2} \mathrm{Cl}_{2}$ of $\mathbf{8}$ (Table S9) $\mathrm{S} 45$

Redox potentials and reversibility data of 8 (Table S10) $\quad$ S46

Calculation of $n_{\mathrm{p} 3}$ by Bard-Anson's method of 8 (Table S11) S46

8. Triblock copolymer 9

$\begin{array}{ll}\text { Synthesis } & \text { S47 }\end{array}$

Kinetic study $\quad$ S47

${ }^{1} \mathrm{H}$ NMR spectrum of 9 in DMSO- $d_{6}$ (Figure S53)

${ }^{1} \mathrm{H}$ NMR spectrum of 9 in $\mathrm{CD}_{2} \mathrm{Cl}_{2}$ (Figure S54) $\quad \mathrm{S} 48$

${ }^{13} \mathrm{C}$ NMR spectrum of 9 in $\mathrm{CD}_{2} \mathrm{Cl}_{2}$ (Figure S55) $\quad \mathrm{S} 49$

${ }^{13} \mathrm{C}$ NMR spectrum of 9 in DMSO- $d_{6}$ (Figure S56) $\quad$ S49

IR spectrum of 9 (Figure S57) $\quad$ S50

UV-Vis spectrum of 9 in $\mathrm{CH}_{2} \mathrm{Cl}_{2}$ (Figure S58) $\quad \mathrm{S} 50$

MALDI-TOF MS spectrum of 9 (Figure S59) $\quad$ S51

${ }^{1} \mathrm{H}$ NMR spectrum in $\mathrm{CD}_{2} \mathrm{Cl}_{2}$ of the precipitate from the ROMP reaction mixture $\quad \mathrm{S} 52$ for the synthesis of $\mathbf{9}$ after the addition of monomer $\mathbf{4}$ with overnight stirring 
(Figure S60)

${ }^{1} \mathrm{H}$ NMR spectrum in $\mathrm{CDCl}_{3}$ of the products in washing liquors and filtrate from the ROMP reaction mixture for the synthesis of 9 after the addition of monomer 4 with overnight stirring (Figure S61)

$n_{\mathrm{p} 2}$ of the third CcX block using the ${ }^{1} \mathrm{H}$ NMR spectrum in DMSO- $d_{6}$ of 9

(Table S12)

Redox potentials and reversibility data of 9 (Table S13)

S53

Calculation of $n_{\mathrm{p} 3}$ by Bard-Anson's method of 9 (Table S14)

S54

9. References

S54 


\section{General data}

Cis-5-norbornene-exo-2,3-dicarboxylic anhydride (95\%, NDA), ethyl vinyl ether (99\%, EVE) and Grubbs $2^{\text {nd }}$ generation catalyst were purchased from Aldrich, and used directly. Grubbs $3^{\text {rd }}$ generation catalyst $\quad{ }^{\text {s1 }}{ }^{\text {chlorocarbonyl ferrocene }} \quad(\mathrm{FcCOCl}),{ }^{\mathrm{s} 2}$ $N$-[11'-amine-3',6',9'-trioxahendecyl]-cis-5-norbornene-exo-2,3-dicarboximide $\quad \mathbf{1 3}$, ${ }^{\mathrm{s} 2}$ Fc-containing monomer $3{ }^{\mathrm{s} 2}$ chlorocarbonyl pentamethylferrocene $(\mathrm{Fc} * \mathrm{COCl}),{ }^{\mathrm{s} 3} \mathrm{Fc}^{*}$-containing monomer 2, ${ }^{\mathrm{s} 3}$ chlorocarbonylcobaltocenium hexafluorophosphate $\left(\left[\mathrm{Co}\left(\eta^{5}-\mathrm{C}_{5} \mathrm{H}_{5}\right)\left(\eta^{5}-\mathrm{C}_{5} \mathrm{H}_{4} \mathrm{COCl}\right)\right]\left[\mathrm{PF}_{6}\right]\right) \quad{ }^{s}, \quad, \quad N$-(2-aminoethyl)-cis-5-norbornene-exo-2, 3 -dicarboximide $14,{ }^{\mathrm{s} 5}$ and the cationic organocobalt monomer $4^{\mathrm{s} 6}$ were prepared by the methods reported in the literatures. All the other chemicals were from commercial sources and used as received. All the solvents used were dried and freshly distilled.

${ }^{1} \mathrm{H}$ NMR (300, 400, $\left.600 \mathrm{MHz}\right)$ and ${ }^{13} \mathrm{C}$ NMR $(50,75,150 \mathrm{MHz})$ spectra were recorded at $25{ }^{\circ} \mathrm{C}$ with a Bruker AC $(200,300,400,600 \mathrm{MHz})$ spectrometers. All the chemical shifts are reported in parts per million ( $\delta, \mathrm{ppm})$ with reference to tetramethylsilane (TMS). Mass spectra were recorded using an Applied Biosystems Voyager-DE STR-MALDI-TOF spectrometer. The infrared spectra were recorded on an ATI Mattson Genesis series FT-IR spectrophotometer in the range $400-4000 \mathrm{~cm}^{-1}$. UV-visible absorption spectra were measured with a Perkin-Elmer Lambda 19 UV-vis. spectrometer.

Cyclic voltammetry (CV) measurements was recorded on a PAR 273 potentiostat under nitrogen atmosphere at $20{ }^{\circ} \mathrm{C}$ using dry dichloromethane $\left(\mathrm{CH}_{2} \mathrm{Cl}_{2}\right)$ or dimethylformamide (DMF) as solvent and $\left[n-\mathrm{Bu}_{4} \mathrm{~N}\right]\left[\mathrm{PF}_{6}\right] 0.1 \mathrm{M}$ as supporting electrolyte. The working and counter electrodes were $\mathrm{Pt}$, and the reference electrode was $\mathrm{Ag}$. The internal reference was $\left[\mathrm{FeCp}_{2}\right]\left(\mathrm{Cp}^{*}=\right.$ $\left.\eta^{5}-\mathrm{C}_{5} \mathrm{Me}_{5}\right)$, and the scan rate was $400 \mathrm{mV} \cdot \mathrm{s}^{-1}$. The Bard-Anson electrochemical method ${ }^{\mathrm{s} 7}$ was used to calculate the number of electrons involved in the reduction wave of the copolymers. The experiments were conducted by preparing a known amount of copolymer in dry $\mathrm{CH}_{2} \mathrm{Cl}_{2}$ or DMF, then a known amount of $\left[\mathrm{FeCp}_{2}{ }_{2}\right]$ in $\mathrm{CH}_{2} \mathrm{Cl}_{2}$ or DMF was added to the solution. After recording the $\mathrm{CV}$, the intensities of the oxidation waves of the copolymer and the internal reference $\left[\mathrm{FeCp}_{2}{ }_{2}\right]$ were measured. The values were introduced into the Bard-Anson equation ${ }^{\mathrm{s} 7}: \mathrm{n}_{\mathrm{p}}=$ $\left(i_{d p} / C_{p}\right) /\left(i_{d m} / C_{m}\right)\left(M_{p} / M_{m}\right)^{0.275}$ to provide the final number of transferred electrons $\left(n_{p}\right)$.

Size exclusion chromatography (SEC) measurements were carried out using the PL-GPC 50 plus Integrated GPC system from Polymer laboratories-Varian equipped with refractometric and UV detectors, column oven and integrated degasser. Columns from TOSOH: TSKgel TOSOH, HXL-L (guard column $6.0 \mathrm{~mm}$ ID $\times 4.0 \mathrm{~cm} \mathrm{~L}$ ), G4000HXL $(7.8 \mathrm{~mm} \mathrm{ID} \times 30.0 \mathrm{~cm} \mathrm{~L}$ ), G3000HXL $(7.8 \mathrm{~mm} \mathrm{ID} \times 30.0 \mathrm{~cm} \mathrm{~L})$, G2000HXL $(7.8 \mathrm{~mm} \mathrm{ID} \times 30.0 \mathrm{~cm} \mathrm{~L})$. Flow Marker: TCB (trichlorobenzene, $\mathrm{C}_{6} \mathrm{H}_{3} \mathrm{Cl}_{3}$ ), Flow: $1.0 \mathrm{ml} / \mathrm{min}$, Solvent: tetrahydrofuran (THF) from Aldrich, loop: $100 \mu \mathrm{l}$.

Abbreviations: $\mathrm{Cp}=\eta^{5}-\mathrm{C}_{5} \mathrm{H}_{4}$ - (monosubstituted cyclopentadienyl) or $\eta^{5}-\mathrm{C}_{5} \mathrm{H}_{5} ; \mathrm{Fc}=$ ferrocenyl, $\mathrm{FcH}=$ ferrocene, $\mathrm{Fc}^{*}=1,2,3,4,5$-pentamethylferrocenyl; $\mathrm{Fc}^{*} \mathrm{H}=$ pentamethylferrocene; $\mathrm{CcX}=\left[\mathrm{Co}\left(\eta^{5}-\mathrm{C}_{5} \mathrm{H}_{4}-\right)\left(\eta^{5}-\mathrm{C}_{5} \mathrm{H}_{5}\right)\right]\left[\mathrm{PF}_{6}\right] ; \mathrm{CcHX}=\left[\mathrm{Co}\left(\eta^{5}-\mathrm{C}_{5} \mathrm{H}_{5}\right)_{2}\right]\left[\mathrm{PF}_{6}\right]$. 


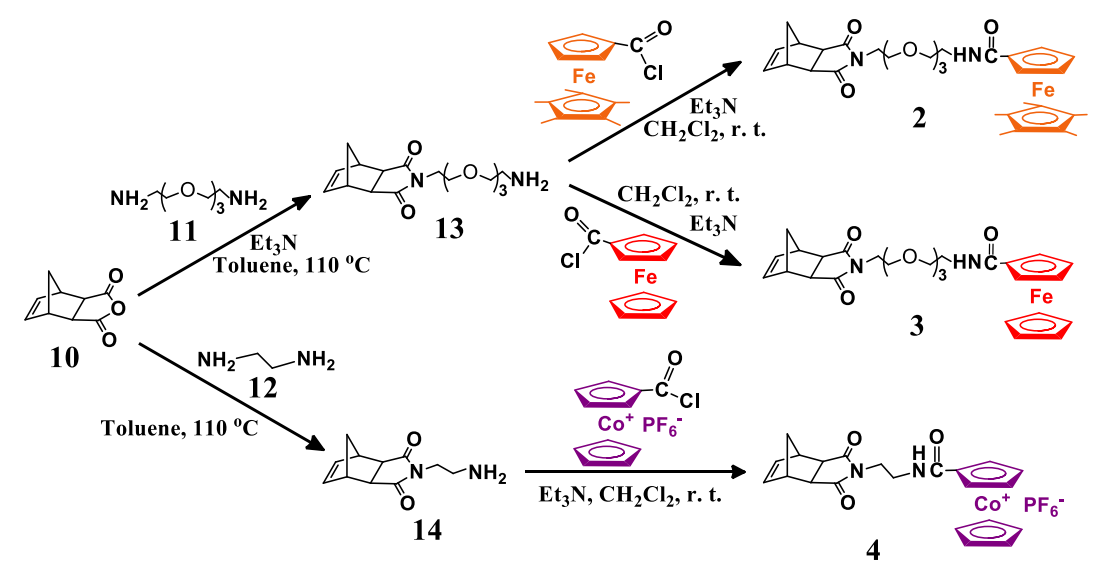

Scheme S1 Synthetic route to metal-containing monomers.

\section{Synthesis and kinetic study of the ROMP of monomer $2^{\mathrm{s} 3}$}

To a solution of pentamethylferrocene carboxylic acid $(0.27 \mathrm{~g}, 0.90 \mathrm{mmol})$ in dry $\mathrm{CH}_{2} \mathrm{Cl}_{2}(40$ $\mathrm{mL})$, oxalyl chloride $(0.40 \mathrm{~mL}, 4.5 \mathrm{mmol})$ was added dropwise at $0{ }^{\circ} \mathrm{C}$ under $\mathrm{N}_{2}$ atmosphere. Then, the mixture was stirred overnight at $20^{\circ} \mathrm{C}$ and dried in vacuo. The residual yellow-brown solid of crude chlorocarbonyl pentamethylferrocene was dissolved in dry $\mathrm{CH}_{2} \mathrm{Cl}_{2}(10 \mathrm{~mL})$ and added dropwise to a $\mathrm{CH}_{2} \mathrm{Cl}_{2}$ solution $(10 \mathrm{~mL})$ of $\mathbf{1 3}(0.20 \mathrm{~g}, 0.59 \mathrm{mmol})$ and triethylamine $(0.83$ $\mathrm{mL}, 5.9 \mathrm{mmol}$ ). The obtained mixture was stirred overnight at $20{ }^{\circ} \mathrm{C}$ under $\mathrm{N}_{2}$ atmosphere, then washed with $10 \% \mathrm{~K}_{2} \mathrm{CO}_{3}$ solution $(50 \mathrm{~mL})$ and distilled water $(2 \times 50 \mathrm{~mL})$. The collected organic solution was dried over anhydrous $\mathrm{Na}_{2} \mathrm{SO}_{4}$, filtered, and the solvent was removed in vacuo. The product 2 was purified by using column chromatography with $\mathrm{CH}_{2} \mathrm{Cl}_{2} /$ methanol $(1: 10 \mathrm{v} / \mathrm{v})$ as eluent and obtained as a red-brown sticky oil (Yield: $0.32 \mathrm{~g}, 87.2 \%) .{ }^{1} \mathrm{H} \mathrm{NMR}\left(300 \mathrm{MHz}, \mathrm{CDCl}_{3}\right.$, $25{ }^{\circ} \mathrm{C}$, TMS), $\delta_{\text {ppm }}: 6.23$ (t, J = 3.7 Hz, 2H, CH=CH), 6.10 (t, J = 9.2 Hz, 1H, NHCO), 4.1 (t, J = $3.8 \mathrm{~Hz}, 2 \mathrm{H}$, sub. Cp), 3.83 (t, J = 3.8 Hz, 2H, sub. Cp), 3.70-3.53(m, 16H, $4 \times \mathrm{CH}_{2} \mathrm{CH}_{2}$ ), 3.20 (t, J $=3.2 \mathrm{~Hz}, 2 \mathrm{H},=\mathrm{CH}-\mathrm{CH}), 2.62(\mathrm{~d}, \mathrm{~J}=1.2 \mathrm{~Hz}, 2 \mathrm{H}, \mathrm{CO}-\mathrm{CH}), 1.78\left(\mathrm{~s}, 15 \mathrm{H}, 5 \times \mathrm{CH}_{3}\right), 1.43(\mathrm{~d}, \mathrm{~J}=9.8$ $\mathrm{Hz}, 1 \mathrm{H}, \mathrm{CH}_{2}$-bridge), 1.31 (d, J $=9.8 \mathrm{~Hz}, 1 \mathrm{H}, \mathrm{CH}_{2}$-bridge). ${ }^{13} \mathrm{C} \mathrm{NMR}\left(75 \mathrm{MHz}, \mathrm{CDCl}_{3}, 25{ }^{\circ} \mathrm{C}\right.$, TMS)), $\delta_{\mathrm{ppm}}: 178.0(\mathrm{CON}), 169.2(\mathrm{CONH}), 137.8(\mathrm{CH}=\mathrm{CH}), 81.1\left(\mathrm{Cp}^{*}\right)\left(\mathrm{Cp}^{*}=\eta^{5}-\mathrm{C}_{5} \mathrm{Me}_{5}\right), 74.4$ (sub. Cp), 70.6, 70.2, $70.0\left(\mathrm{CH}_{2}\right.$ and sub.Cp), $66.9\left(-\mathrm{CH}_{2} \mathrm{NH}\right), 47.8(\mathrm{CO}-\mathrm{CH}), 45.3(=\mathrm{CH}-\mathrm{CH})$, $42.7\left(\mathrm{CH}_{2}\right.$-bridge), $39.2\left(\mathrm{CH}_{2}-\mathrm{NCO}\right), 37.7\left(-\mathrm{CH}_{2} \mathrm{CH}_{2}-\mathrm{NCO}\right), 10.5\left(\mathrm{CH}_{3}\right)$. MS (ESI $\left.\mathrm{m} / z\right)$, calcd. for $\mathrm{C}_{33} \mathrm{H}_{44} \mathrm{~N}_{2} \mathrm{O}_{6} \mathrm{Fe}: 620.6$; found: $643.2\left(\mathrm{M}+\mathrm{Na}^{+}\right)$.

\section{Kinetic study of the ROMP of monomer 2}

A kinetic study was carried out in order to determine the ROMP rate of monomer 2. First, monomer $2(0.52 \mathrm{~g}, 0.8384 \mathrm{mmol})$ in $5.0 \mathrm{~mL}$ dry $\mathrm{CH}_{2} \mathrm{Cl}_{2}$ was added into the solution of Grubbs $3^{\text {rd }}$ generation catalyst $1(0.0297 \mathrm{~g}, 0.0335 \mathrm{mmol})$ in $0.5 \mathrm{~mL}$ dry $\mathrm{CH}_{2} \mathrm{Cl}_{2}$. Then, the obtained reaction mixture was vigorously stirred at r. t. under $\mathrm{N}_{2}$ atmosphere. At different intervals $(10,15$, 30 and 60 minutes, respectively), a $0.5 \mathrm{~mL}$ sample of the reaction mixture was taken out, quenched with $0.2 \mathrm{~mL}$ of EVE, vacuumed and checked for the ${ }^{1} \mathrm{H}$ NMR spectrum in $\mathrm{CDCl}_{3}$. The 
monomer conversion was deemed to be $100 \%$ when the signal of the olefin protons for monomer 2 at $6.23 \mathrm{ppm}$ disappeared. It was found that the conversion of monomer 2 achieved $100 \%$ after 10 minutes stirring.
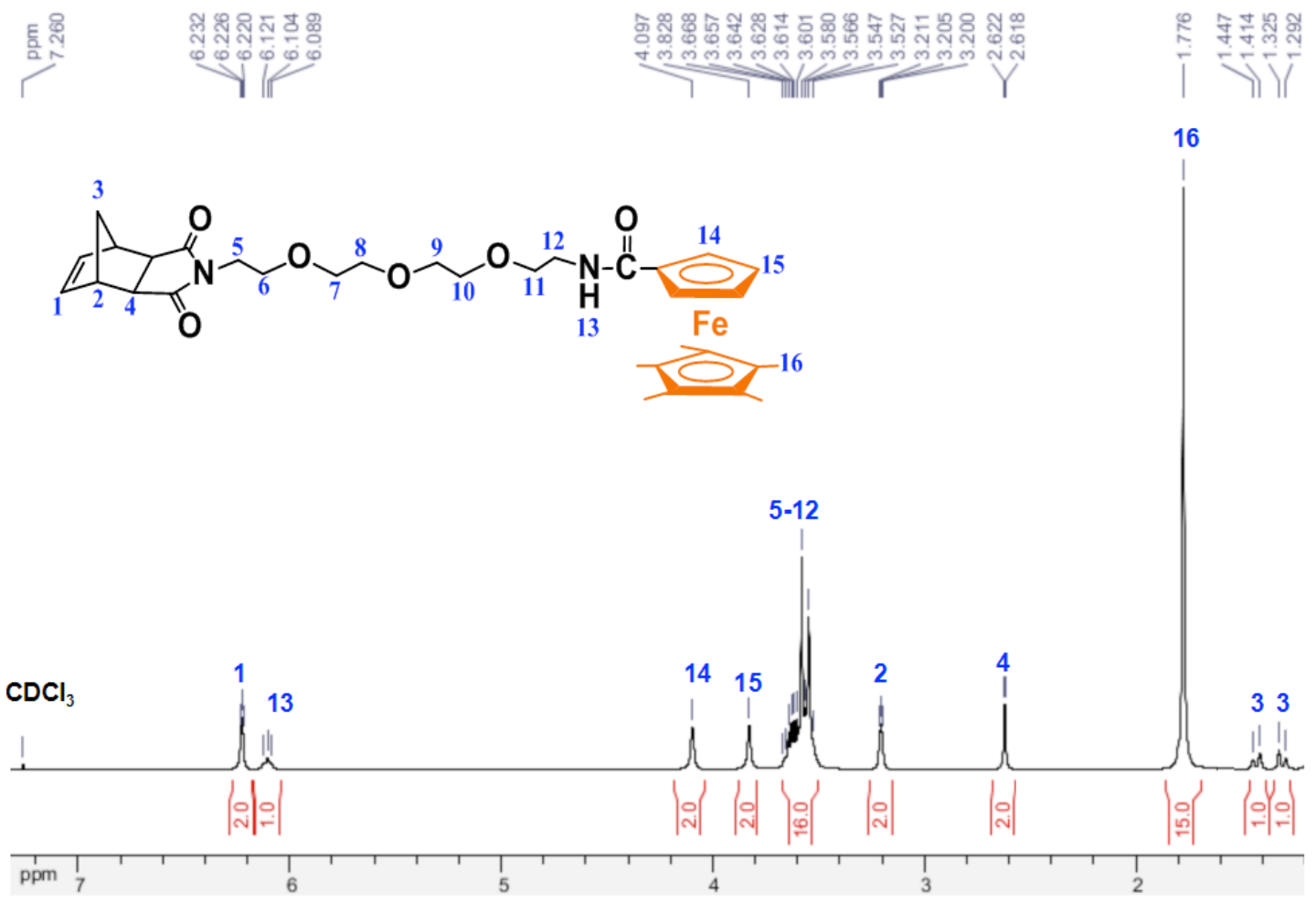

Figure $\mathbf{S 1}{ }^{1} \mathrm{H}$ NMR spectrum of monomer 2 in $\mathrm{CDCl}_{3}$.
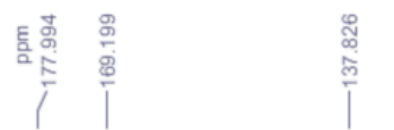

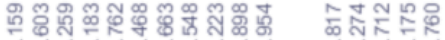

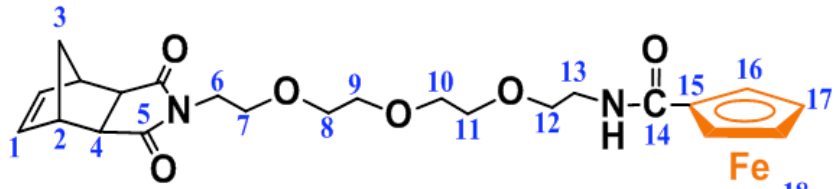
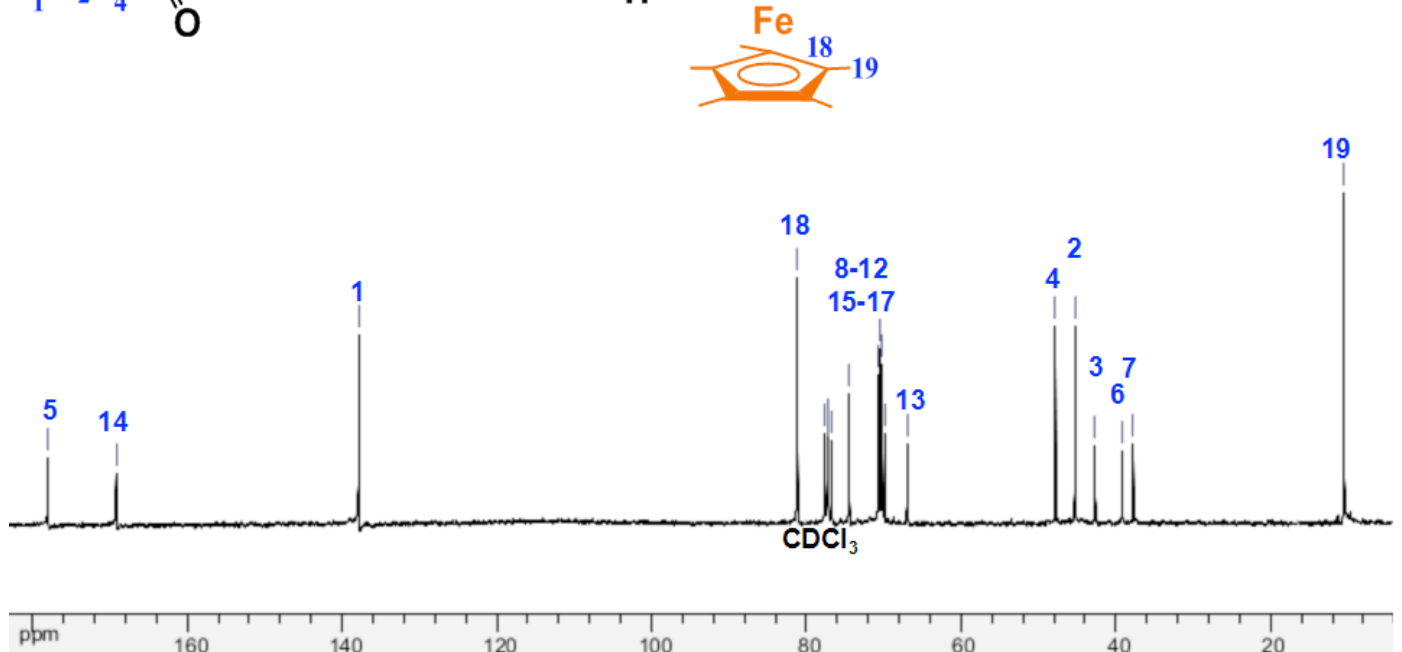

Figure $\mathbf{S 2}{ }^{13} \mathrm{C}$ NMR spectrum of monomer 2 in $\mathrm{CDCl}_{3}$. 


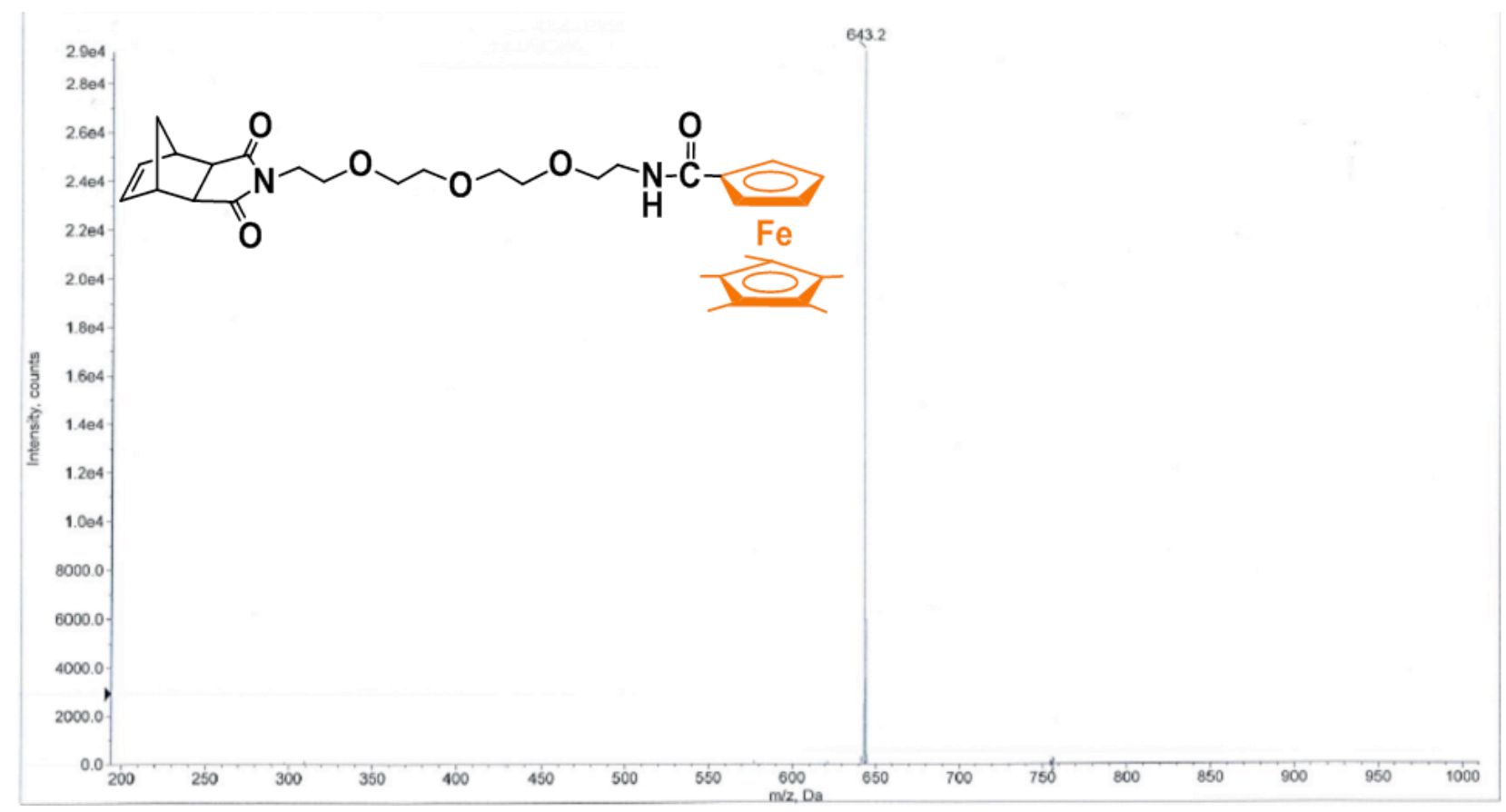

Figure S3 ESI mass spectrum of monomer 2.

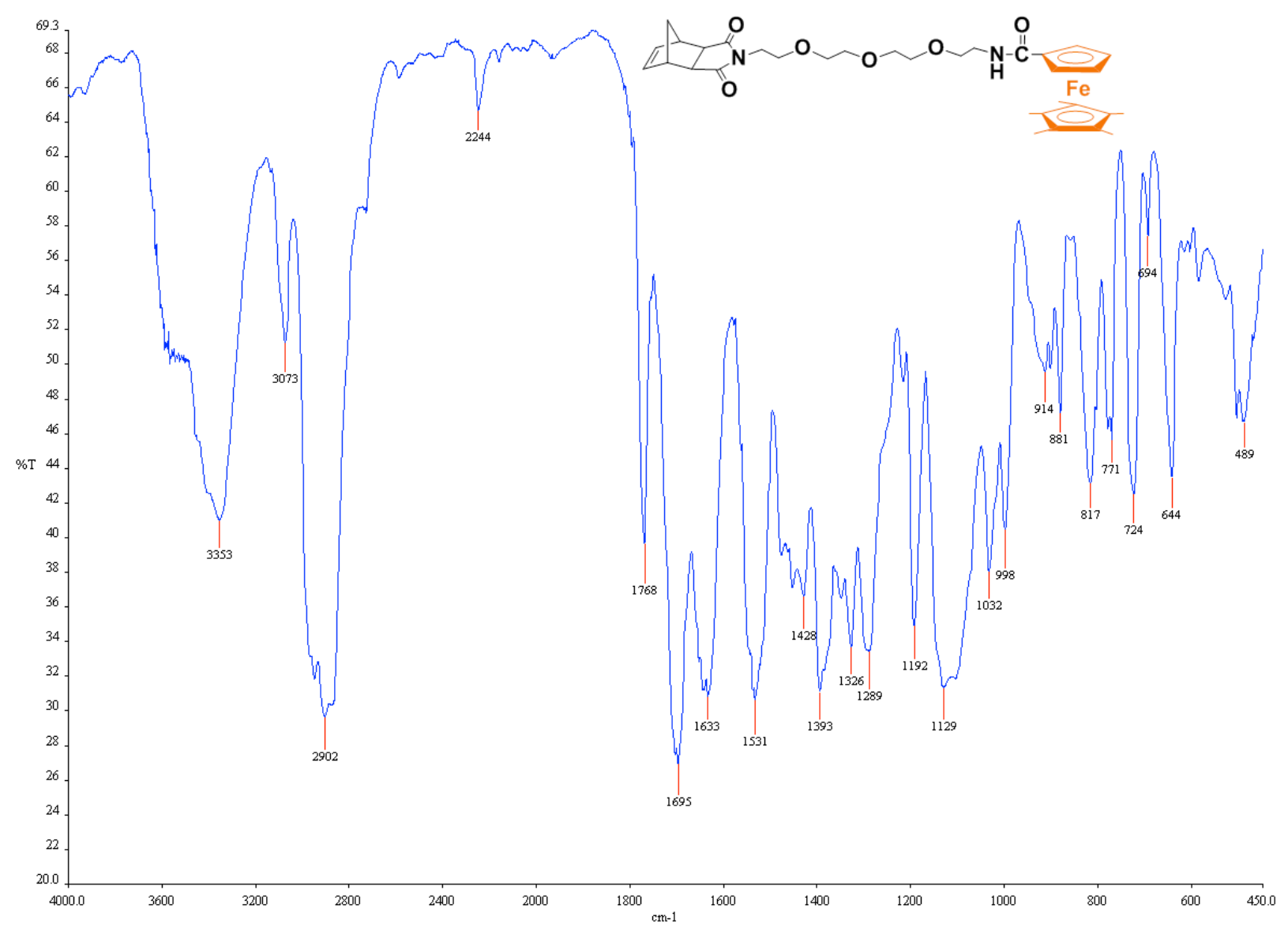

Figure S4 IR spectrum of monomer 2.

$3453 \mathrm{~cm}^{-1}\left(v_{\mathrm{NH}}\right), 2902 \mathrm{~cm}^{-1}\left(v_{\mathrm{CH} 3}\right), 1768 \mathrm{~cm}^{-1}\left(v_{\mathrm{C}=\mathrm{C}}\right), 1695 \mathrm{~cm}^{-1}\left(v_{\mathrm{NC}=\mathrm{O}}\right), 1633 \mathrm{~cm}^{-1}\left(v_{\mathrm{NHC}}\right), 817$ $\mathrm{cm}^{-1}\left(v_{\text {FeII }}\right)$ 


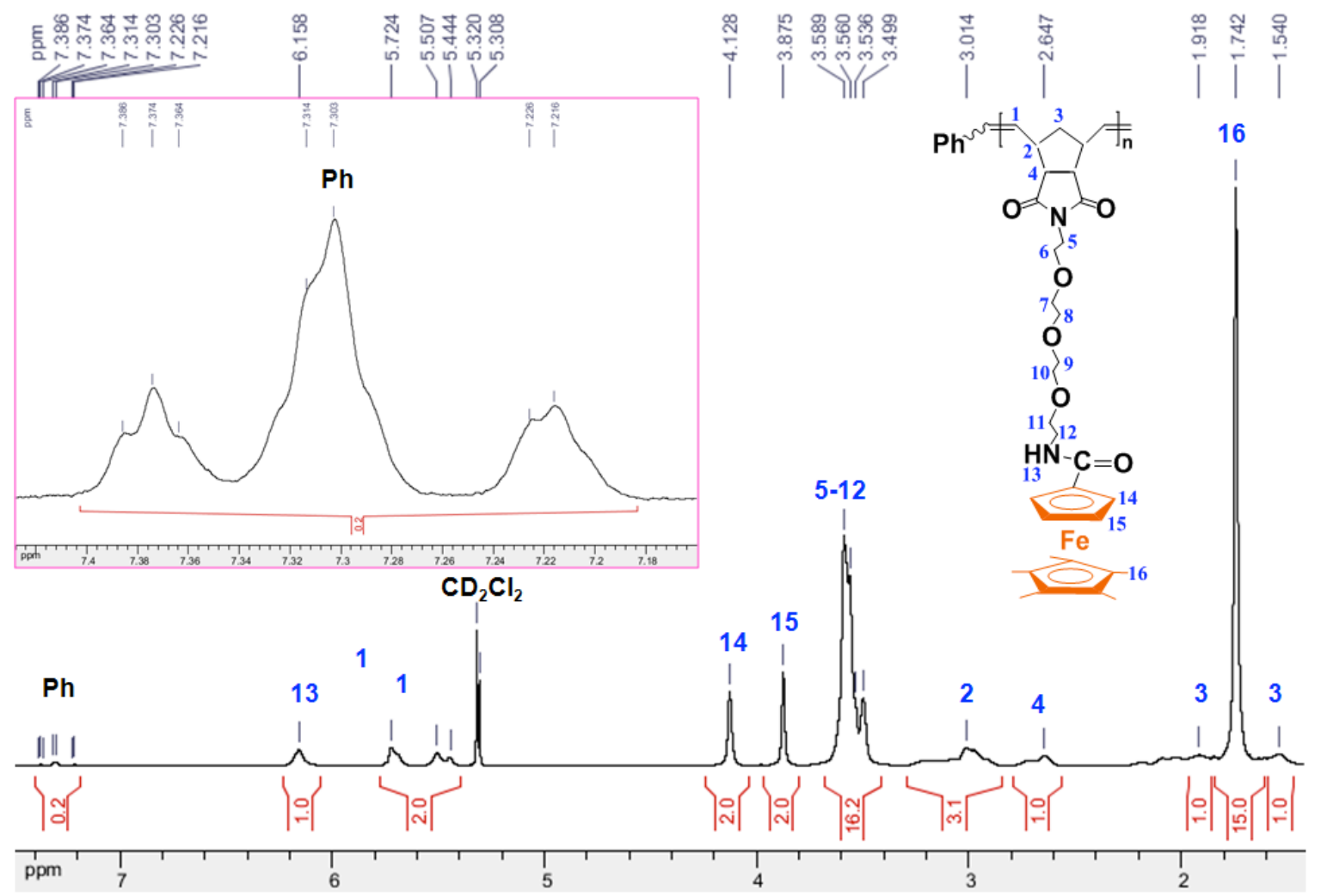

Figure S5 ${ }^{1} \mathrm{H}$ NMR spectrum of homopolymer of 2 in $\mathrm{CD}_{2} \mathrm{Cl}_{2}$.

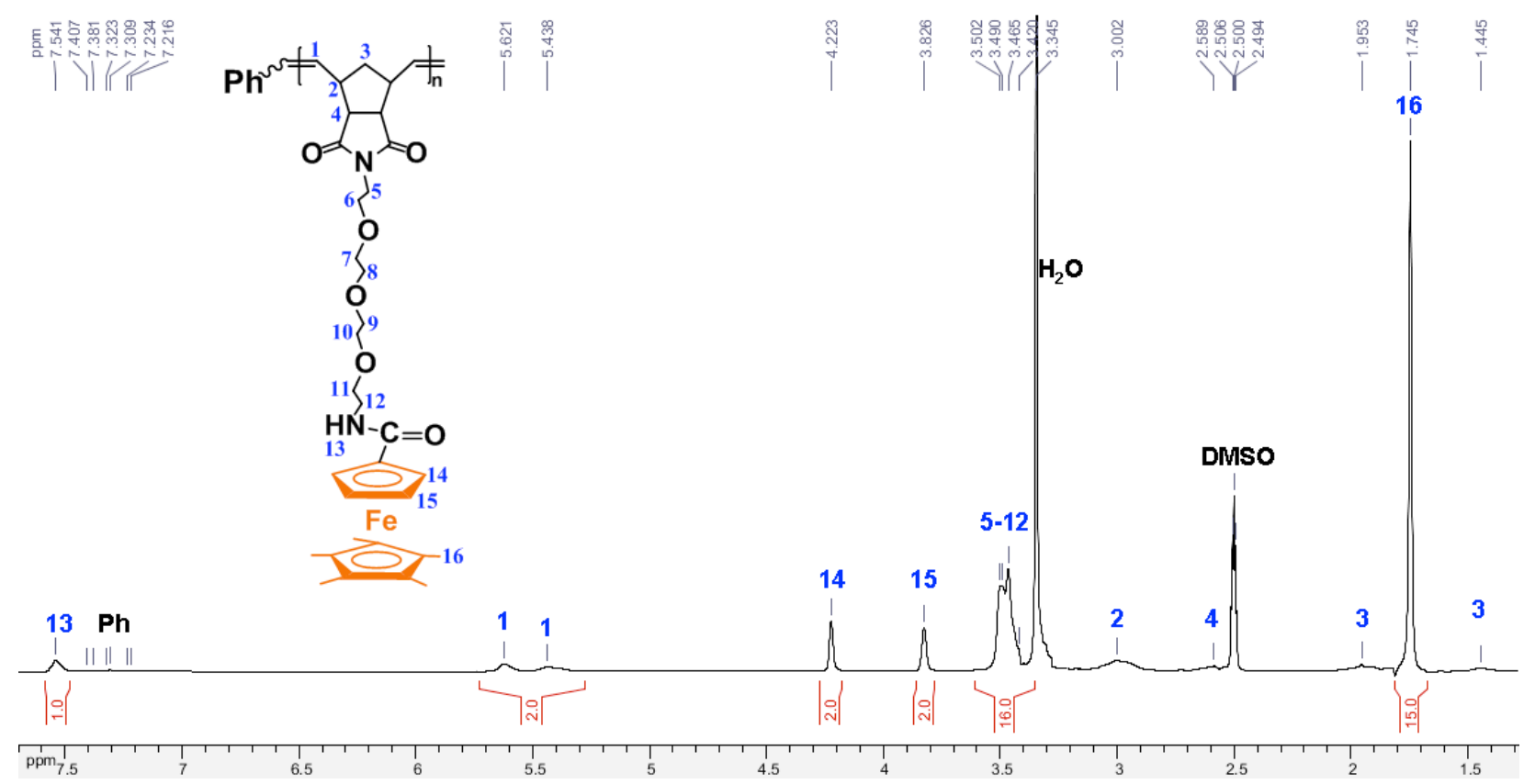

Figure S6 ${ }^{1} \mathrm{H}$ NMR spectrum of homopolymer of $\mathbf{2}$ in DMSO- $d_{6}$.

${ }^{1} \mathrm{H}$ NMR (300 MHz, DMSO- $d_{6}, 25{ }^{\circ} \mathrm{C}$, TMS), $\delta_{\mathrm{ppm}}: 7.54$ (broad, 1H, NHCO), 7.41-7.22 (m, phenyl), 5.62 and 5.44 (double broad, $2 \mathrm{H}, \mathrm{CH}=\mathrm{CH}$ ), 4.22 (s, 2H, sub. $\mathrm{Cp}$ ), 3.83 (s, 2H, sub. Cp), 3.50-3.42 (m, 16H, $\left.\mathrm{CH}_{2}\left(\mathrm{CH}_{2} \mathrm{OCH}_{2}\right)_{3} \mathrm{CH}_{2}\right), 3.00$ (broad, =CH-CH), 2.59 (broad, CO-CH), 1.95 (broad, $\left.\mathrm{CH}=\mathrm{CHCHCH}_{2}\right), 1.75\left(\mathrm{~s}, 15 \mathrm{H}, \mathrm{CH}_{3}\right.$ of $\left.\left(\eta^{6}-\mathrm{C}_{5} \mathrm{Me}_{6}\right)\right), 1.45\left(\right.$ broad, $\left.\mathrm{CH}=\mathrm{CHCHCH}_{2}\right)$. 


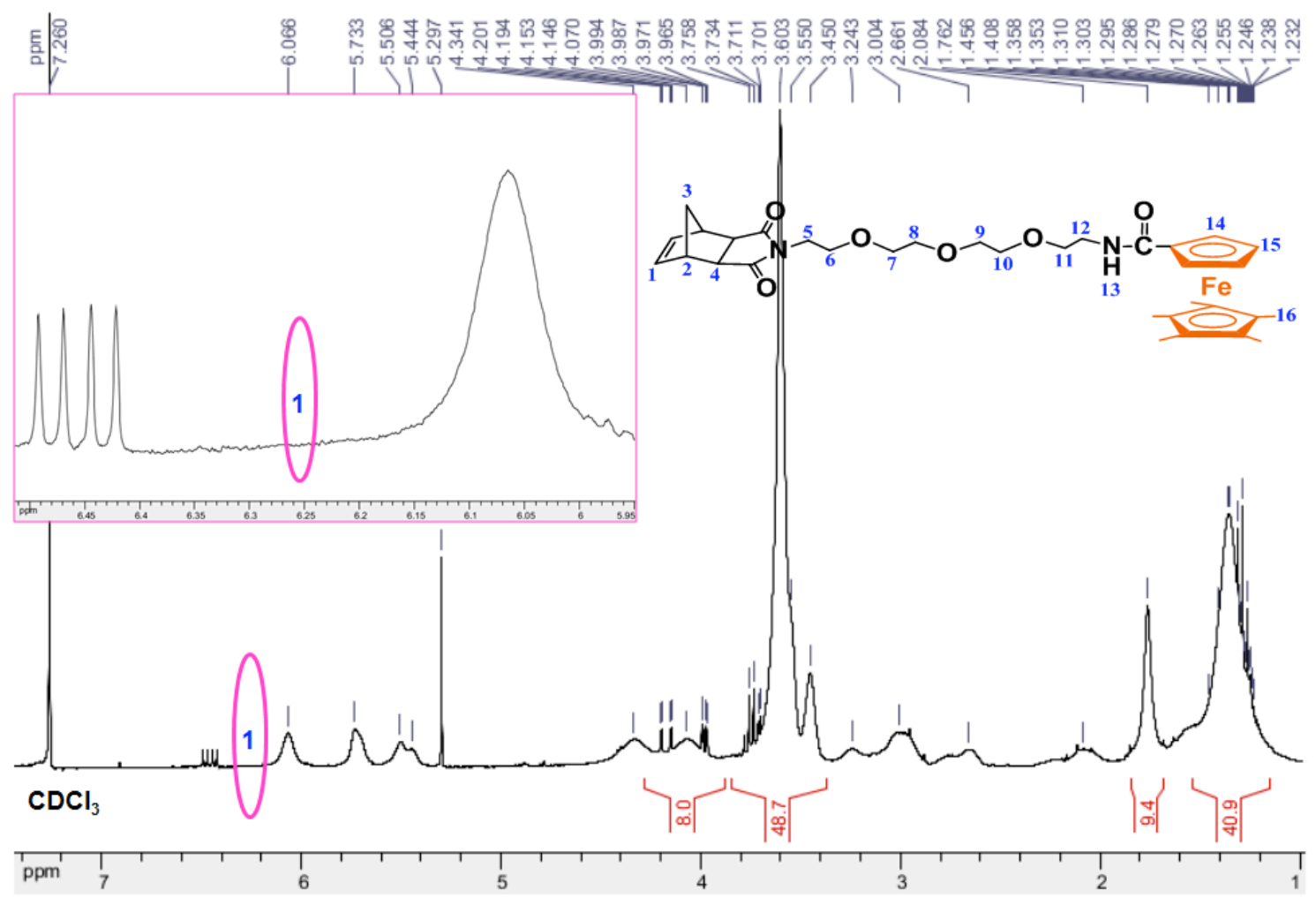

Figure $\mathbf{S} 7{ }^{1} \mathrm{H}$ NMR spectrum $(300 \mathrm{MHz})$ in $\mathrm{CDCl}_{3}$ of the ROMP reaction mixture of monomer 2 after 10 minutes stirring. The ROMP of monomer 2 is complete because no peak at 6.23 ppm was observed.

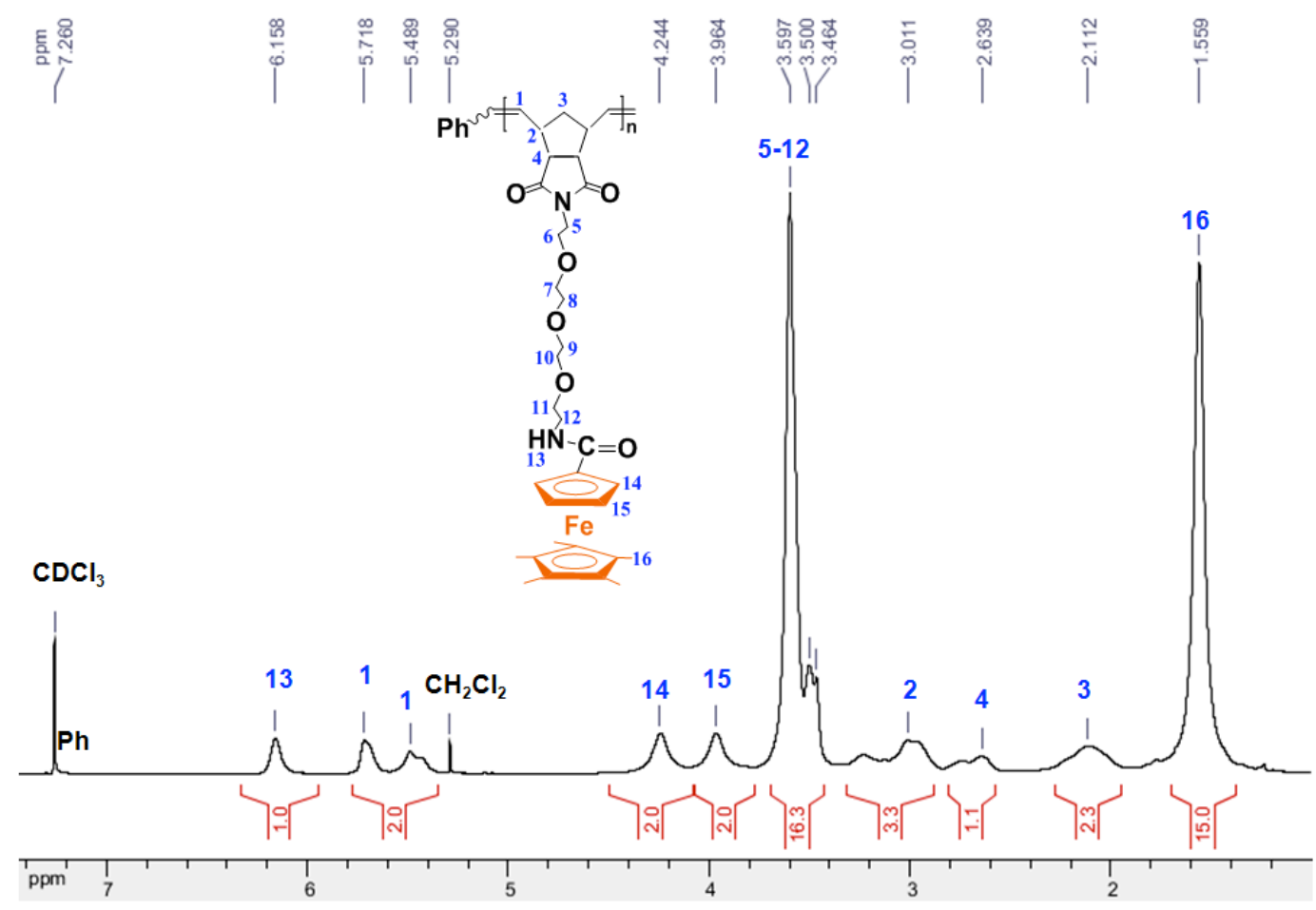

Figure S8 ${ }^{1} \mathrm{H}$ NMR spectrum $(300 \mathrm{MHz})$ in $\mathrm{CDCl}_{3}$ of methanol-washed products from the ROMP reaction mixture of monomer 2 after 10 minutes stirring. The product is the purified homopolymer of $\mathbf{2}$. There is no monomer $\mathbf{2}$ because no signal at $6.23 \mathrm{ppm}$ was observed. 


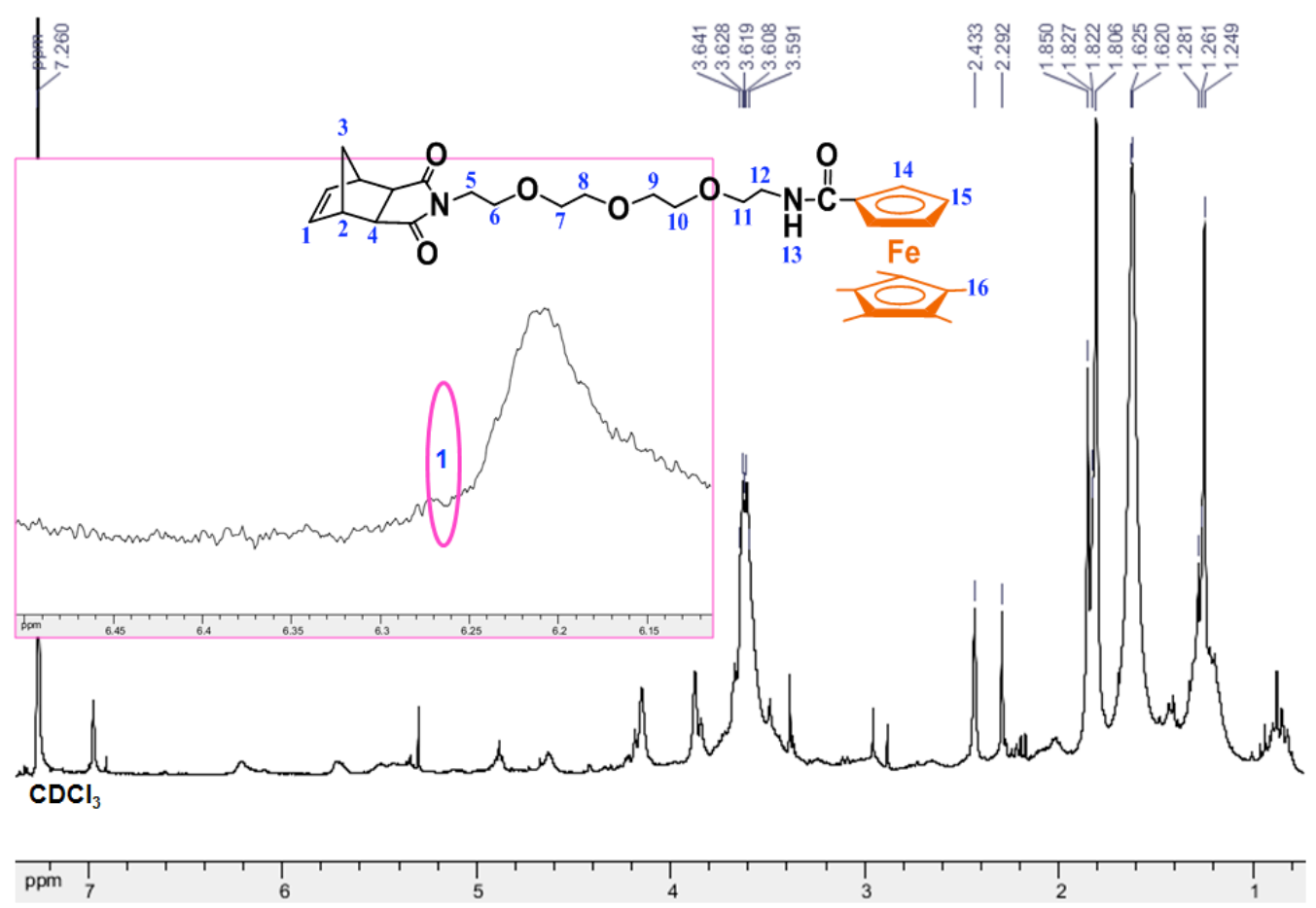

Figure S9 ${ }^{1} \mathrm{H}$ NMR spectrum $(300 \mathrm{MHz})$ in $\mathrm{CDCl}_{3}$ of products in the methanol washing-liquor from the ROMP reaction mixture of monomer 2 after 10 minutes stirring. The ROMP of monomer 2 is complete because no peak at $6.23 \mathrm{ppm}$ for the olefinic protons of monomer 2 was found. 


\section{Synthesis and kinetic study of the ROMP of monomer $3^{\mathrm{s} 2}$}

Triethylamine $(0.1 \mathrm{~mL}, 0.72 \mathrm{mmol})$ was added dropwise at room temperature (r. t.) under nitrogen $\left(\mathrm{N}_{2}\right)$ atmosphere to a suspension of ferrocene carboxylic acid $(0.4 \mathrm{~g}, 1.74 \mathrm{mmol})$ in dry $\mathrm{CH}_{2} \mathrm{Cl}_{2}(35 \mathrm{~mL})$. Then, oxalyl chloride $(0.75 \mathrm{~mL}, 8.7 \mathrm{mmol})$ was added dropwise at $0{ }^{\circ} \mathrm{C}$. The obtained mixture was stirred overnight at r. t. and dried in vacuo. The residual red solid of crude chlorocarbonyl ferrocene $(\mathrm{FcCOCl})$ was dissolved in dry $\mathrm{CH}_{2} \mathrm{Cl}_{2}(15 \mathrm{~mL})$ and added dropwise to a $\mathrm{CH}_{2} \mathrm{Cl}_{2}$ solution $(20 \mathrm{~mL})$ of $\mathbf{1 3}(0.2 \mathrm{~g}, 0.59 \mathrm{mmol})$ and triethylamine $(1.5 \mathrm{~mL}, 10.7 \mathrm{mmol})$. The mixture was stirred overnight under $\mathrm{N}_{2}$ atmosphere at $r$. t., then washed with saturated $\mathrm{NaHCO}_{3}$ solution $(1 \times 100 \mathrm{~mL})$ and distilled water $(3 \times 100 \mathrm{~mL})$. The organic solution was dried over anhydrous $\mathrm{Na}_{2} \mathrm{SO}_{4}$, filtered, and the solvent was removed in vacuo. The product 3 was purified by column chromatography with $\mathrm{CH}_{2} \mathrm{Cl}_{2} /$ methanol $(1 \% \rightarrow 20 \%)$ as eluent and obtained as a brown sticky oil. Yield: $0.258 \mathrm{~g}, 79.4 \%$. ${ }^{1} \mathrm{H}$ NMR (300 MHz, $\mathrm{CDCl}_{3}$ ), $\delta_{\text {ppm }}: 6.45$ (t, J = $9.9 \mathrm{~Hz}$, 1H, NHCO), 6.25 (t, J = 3.6 Hz, 2H, CH=CH), 4.69 (t, J = 3.6 Hz, 2H, sub. Cp), 4.30 (t, J = 3.6 $\mathrm{Hz}, 2 \mathrm{H}$, sub. Cp), 4.17 (s, 5H, free Cp), 3.70-3.54 (m, 16H, $\left.4 \times \mathrm{CH}_{2} \mathrm{CH}_{2}\right), 3.23(\mathrm{t}, \mathrm{J}=3.4 \mathrm{~Hz}, 2 \mathrm{H}$, $=\mathrm{CH}-\mathrm{CH}), 2.65(\mathrm{~d}, \mathrm{~J}=0.9 \mathrm{~Hz}, 2 \mathrm{H}, \mathrm{CO}-\mathrm{CH}), 1.45\left(\mathrm{~d}, \mathrm{~J}=9.9 \mathrm{~Hz}, 1 \mathrm{H}, \mathrm{CH}_{2}\right.$-bridge $), 1.32$ (d, J = $10.0 \mathrm{~Hz}, 1 \mathrm{H}, \mathrm{CH}_{2}$-bridge). ${ }^{13} \mathrm{C} \mathrm{NMR}\left(50 \mathrm{MHz}, \mathrm{CDCl}_{3}\right), \delta_{\mathrm{ppm}}: 177.8(\mathrm{CON}), 170.2$ (CONH), $137.7(\mathrm{CH}=\mathrm{CH}), 70.4,70.2,70.1,70.0,69.7,69.6,68.2\left(-\mathrm{OCH}_{2} \mathrm{CH}_{2} \mathrm{OCH}_{2} \mathrm{CH}_{2} \mathrm{OCH}_{2-}\right.$, sub. Cp and free $\mathrm{Cp}), 66.8\left(-\mathrm{CH}_{2} \mathrm{NH}\right), 47.7(\mathrm{CO}-\mathrm{CH}), 45.1(=\mathrm{CH}-\mathrm{CH}), 42.6\left(\mathrm{CH}_{2}\right.$-bridge $), 39.2$ $\left(\boldsymbol{C} \mathrm{H}_{2}-\mathrm{NCO}\right), 37.7$ (- $\left.\mathrm{CH}_{2} \mathrm{CH}_{2}-\mathrm{NCO}\right)$. MS (ESI $\left.m / z\right)$, calcd. for $\mathrm{C}_{28} \mathrm{H}_{34} \mathrm{~N}_{2} \mathrm{O}_{6} \mathrm{Fe}$ : 550.4; found: 573.2 $\left(\mathrm{M}+\mathrm{Na}^{+}\right)$.

\section{Kinetic study of the ROMP of monomer 3}

A kinetic study was carried out in order to determine the ROMP rate of monomer 3. First, monomer 3 ( $0.46 \mathrm{~g}, 0.84 \mathrm{mmol})$ in $5.0 \mathrm{~mL}$ dry $\mathrm{CH}_{2} \mathrm{Cl}_{2}$ was added into the solution of Grubbs $3^{\text {rd }}$ generation catalyst $1(0.030 \mathrm{~g}, 0.033 \mathrm{mmol})$ in $0.5 \mathrm{~mL}$ dry $\mathrm{CH}_{2} \mathrm{Cl}_{2}$. Then, the obtained reaction mixture was vigorously stirred at $r$. t. under $\mathrm{N}_{2}$ atmosphere. At different intervals $(5,15,30$ and 60 minutes, respectively), a $0.5 \mathrm{~mL}$ sample of the reaction mixture was taken out, quenched with $0.2 \mathrm{~mL}$ of EVE, precipitated by adding $5.0 \mathrm{~mL}$ of methanol. The obtained precipitate was washed with methanol $(3 \times 5 \mathrm{~mL})$, vacuumed and checked for the ${ }^{1} \mathrm{H}$ NMR spectrum in $\mathrm{CDCl}_{3}$. All the washing liquors and filtrate were collected, the solvent was removed in vacuo, and the ${ }^{1} \mathrm{H} N M R$ spectrum of the residue was recorded in $\mathrm{CDCl}_{3}$, too. The monomer conversion was deemed to be $100 \%$ when the signal of the olefin protons for monomer 3 at $6.25 \mathrm{ppm}$ disappeared. It was found that the conversion of monomer 3 achieved $100 \%$ after 15 minutes stirring. 




Figure S10 ${ }^{1} \mathrm{H}$ NMR spectrum of monomer 3 in $\mathrm{CDCl}_{3}$.

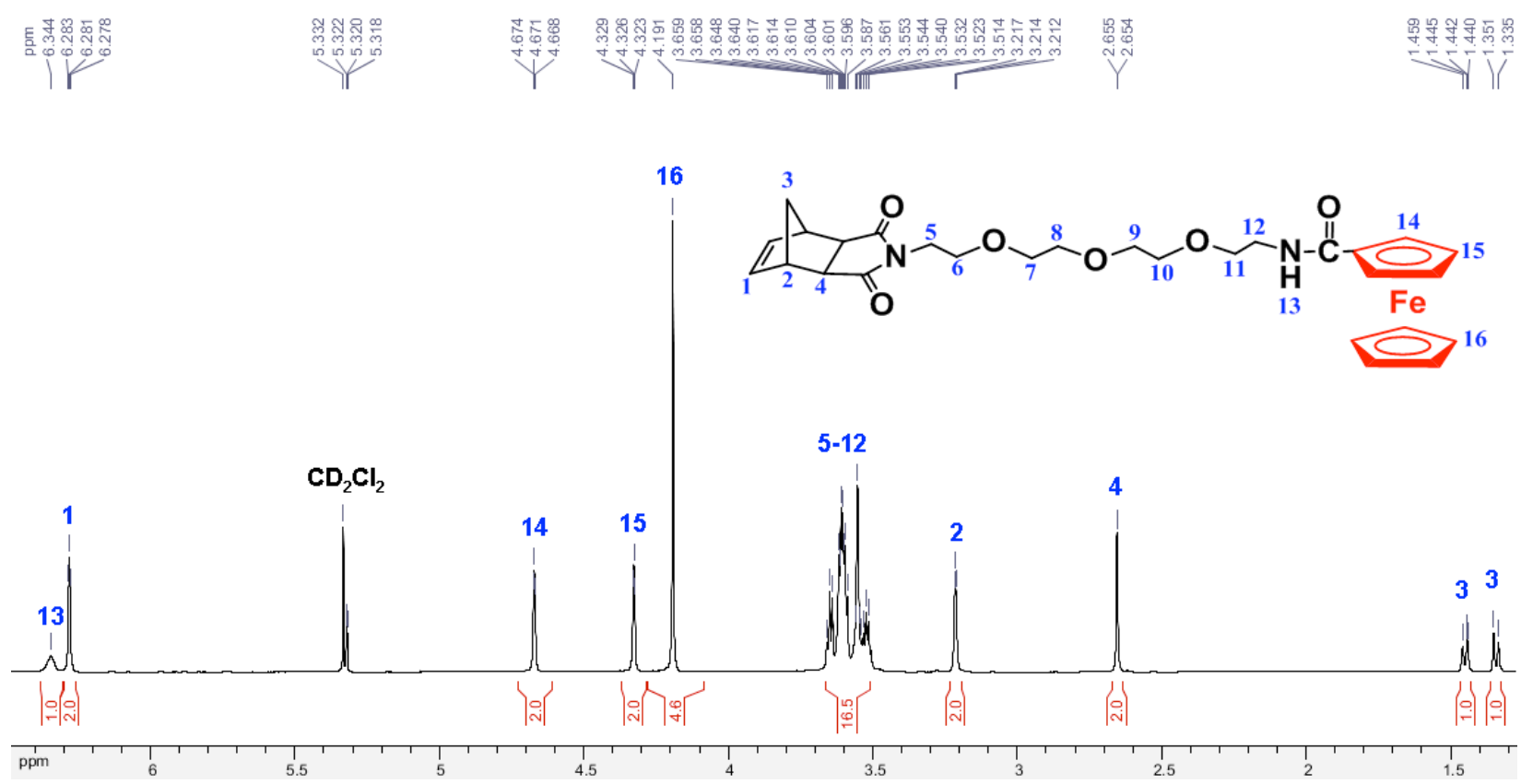

Figure S11 ${ }^{1} \mathrm{H}$ NMR spectrum of monomer 3 in $\mathrm{CD}_{2} \mathrm{Cl}_{2}$. 
|

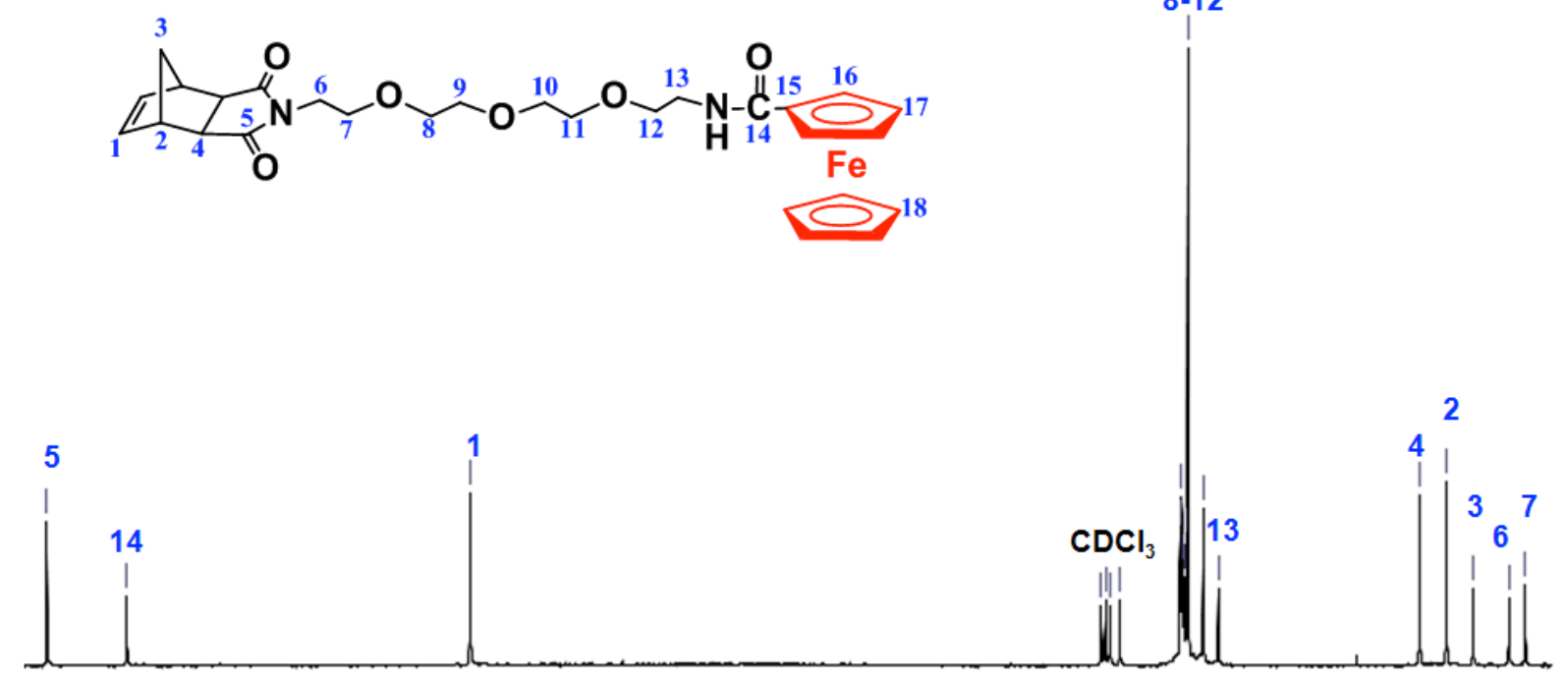



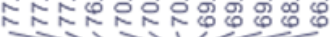

15-18

8-12

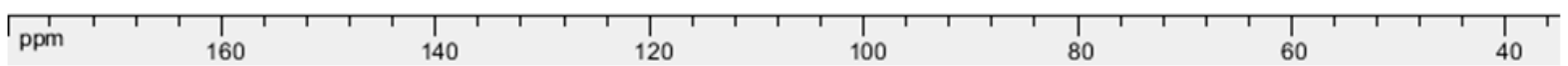

Figure S12 ${ }^{13} \mathrm{C}$ NMR spectrum of monomer 3 in $\mathrm{CDCl}_{3}$.

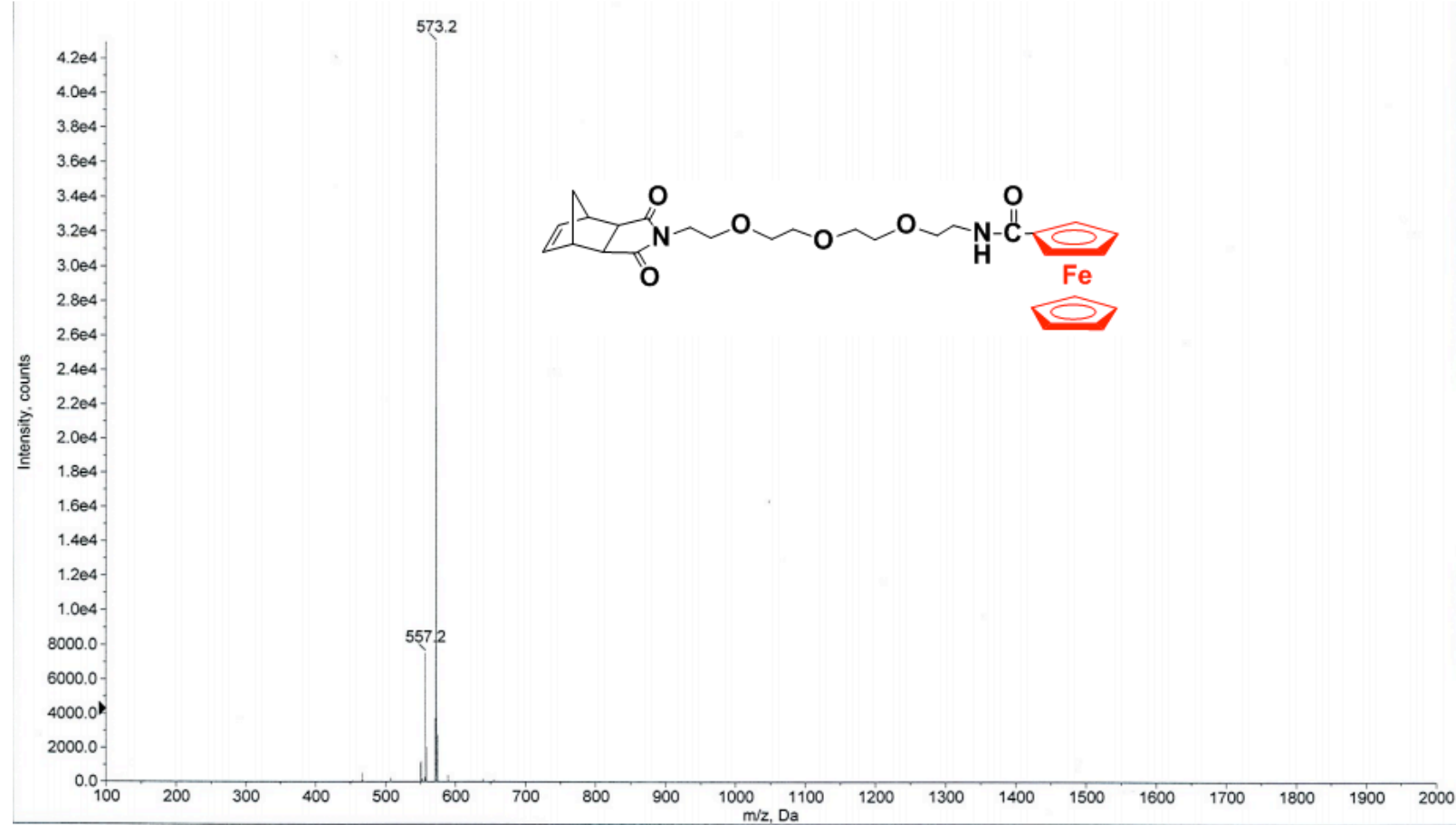

Figure S13 ESI mass spectrum of monomer 3. 


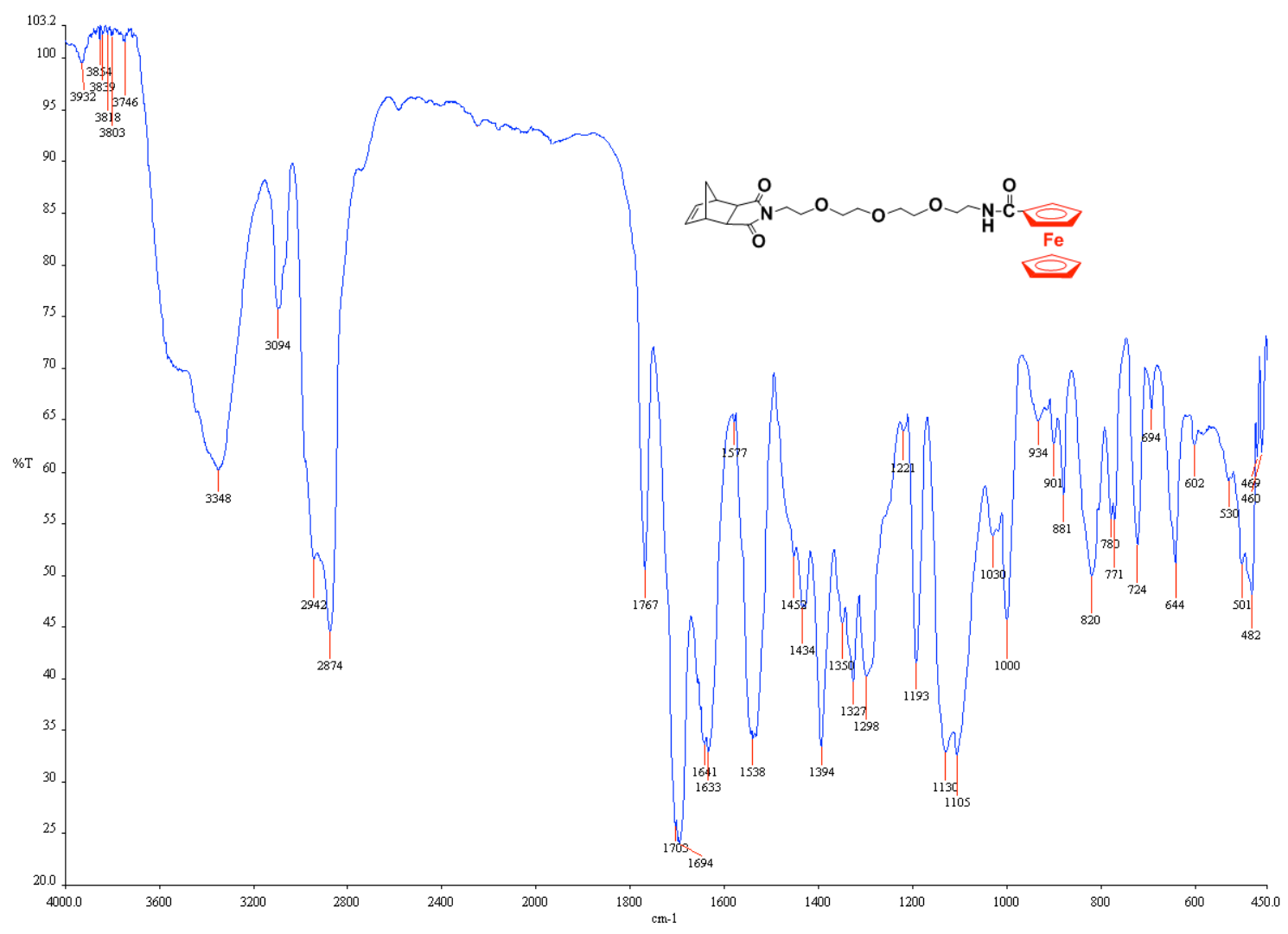

Figure S14 IR spectrum of monomer 3.

$3448 \mathrm{~cm}^{-1}\left(v_{\mathrm{NH}}\right), 2874 \mathrm{~cm}^{-1}\left(v_{\mathrm{CH} 2}\right), 1767 \mathrm{~cm}^{-1}\left(v_{\mathrm{C}=\mathrm{C}}\right), 1694 \mathrm{~cm}^{-1}\left(v_{\mathrm{NC}=\mathrm{O}}\right), 1633 \mathrm{~cm}^{-1}\left(v_{\mathrm{NHC}=\mathrm{O}}\right), 820$ $\mathrm{cm}^{-1}\left(v_{\mathrm{FeII}}\right)$

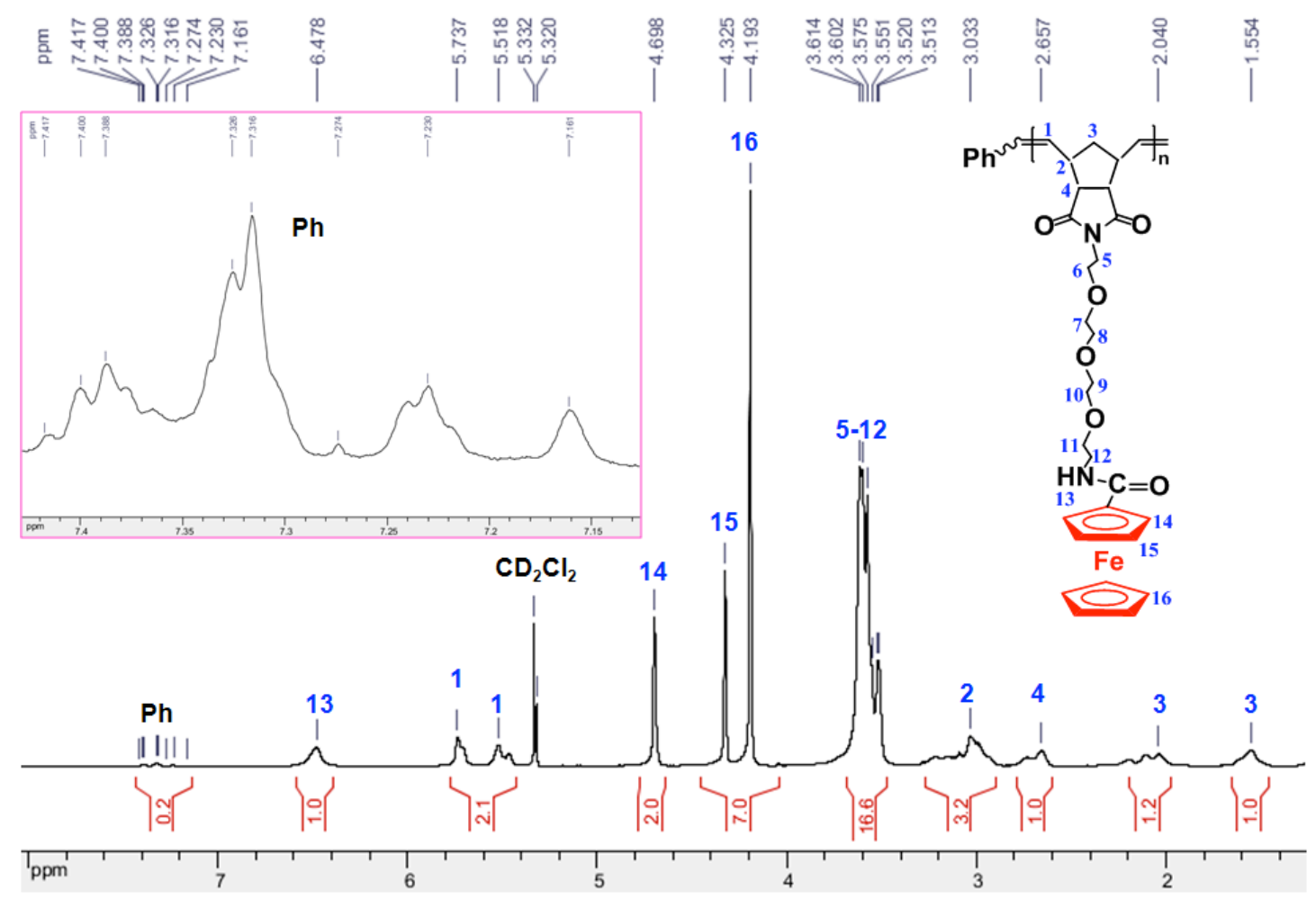

Figure $\mathbf{S 1 5}{ }^{1} \mathrm{H}$ NMR spectrum $(600 \mathrm{MHz})$ of homopolymer of 3 in $\mathrm{CD}_{2} \mathrm{Cl}_{2}$. 


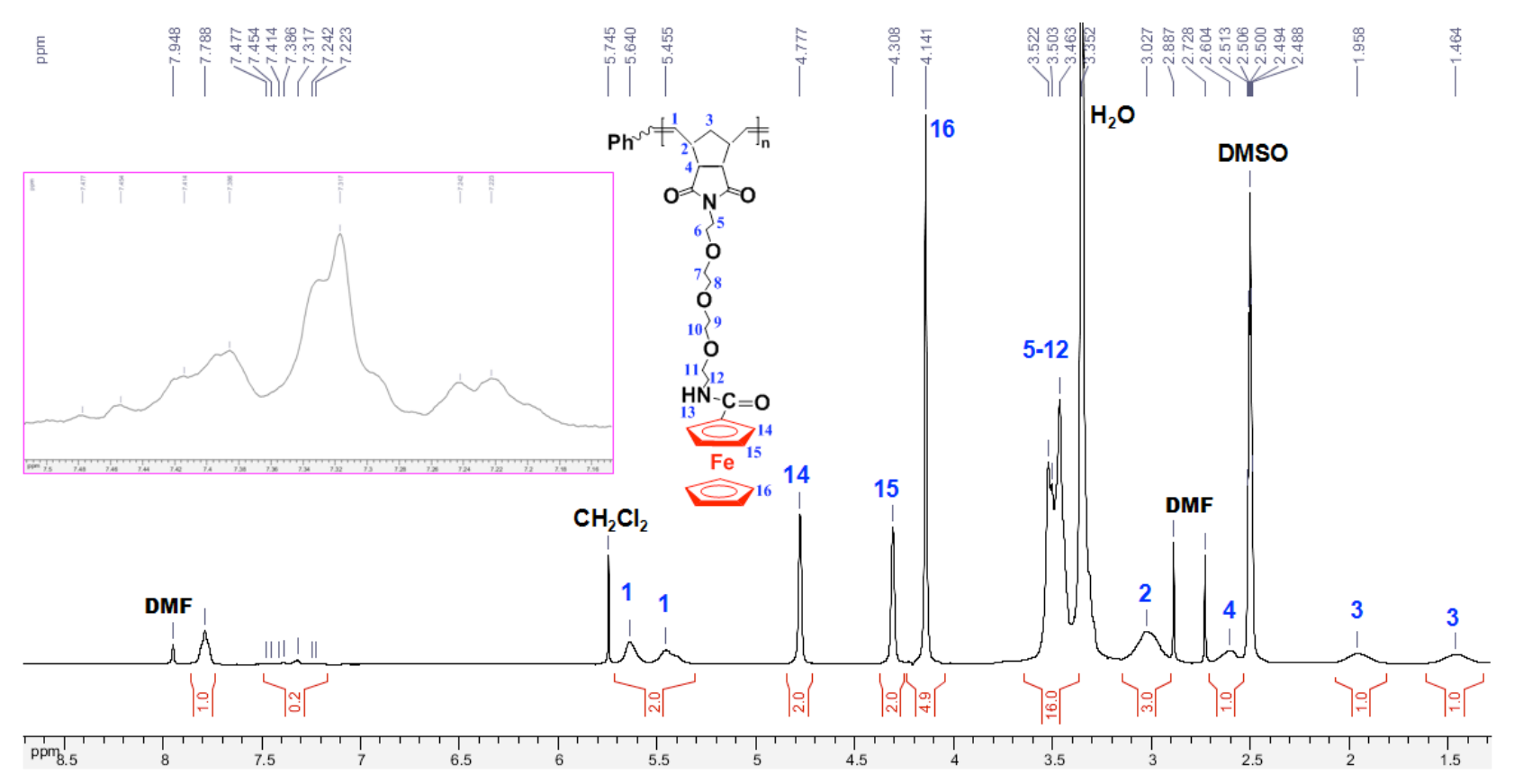

Figure S16 ${ }^{1} \mathrm{H}$ NMR spectrum (400 MHz) of homopolymer of 3 in DMSO- $d_{6}$.



Figure $\mathbf{S 1 7}{ }^{1} \mathrm{H}$ NMR spectrum $(300 \mathrm{MHz})$ in $\mathrm{CDCl}_{3}$ of the ROMP reaction mixture of monomer $\mathbf{3}$ after 5 minutes stirring. The ROMP of monomer $\mathbf{3}$ is not complete because the peak at 6.28 ppm for the olefinic protons of monomer $\mathbf{3}$ is still observed. 




Figure $\mathbf{S 1 8}{ }^{1} \mathrm{H}$ NMR spectrum $(300 \mathrm{MHz})$ in $\mathrm{CDCl}_{3}$ of the precipitate from the ROMP reaction mixture of monomer 3 after 5 minutes stirring. The precipitate is the purified homopolymer of 3 . There is no monomer 3 because no signal at $6.27 \mathrm{ppm}$ or so was observed.

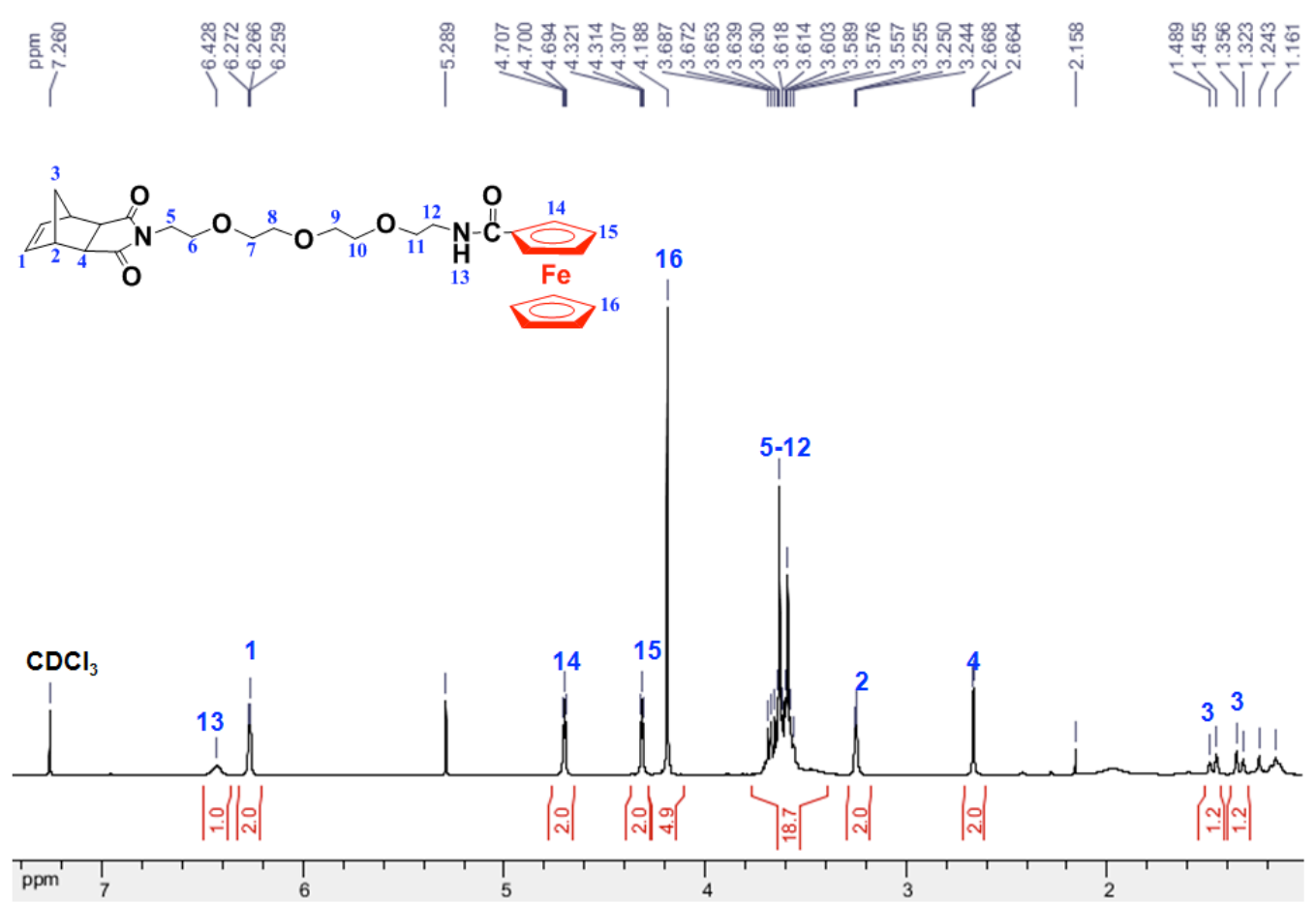

Figure $\mathbf{S 1 9}{ }^{1} \mathrm{H}$ NMR spectrum $(300 \mathrm{MHz})$ in $\mathrm{CDCl}_{3}$ of products in filtrate and washing-liquors from the ROMP reaction mixture of monomer 3 after 5 minutes stirring. The ROMP of monomer $\mathbf{3}$ is not complete because the peaks for monomer $\mathbf{3}$ were observed. 


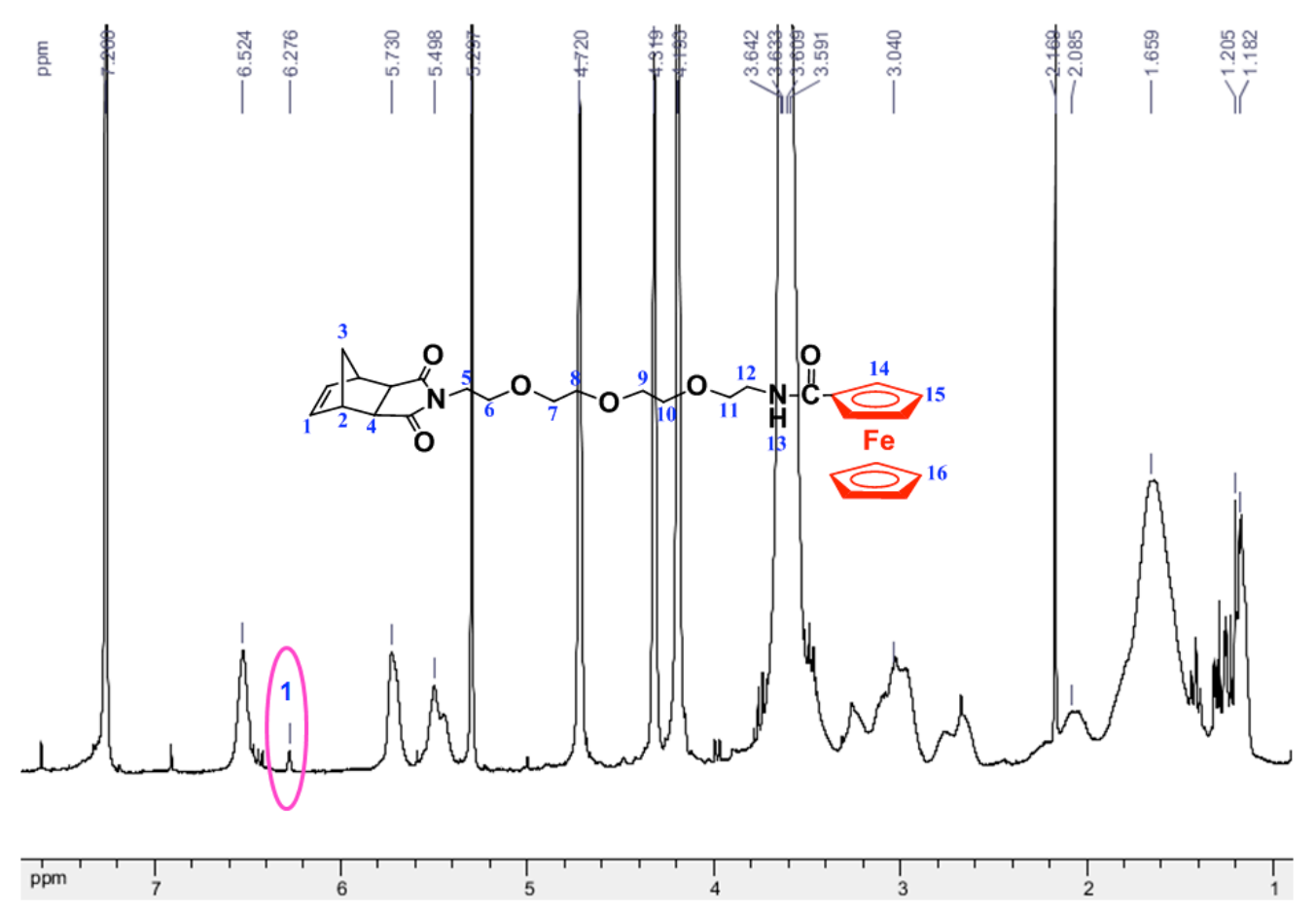

Figure S20 Enlarged ${ }^{1} \mathrm{H}$ NMR spectrum $(300 \mathrm{MHz})$ in $\mathrm{CDCl}_{3}$ of the ROMP reaction mixture of monomer $\mathbf{3}$ after 10 minutes stirring. The ROMP of monomer $\mathbf{3}$ is not complete because the small peak at $6.28 \mathrm{ppm}$ for the olefinic protons of monomer 3 is still observed.

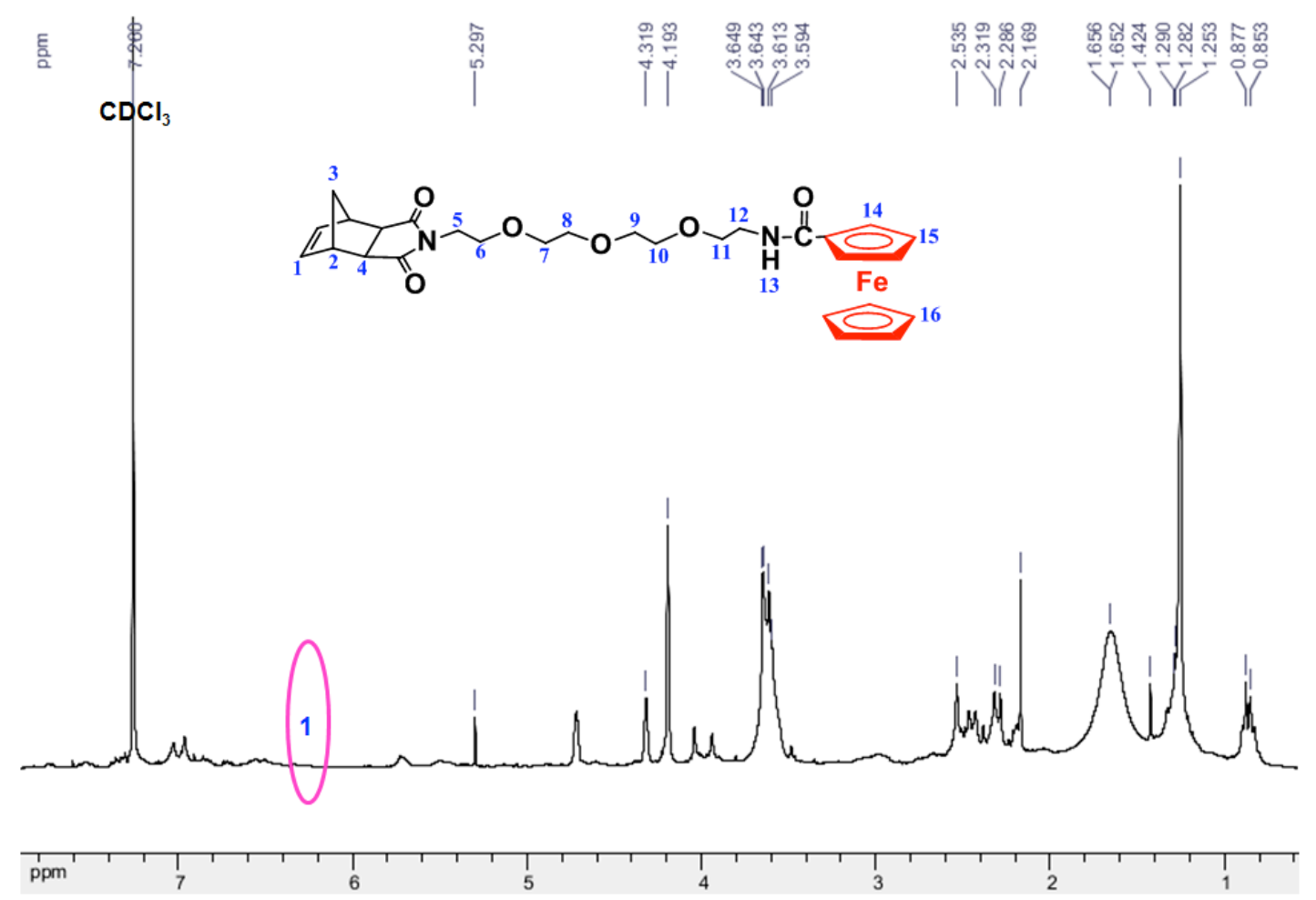

Figure S21 ${ }^{1} \mathrm{H}$ NMR spectrum $(300 \mathrm{MHz})$ in $\mathrm{CDCl}_{3}$ of the products in filtrate and washing liquors from the ROMP reaction mixture of monomer 3 after 15 minutes stirring. The ROMP of monomer $\mathbf{3}$ is complete because no peak at $6.27 \mathrm{ppm}$ for the olefinic protons of monomer $\mathbf{3}$ was found. 


\section{Synthesis and kinetic study of the ROMP of monomer $4^{\mathrm{s} 6}$}

Cobalticenium carboxylic acid hexafluorophosphate $(0.826 \mathrm{~g}, 2.18 \mathrm{mmol})$ was refluxed in $80 \mathrm{~mL}$ of $\mathrm{SOCl}_{2}$ under $\mathrm{N}_{2}$ atmosphere for $48 \mathrm{~h}$. Then, the excess $\mathrm{SOCl}_{2}$ was removed using a trap-to-trap system in vacuo, and the resulting yellow-green solid, chlorocarbonyl cobalticenium hexafluorophosphate was dissolved in dry $\mathrm{CH}_{2} \mathrm{Cl}_{2}(60 \mathrm{~mL})$ under $\mathrm{N}_{2}$ atmosphere. The mixture of $\mathrm{N}$-(2-aminoethyl)-cis-5-norbornene-exo-2, 3-dicarboximide 14 (0.3 g, $1.46 \mathrm{mmol})$ and triethylamine $(2.1 \mathrm{~mL})$ in dry $\mathrm{CH}_{2} \mathrm{Cl}_{2}(10 \mathrm{~mL})$ was added dropwise to the above solution, and the obtained mixture was stirred overnight at r. t. under $\mathrm{N}_{2}$ atmosphere, then dried in vacuo to remove the solvent and excess triethylamine. The residual green-brown solid was dissolved in $100 \mathrm{~mL} \mathrm{CH}_{2} \mathrm{Cl}_{2}$, washed with a saturated $\mathrm{NaHCO}_{3}$ solution $(3 \times 50 \mathrm{~mL})$ then an aqueous solution of $\mathrm{HPF}_{6}(50 \mathrm{~mL})$. The organic solution was dried with anhydrous $\mathrm{Na}_{2} \mathrm{SO}_{4}$, filtered, and the solvent was removed in vacuo. The product was purified by precipitation from acetone with diethyl ether $\left(\mathrm{Et}_{2} \mathrm{O}\right)$ providing the monomer 4 as a yellow-green powder $(0.66 \mathrm{~g}, 80 \%$ yield $) .{ }^{1} \mathrm{H}$ NMR (300 MHz, acetone- $\left.d_{6}\right), \delta_{\mathrm{ppm}}: 8.11(\mathrm{t}, \mathrm{J}=9.6 \mathrm{~Hz}, 1 \mathrm{H}, \mathrm{NHCO}), 6.32(\mathrm{t}, \mathrm{J}=3.9 \mathrm{~Hz}, 2 \mathrm{H}$, $\mathrm{CH}=\mathrm{CH}), 6.21\left(\mathrm{t}, \mathrm{J}=4.3 \mathrm{~Hz}, 2 \mathrm{H}\right.$, sub. $\left.\mathrm{Cp}, \mathrm{Cp}=\eta^{5}-\mathrm{C}_{5} \mathrm{H}_{5}\right), 5.99(\mathrm{~s}, 5 \mathrm{H}$, free Cp), 5.97 (t, J = 4.3 $\mathrm{Hz}, 2 \mathrm{H}$, sub. Cp), 3.74-3.71 (m, 2H, $\left.\mathrm{CH}_{2}\right), 3.56-3.50\left(\mathrm{~m}, 2 \mathrm{H}, \mathrm{CH}_{2}\right), 3.17(\mathrm{t}, \mathrm{J}=3.6 \mathrm{~Hz}, 2 \mathrm{H}$, $=\mathrm{CH}-\mathrm{CH}), 2.77(\mathrm{~d}, \mathrm{~J}=1.5 \mathrm{~Hz}, 2 \mathrm{H}, \mathrm{CO}-\mathrm{CH}), 1.46\left(\mathrm{~d}, \mathrm{~J}=9.7 \mathrm{~Hz}, 1 \mathrm{H}, \mathrm{CH}_{2}\right.$-bridge $), 1.33$ (d, J = $9.7 \mathrm{~Hz}, 1 \mathrm{H}, \mathrm{CH}_{2}$-bridge). ${ }^{13} \mathrm{C} \mathrm{NMR}\left(75 \mathrm{MHz}\right.$, acetone- $\left.d_{6}\right), \delta_{\mathrm{ppm}}: 178.9(\mathrm{CON}), 162.7(\mathrm{CONH})$, 138.6 $(\mathrm{CH}=\mathrm{CH}$ ), 95.9 (free $\mathrm{Cp}$ ), 87.3, 86.7, 84.8 (sub. Cp), $48.7(\mathrm{CO}-\mathrm{CH}), 45.8(=\mathrm{CH}-\mathrm{CH}), 43.5$ $\left(\mathrm{CH}_{2}\right.$-bridge), 39.1, $38.8\left(\mathrm{CH}_{2} \mathrm{CH}_{2}\right)$. MS (ESI m/z), calcd. For $\mathrm{C}_{22} \mathrm{H}_{22} \mathrm{~N}_{2} \mathrm{O}_{3} \mathrm{Co}: 421.4$; found: $421.1\left(\mathrm{M}^{+}\right)$.

\section{Kinetic study of the ROMP of monomer 4}

A kinetic study was carried out in order to determine the ROMP rate of organocobalt monomer 4. First, monomer $4(0.4121 \mathrm{~g}, 0.7277 \mathrm{mmol})$ in $4.0 \mathrm{~mL}$ dry DMF was added into the solution of Grubbs $3^{\text {rd }}$ generation catalyst $1(0.0258 \mathrm{~g}, 0.0291 \mathrm{mmol})$ in $0.5 \mathrm{~mL}$ dry DMF. Then, the obtained reaction mixture was vigorously stirred at r. t. under $\mathrm{N}_{2}$ atmosphere. At different intervals (10, 20, 30 and 60 minutes, respectively), a $0.5 \mathrm{~mL}$ sample of the reaction mixture was taken, quenched with $0.2 \mathrm{~mL}$ of EVE, precipitated by adding $2.0 \mathrm{~mL}$ of $\mathrm{Et}_{2} \mathrm{O}$. The obtained precipitate was washed with $\mathrm{Et}_{2} \mathrm{O}(3 \times 2 \mathrm{~mL})$ and then $\mathrm{CH}_{2} \mathrm{Cl}_{2}(3 \times 2 \mathrm{~mL})$. All the washing liquors and filtrate were collected, the solvent was removed in vacuo, and the ${ }^{1} \mathrm{H}$ NMR spectrum of the residue was recorded in acetone- $d_{6}$. The monomer conversion was deemed to be $100 \%$ when the signal of the olefin protons for monomer 4 at $6.32 \mathrm{ppm}$ disappeared. It was found that the conversion of monomer 4 achieved $100 \%$ after 30 minutes stirring. 




Figure S22 ${ }^{1}$ H NMR spectrum of monomer 4 in acetone- $d_{6}$.

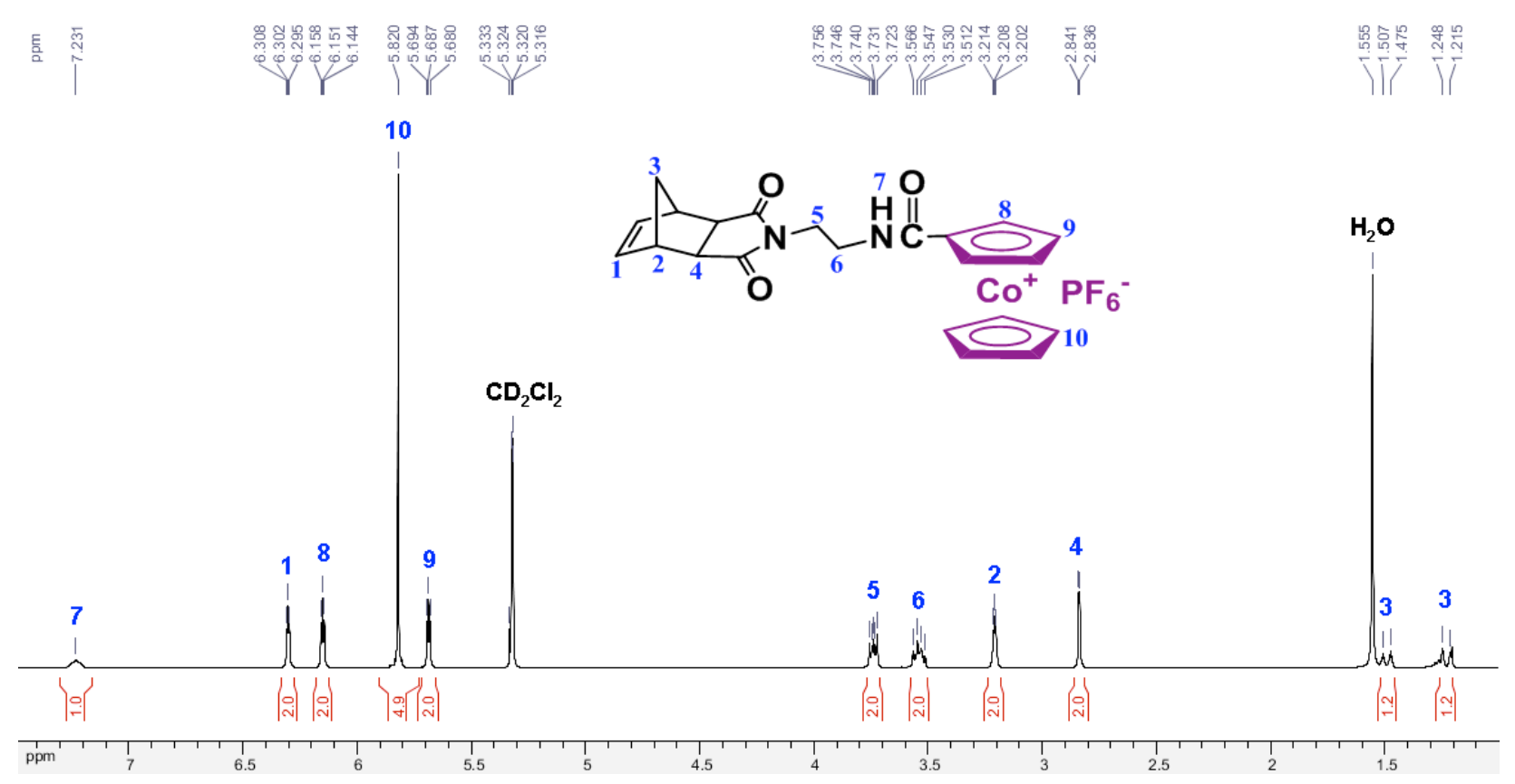

Figure S23 ${ }^{1} \mathrm{H}$ NMR spectrum of monomer 4 in $\mathrm{CD}_{2} \mathrm{Cl}_{2}$.

${ }^{1} \mathrm{H}$ NMR (300 MHz, $\mathrm{CD}_{2} \mathrm{Cl}_{2}$ ), $\delta_{\mathrm{ppm}}: 7.23(\mathrm{t}, \mathrm{J}=9.6 \mathrm{~Hz}, 1 \mathrm{H}, \mathrm{NHCO}), 6.30(\mathrm{t}, \mathrm{J}=3.7 \mathrm{~Hz}, 2 \mathrm{H}$, $\mathrm{CH}=\mathrm{CH}), 6.15\left(\mathrm{t}, \mathrm{J}=4.3 \mathrm{~Hz}, 2 \mathrm{H}\right.$, sub. $\left.\mathrm{Cp}, \mathrm{Cp}=\eta^{5}-\mathrm{C}_{5} \mathrm{H}_{5}\right), 5.82(\mathrm{~s}, 5 \mathrm{H}$, free $\mathrm{Cp}), 5.69(\mathrm{t}, \mathrm{J}=4.3$ $\mathrm{Hz}, 2 \mathrm{H}$, sub. Cp), 3.76-3.72 (m, 2H, $\left.\mathrm{CH}_{2}\right), 3.57-3.51\left(\mathrm{~m}, 2 \mathrm{H}, \mathrm{CH}_{2}\right), 3.21(\mathrm{t}, \mathrm{J}=3.6 \mathrm{~Hz}, 2 \mathrm{H}$, $=\mathrm{CH}-\mathrm{CH}), 2.84(\mathrm{~d}, \mathrm{~J}=1.5 \mathrm{~Hz}, 2 \mathrm{H}, \mathrm{CO}-\mathrm{CH}), 1.49\left(\mathrm{~d}, \mathrm{~J}=9.8 \mathrm{~Hz}, 1 \mathrm{H}, \mathrm{CH}_{2}\right.$-bridge $), 1.23(\mathrm{~d}, \mathrm{~J}=$ $9.8 \mathrm{~Hz}, 1 \mathrm{H}, \mathrm{CH}_{2}$-bridge). 


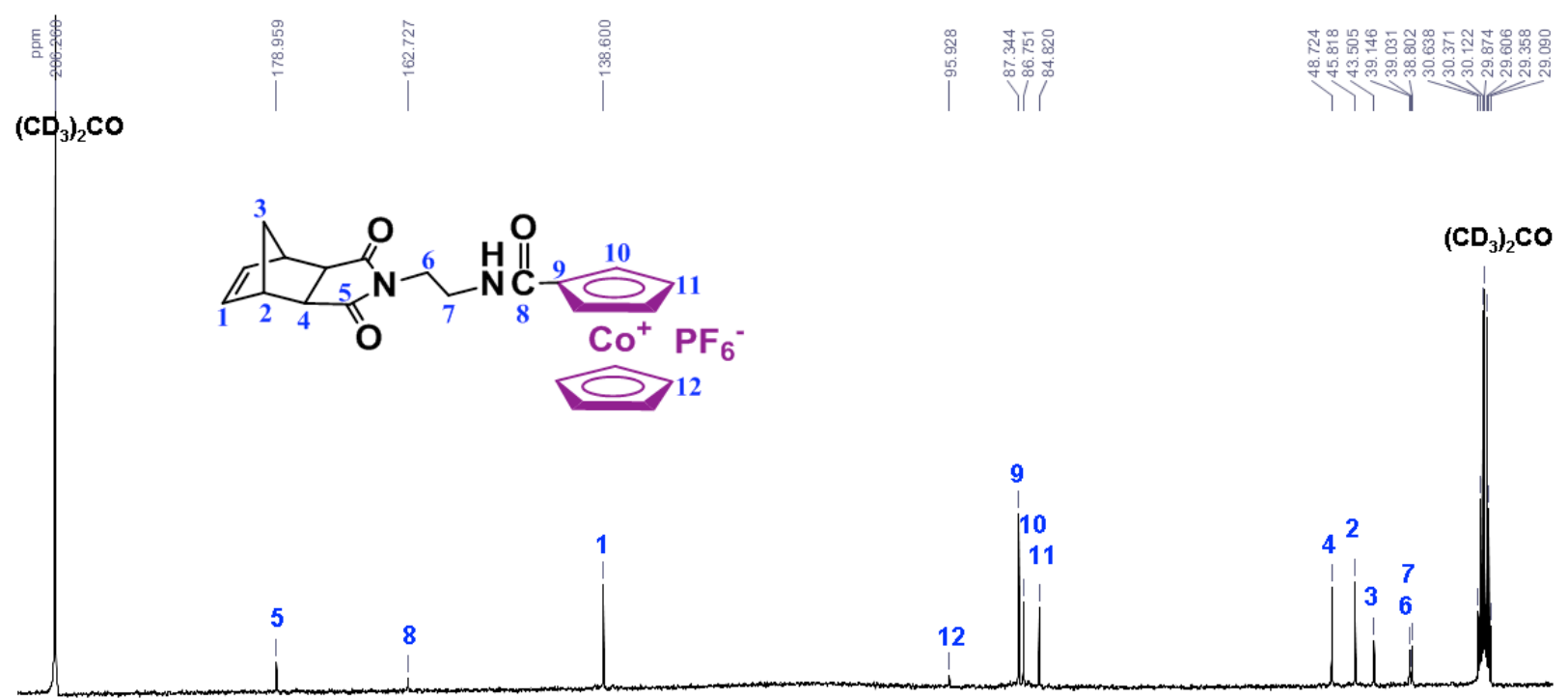

Figure S24 ${ }^{13} \mathrm{C}$ NMR spectrum of monomer 4 in acetone- $d_{6}$.

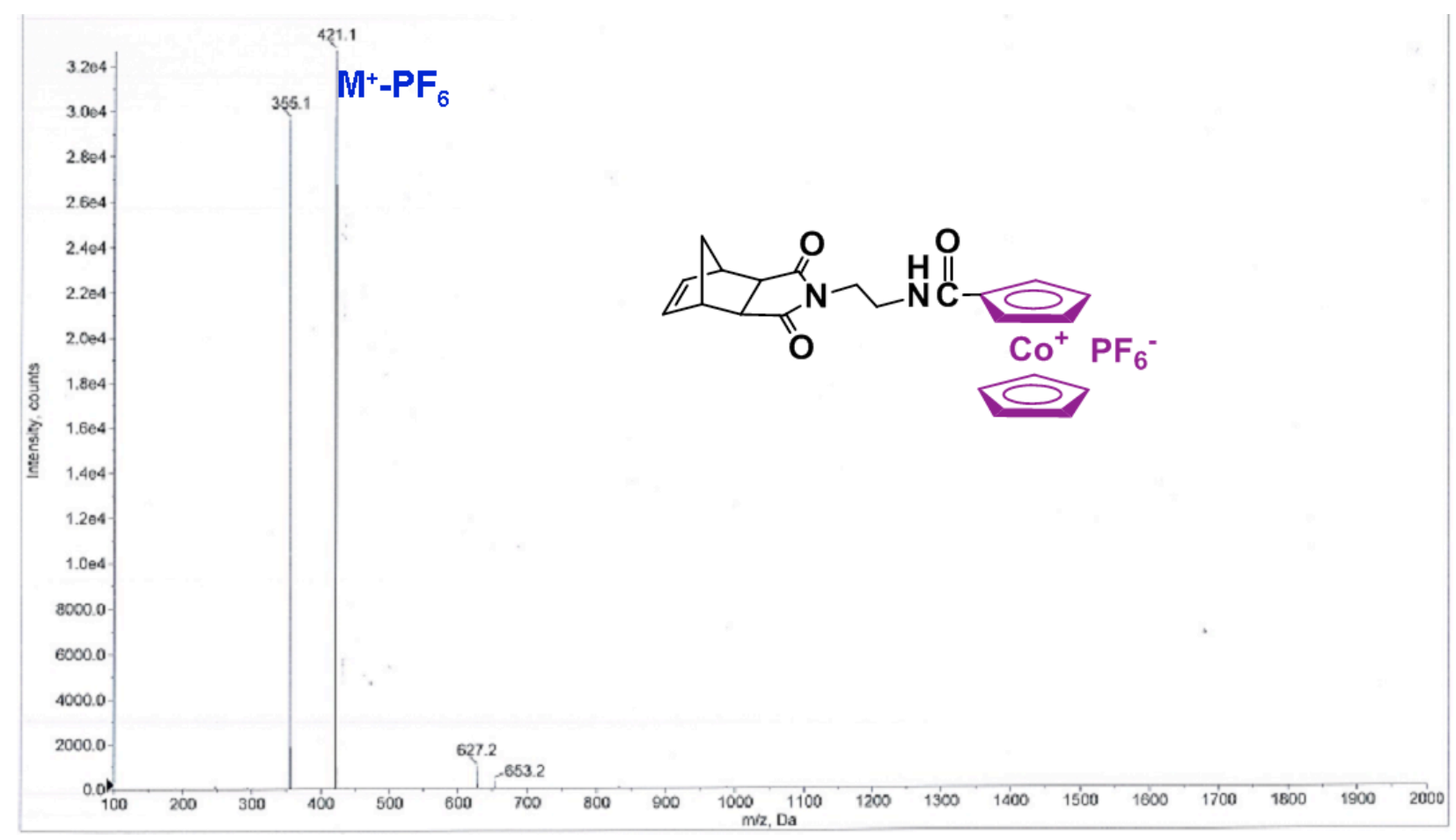

Figure S25 ESI mass spectrum of monomer 4 


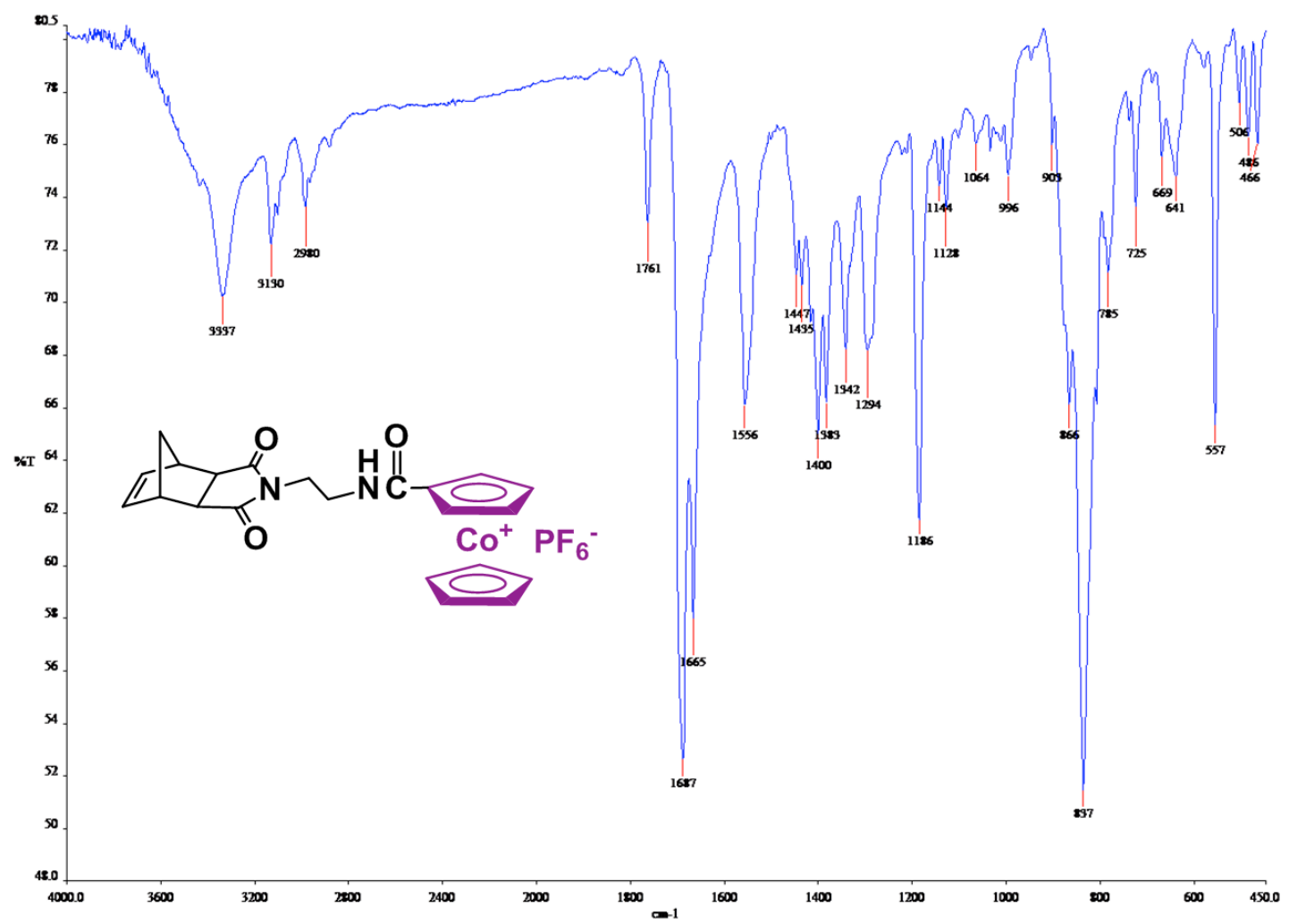

Figure S26 IR spectrum of monomer 4.

$3337 \mathrm{~cm}^{-1}\left(v_{\mathrm{NH}}\right), 1761 \mathrm{~cm}^{-1}\left(v_{\mathrm{C}=\mathrm{C}}\right), 1687 \mathrm{~cm}^{-1}\left(v_{\mathrm{NC}=\mathrm{O}}\right), 1665 \mathrm{~cm}^{-1}\left(v_{\mathrm{NHC}=\mathrm{O}}\right), 837 \mathrm{~cm}^{-1}\left(v_{\mathrm{PF} 6}\right)$.

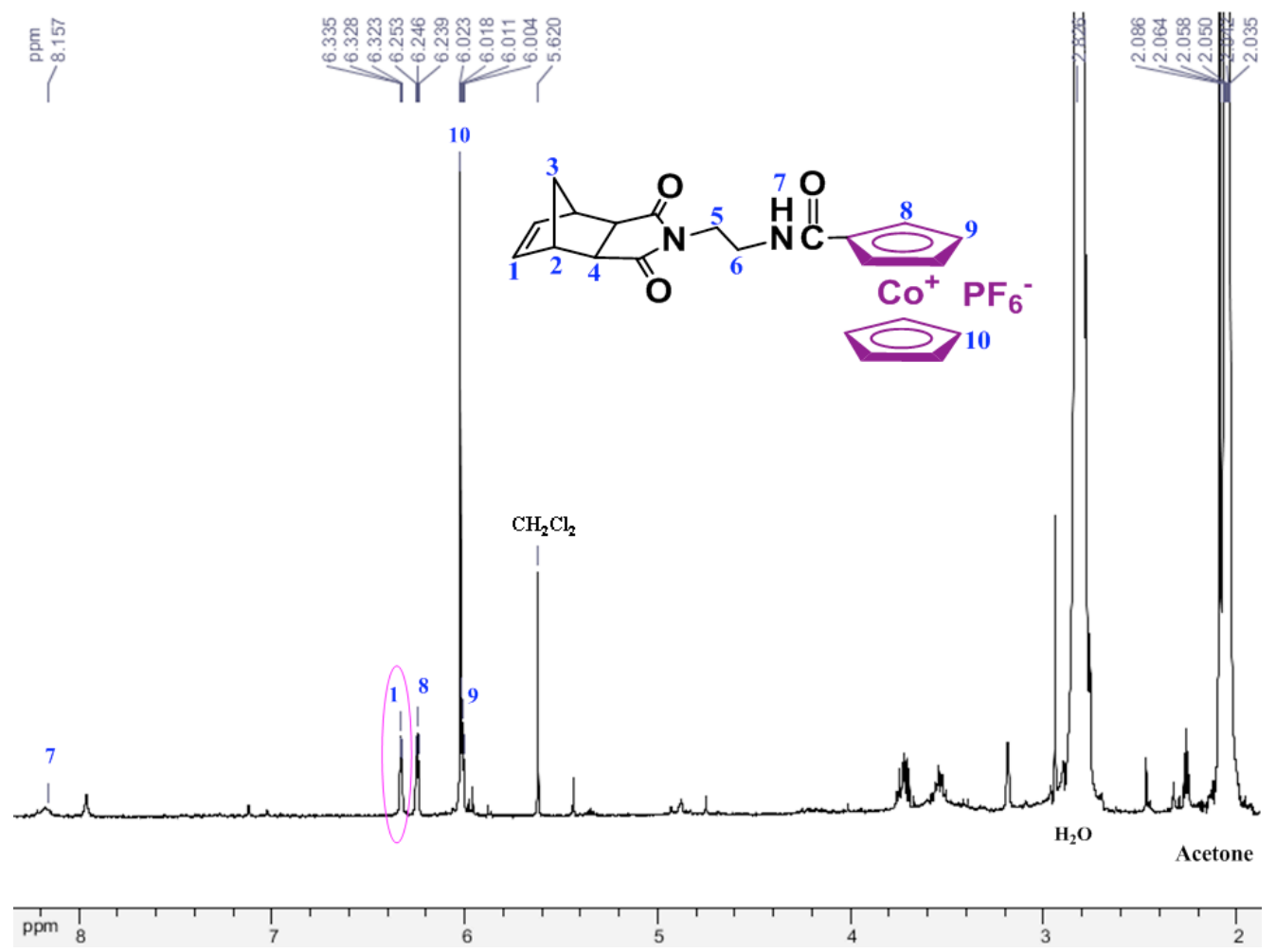

Figure S27 ${ }^{1} \mathrm{H}$ NMR spectrum $(300 \mathrm{MHz})$ in acetone- $d_{6}$ of products in filtrate and washing-liquors from the ROMP reaction mixture of monomer 4 after 10 minutes stirring. The signal surrounded in pink corresponds to the olefin protons of monomer 4 . 


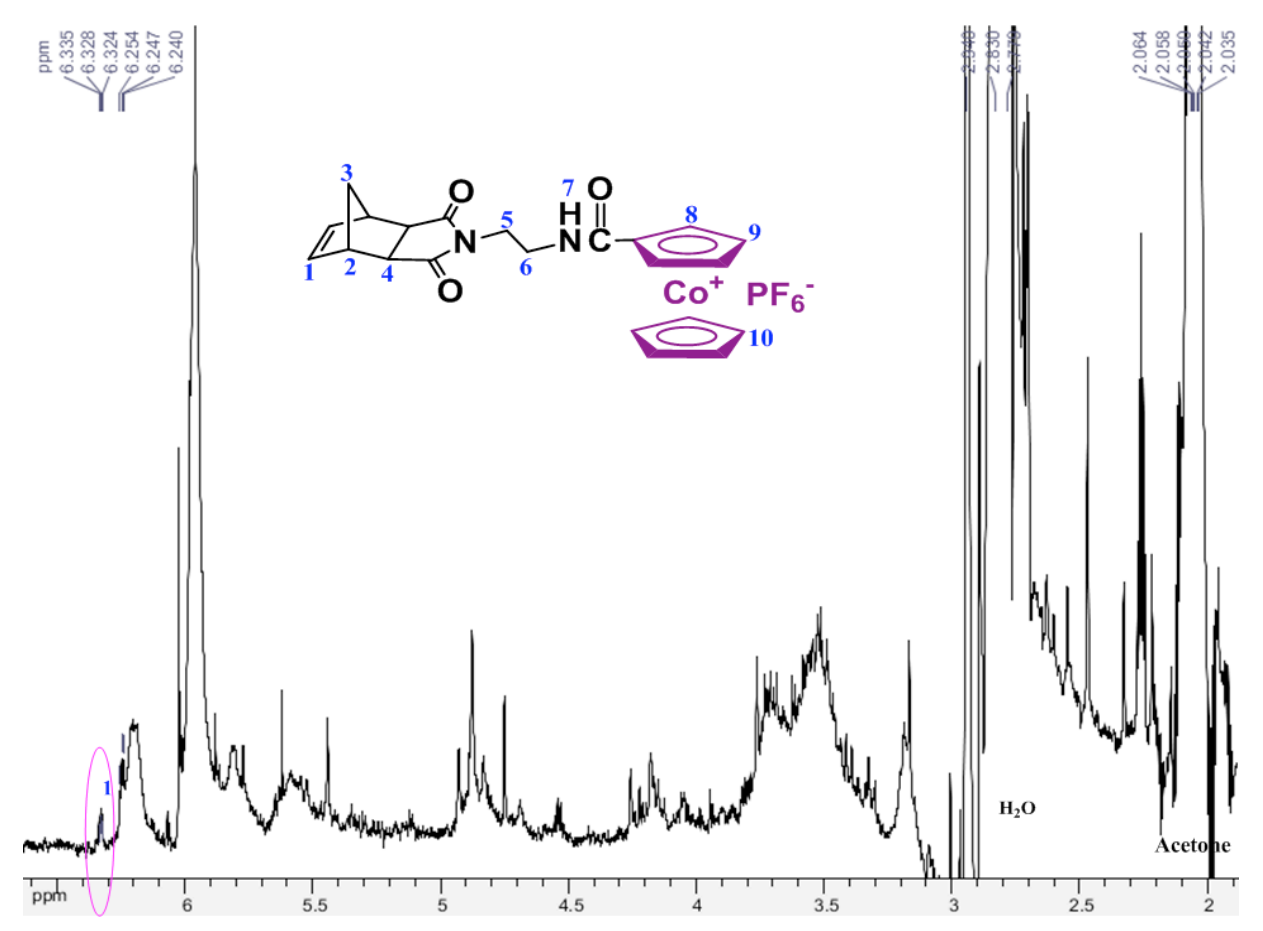

Figure S28 Enlarged ${ }^{1} \mathrm{H}$ NMR spectrum $(300 \mathrm{MHz})$ in acetone- $d_{6}$ of products in filtrate and washing-liquors from the ROMP reaction mixture of monomer 4 after 20 minutes stirring. The signal surrounded in pink corresponds to the olefin protons of monomer 4 . This result shows that a little of monomer $\mathbf{4}$ was left after 20 minutes stirring.
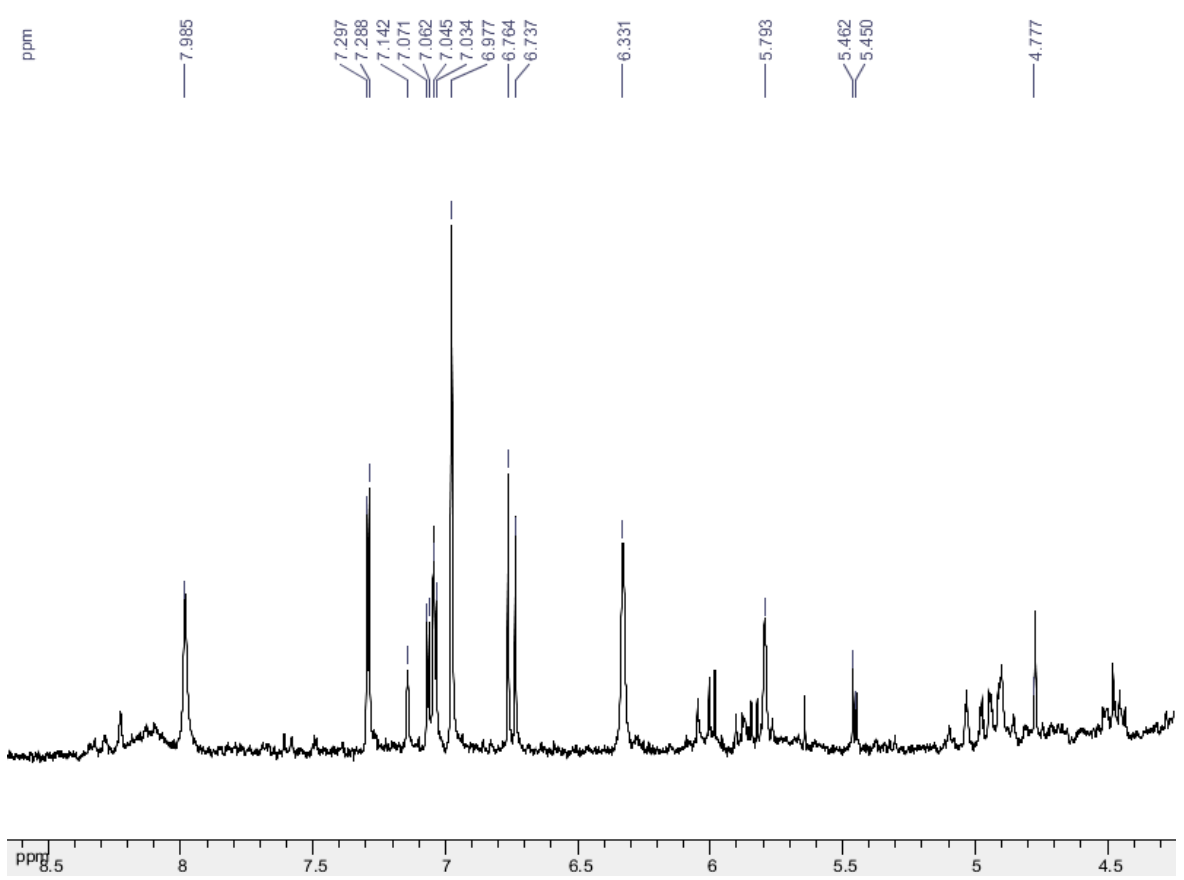

Figure S29 Enlarged ${ }^{1} \mathrm{H}$ NMR spectrum $(300 \mathrm{MHz})$ in acetone- $d_{6}$ of products in filtrate and washing-liquors from the ROMP reaction mixture of monomer 4 after 30 minutes stirring. The peak at $6.33 \mathrm{ppm}$ cannot be assigned to the olefin protons for monomer 4 because no characteristic peak of free $\mathrm{Cp}$ and substituted Cp' was observed nearby. Peaks at 7.30-4.78 probably arise from the proton of catalyst 1 or/ and noise. 


\section{Diblock copolymer 6 Synthesis}

Monomers $2(32.8 \mathrm{mg}, 0.0529 \mathrm{mmol})$ and $4(29.9 \mathrm{mg}, 0.0529 \mathrm{mmol})$ were added into two separate small glass tubes, and dissolved in $0.3 \mathrm{~mL}$ dry $\mathrm{CH}_{2} \mathrm{Cl}_{2}$ and $0.3 \mathrm{~mL}$ dry DMF, respectively. A desired amount of Grubbs catalyst $3^{\text {rd }} \mathbf{1}(1.87 \mathrm{mg}, 0.00212 \mathrm{mmol})$ was added into a small Schlenk flask, flushed with nitrogen, and dissolved in $0.03 \mathrm{~mL}$ of dry $\mathrm{CH}_{2} \mathrm{Cl}_{2}$. First, monomer 2 was transferred to the flask containing the catalyst via a small syringe. The reaction mixture was stirred vigorously for 10 minutes at $r$. t., after which monomer $\mathbf{4}$ in DMF was added into the flask using a small syringe. The polymerization was allowed to continue for another 20 minutes, and then quenched with $0.2 \mathrm{~mL}$ of EVE. The yellow-green solid polymer 6 was purified by precipitating from $\mathrm{CH}_{2} \mathrm{Cl}_{2}$ with $\mathrm{Et}_{2} \mathrm{O}$ three times and dried in vacuo until constant weight. Yield: $92 \%$. ${ }^{1} \mathrm{H}$ NMR (300 MHz, DMSO- $\left.d_{6}\right), \delta_{\mathrm{ppm}}$ : 9.08 (broad, NHCO- $\left(\eta^{5}-\mathrm{C}_{5} \mathrm{H}_{4}\right) \mathrm{Co}\left(\eta^{5}-\mathrm{C}_{5} \mathrm{H}_{5}\right)$ ), 7.46-6.91 (m, NHCO-Fc* and phenyl), 6.21 (s, sub. Cp of $\left.\left(\eta^{5}-\mathrm{C}_{5} \mathrm{H}_{4}\right) \mathrm{Co}\left(\eta^{5}-\mathrm{C}_{5} \mathrm{H}_{5}\right)\right), 5.90$ (s, sub. $\mathrm{Cp}$ of $\left.\left(\eta^{5}-\mathrm{C}_{5} \mathrm{H}_{4}\right) \mathrm{Co}\left(\eta^{5}-\mathrm{C}_{5} \mathrm{H}_{5}\right)\right), 5.85\left(\mathrm{~s}\right.$, free $\mathrm{Cp}$ of $\left.\left(\eta^{5}-\mathrm{C}_{5} \mathrm{H}_{4}\right) \mathrm{Co}\left(\eta^{5}-\mathrm{C}_{5} \mathrm{H}_{5}\right)\right), 5.65$ and 5.48 (double broad, $\mathrm{CH}=\mathrm{CH}$ ), 3.51-3.28 (broad, $\mathrm{CH}_{2}\left(\mathrm{CH}_{2} \mathrm{OCH}_{2}\right)_{3} \mathrm{CH}_{2}, \mathrm{NCH}_{2} \mathrm{CH}_{2} \mathrm{~N}$ and $\mathrm{H}_{2} \mathrm{O}$ ), 3.04 (broad, $=\mathrm{CH}-\mathrm{CH}), 2.50$ (broad, DMSO and $\mathrm{CO}-\mathrm{CH}), 1.98\left(\mathrm{broad}, \mathrm{CH}_{3}\right.$ of $\left.\left(\eta^{6}-\mathrm{C}_{5} \mathrm{Me}_{6}\right)\right), 1.46$ (broad, $\mathrm{CH}=\mathrm{CHCHCH}_{2}$ ).

\section{Kinetic Study}

In order to know when the polymerization for the second block can finish, the kinetic study was conducted as following: Monomer $2(0.413 \mathrm{~g}, 0.666 \mathrm{mmol})$ in $4 \mathrm{~mL}$ dry $\mathrm{CH}_{2} \mathrm{Cl}_{2}$ was added into the solution of Grubbs catalyst $3^{\text {rd }} \mathbf{1}(0.0236 \mathrm{~g}, 0.0266 \mathrm{mmol})$ in $0.3 \mathrm{~mL}$ dry $\mathrm{CH}_{2} \mathrm{Cl}_{2}$. The reaction mixture was stirred vigorously for 10 minutes at $r$. t. under $\mathrm{N}_{2}$ atmosphere. Then, monomer 4 $(0.377 \mathrm{~g}, 0.666 \mathrm{mmol})$ in $4 \mathrm{~mL}$ dry DMF was added, and after10, 20, 30, 45, 60, and 90 minutes, respectively, $0.5 \mathrm{~mL}$ of samples were taken out, quenched with $0.5 \mathrm{~mL}$ of EVE and precipitated by adding $5.0 \mathrm{~mL}$ of $\mathrm{Et}_{2} \mathrm{O}$. The obtained precipitate was washed with $\mathrm{Et}_{2} \mathrm{O}(3 \times 5 \mathrm{~mL})$, vacuumed and then checked for ${ }^{1} \mathrm{H}$ NMR spectrum in $\mathrm{CD}_{2} \mathrm{Cl}_{2}$. All the washing liquors and filtrate were collected, the solvent was removed in vacuo, and the ${ }^{1} \mathrm{H}$ NMR spectrum of the residue was recorded in acetone- $d_{6}$. The monomer conversion was deemed to be $100 \%$ when the signal of the olefin protons for monomer 4 at $6.30 \mathrm{ppm}$ in $\mathrm{CD}_{2} \mathrm{Cl}_{2}$ and $6.32 \mathrm{ppm}$ in acetone- $d_{6}$ disappeared. Actually, the polymerization for the second block can finish in 20 minutes with $100 \%$ monomer conversion. 


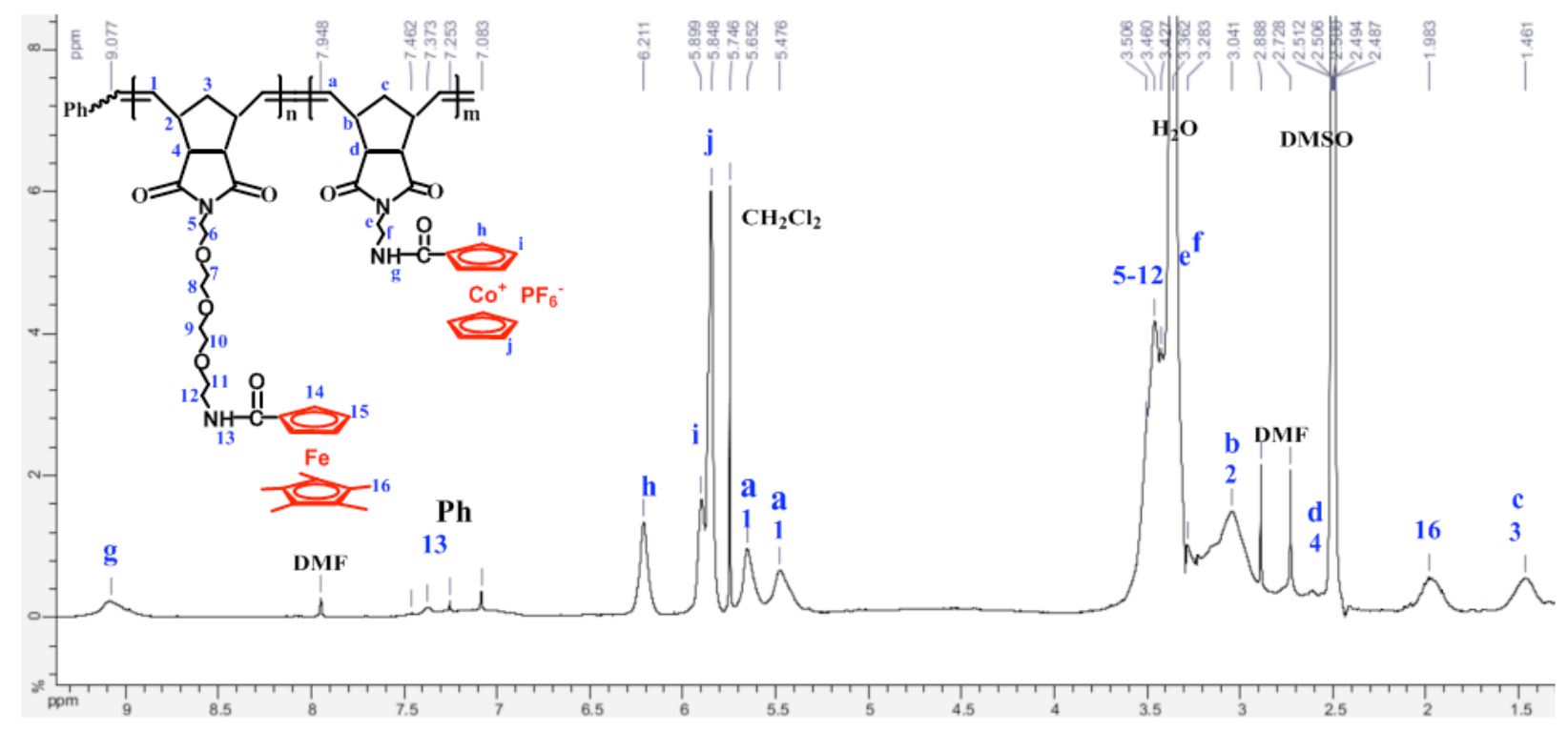

Figure S30 ${ }^{1} \mathrm{H}$ NMR spectrum of diblock copolymer 6 in DMSO- $d_{6}$.

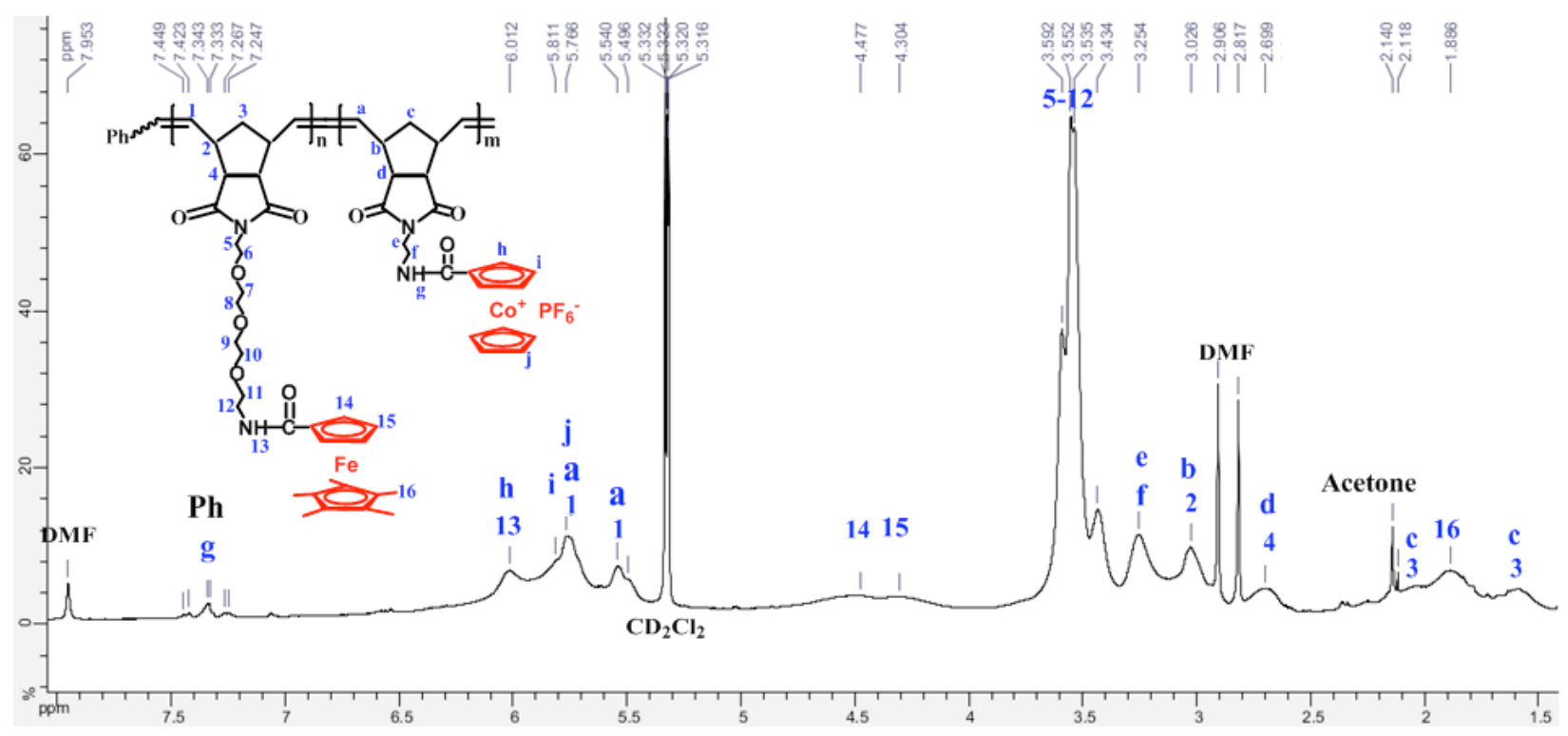

Figure $\mathbf{S 3 1}{ }^{1} \mathrm{H}$ NMR spectrum of diblock copolymer $\mathbf{6}$ in $\mathrm{CD}_{2} \mathrm{Cl}_{2}$.

${ }^{1} \mathrm{H}$ NMR $\left(300 \mathrm{MHz}, \mathrm{CD}_{2} \mathrm{Cl}_{2}\right)$, $\delta_{\mathrm{ppm}}: 7.45-7.25$ (m, NHCO- $\left(\eta^{5}-\mathrm{C}_{5} \mathrm{H}_{4}\right) \mathrm{Co}\left(\eta^{5}-\mathrm{C}_{5} \mathrm{H}_{5}\right)$ and phenyl), 6.01 (broad, NHCO-pentamethylferrocene and sub. $\mathrm{Cp}$ of $\left(\eta^{5}-\mathrm{C}_{5} \mathrm{H}_{4}\right) \mathrm{Co}\left(\eta^{5}-\mathrm{C}_{5} \mathrm{H}_{5}\right), 5.81,5.77$ (broad, $\mathrm{CH}=\mathrm{CH}$, sub. and free $\mathrm{Cp}$ of $\left.\left(\eta^{5}-\mathrm{C}_{5} \mathrm{H}_{4}\right) \mathrm{Co}\left(\eta^{5}-\mathrm{C}_{5} \mathrm{H}_{5}\right)\right), 5.54(\operatorname{broad}, \mathrm{CH}=\mathrm{CH}), 4.48,4.30$ (double broad, sub. $\mathrm{Cp}$ of of pentamethylferrocene), 3.59-3.43 (m, $\left.\mathrm{CH}_{2}\left(\mathrm{CH}_{2} \mathrm{OCH}_{2}\right)_{3} \mathrm{CH}_{2}\right), 3.25$ (braod, $\mathrm{NCH}_{2} \mathrm{CH}_{2} \mathrm{~N}$ ), 3.03 (broad, $=\mathrm{CH}-\mathrm{CH}$ ), 2.70 (broad, $\mathrm{CO}-\mathrm{CH}$ ), 2.05 (broad, $\left.\mathrm{CH}=\mathrm{CHCHCH} \boldsymbol{H}_{2}\right), 1.89\left(\right.$ broad, $\mathrm{CH}_{3}$ of $\left.\left(\eta^{6}-\mathrm{C}_{6} \mathrm{Me}_{6}\right)\right), 1.59$ (broad, $\left.\mathrm{CH}=\mathrm{CHCHCH} \boldsymbol{H}_{2}\right)$. 




Figure $\mathbf{S 3 2}{ }^{13} \mathrm{C}$ NMR spectrum of diblock copolymer 6 in $\mathrm{CD}_{2} \mathrm{Cl}_{2}$.

${ }^{13} \mathrm{C}$ NMR (50 MHz, $\left.\mathrm{CD}_{2} \mathrm{Cl}_{2}\right)$, $\delta$ ppm: $178.2(\mathrm{CON}), 168.4(\mathrm{CONH}), 133.8,131.9(\mathrm{CH}=\mathrm{CH}), 87.0$, 86.2, $85.5\left(\left(\eta^{5}-C_{5} \mathrm{H}_{4}\right) \mathrm{Co}\left(\eta^{5}-\mathrm{C}_{5} \mathrm{H}_{5}\right)\right.$ and $\left.\left(\eta^{5}-C_{5} \mathrm{Me}_{5}\right)\right), 70.4,70.1,70.0,69.8,68.7,67.0\left(\mathrm{CH}_{2}\right), 51.1$ $(\mathrm{CO}-\mathrm{CH}), 48.1 \quad(=\mathrm{CH}-\mathrm{CH}), 46.2,45.9 \quad\left(\mathrm{CH}_{2}\right.$ of cyclopentane $), 43.0,42.6,39.1,37.8$ $\left(-\mathrm{CH}_{2} \mathrm{CH}_{2} \mathrm{NCO}\right), 10.3\left(\mathrm{CH}_{3}\right.$ of $\left.\eta^{5}-\mathrm{C}_{5} \mathrm{Me}_{5}\right)$.

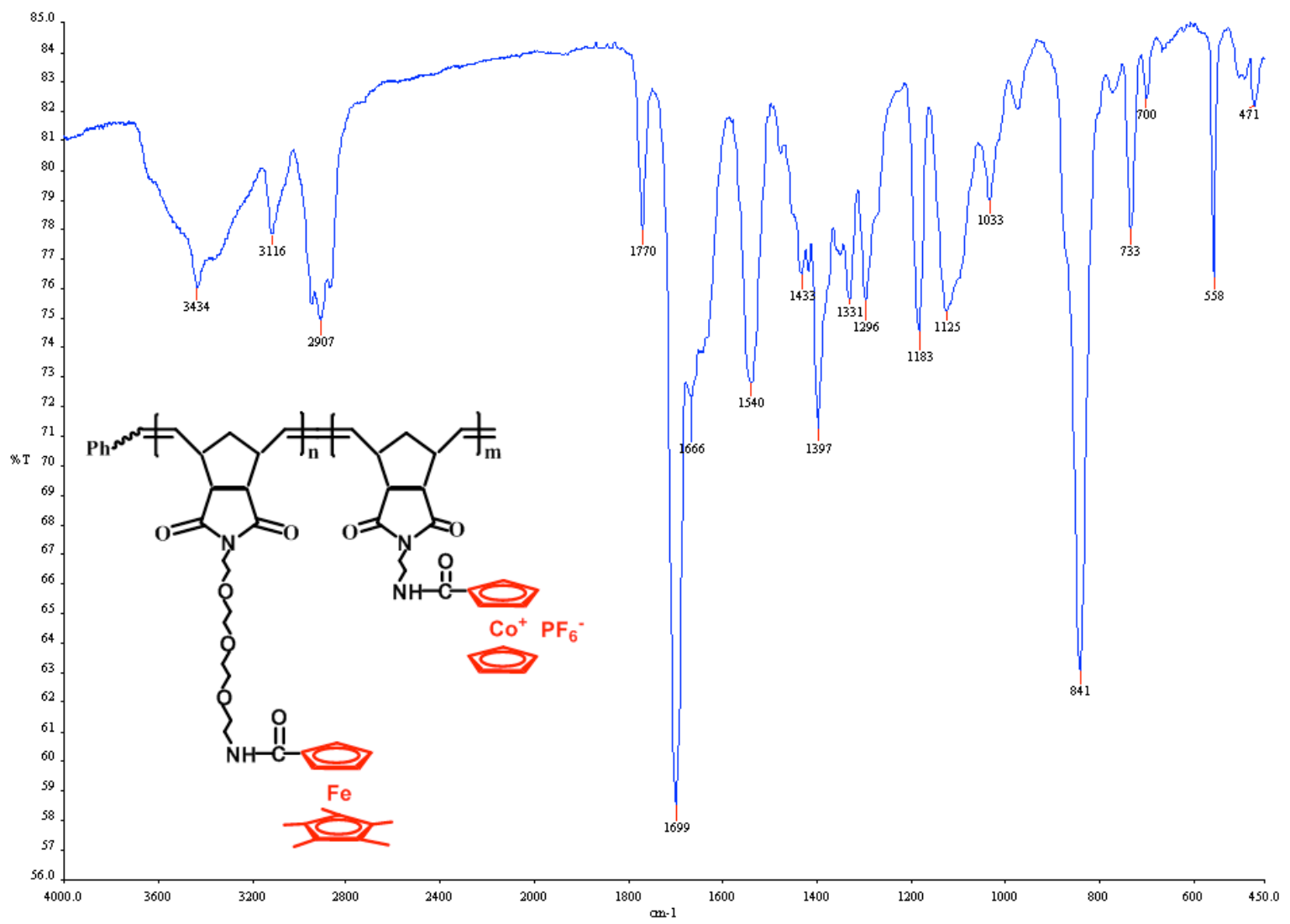

Figure S33 IR spectrum of diblock copolymer 6.

$3434 \mathrm{~cm}^{-1}(\mathrm{NH}), 2907 \mathrm{~cm}^{-1}\left(\mathrm{CH}_{3}\right), 1770 \mathrm{~cm}^{-1}(\mathrm{C}=\mathrm{C}), 1699 \mathrm{~cm}^{-1}(\mathrm{NC}=\mathrm{O}), 1666 \mathrm{~cm}^{-1}(\mathrm{NHC}=\mathrm{O})$, $841 \mathrm{~cm}^{-1}\left(\mathrm{PF}_{6}\right)$. 




Figure S34 UV-Vis spectrum of diblock copolymer 6 in $\mathrm{CH}_{2} \mathrm{Cl}_{2}$.

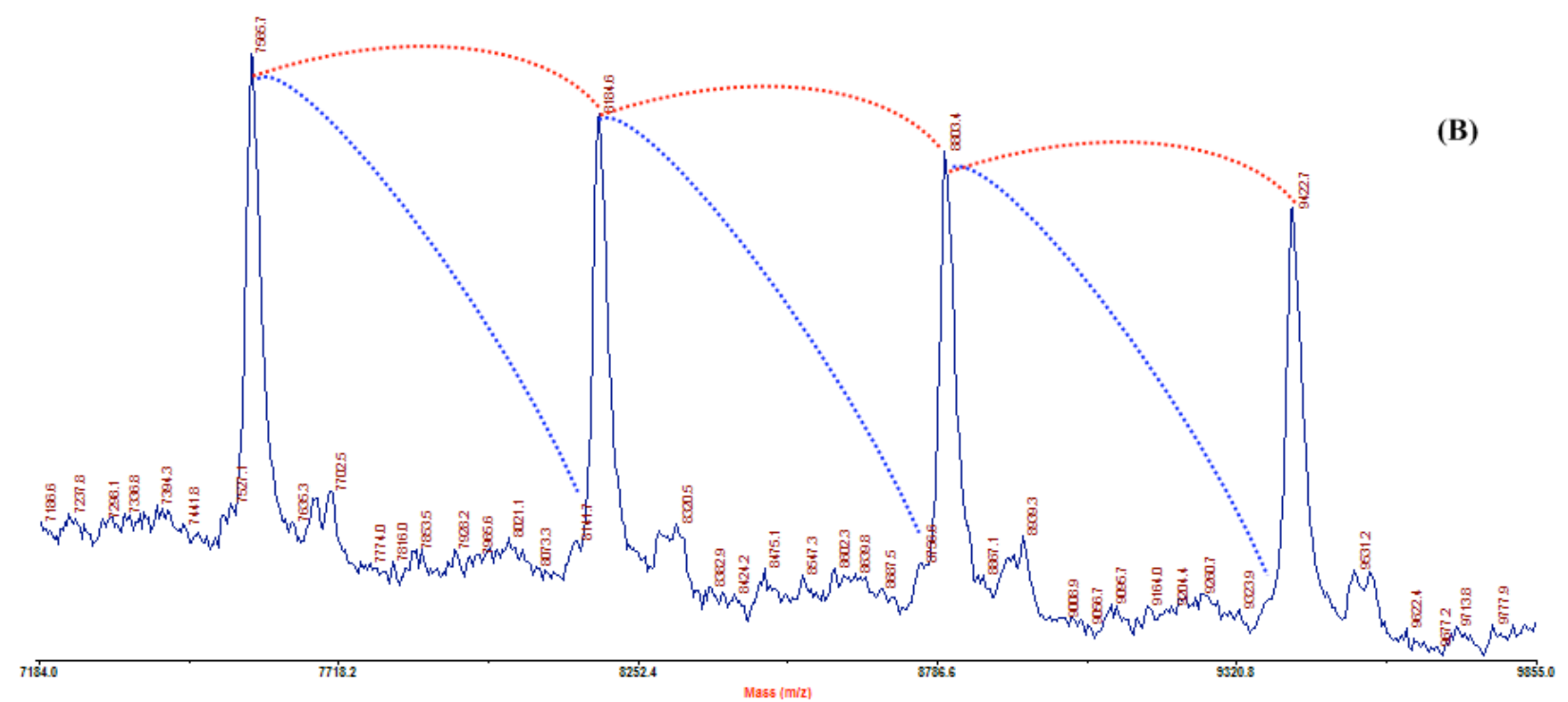

Figure S35 MALDI-TOF MS spectrum of diblock copolymer 6. The feed molar ratio of monomers 2 and 4 to 1 is $25: 25: 1$. (A) is the region of 4999-20000 in the spectrum (See Figure 2 in the main text); and (B) is the enlarge region of the spectrum from 7184 to 9855 . The red dotted lines are corresponding to the difference between molecular peaks of a value of $620 \pm 1 \mathrm{Da}$ (MW of monomer 2). The blue dotted lines are corresponding to the difference between molecular peaks of a value of $566 \pm 1 \mathrm{Da}$ (MW of monomer 4). 


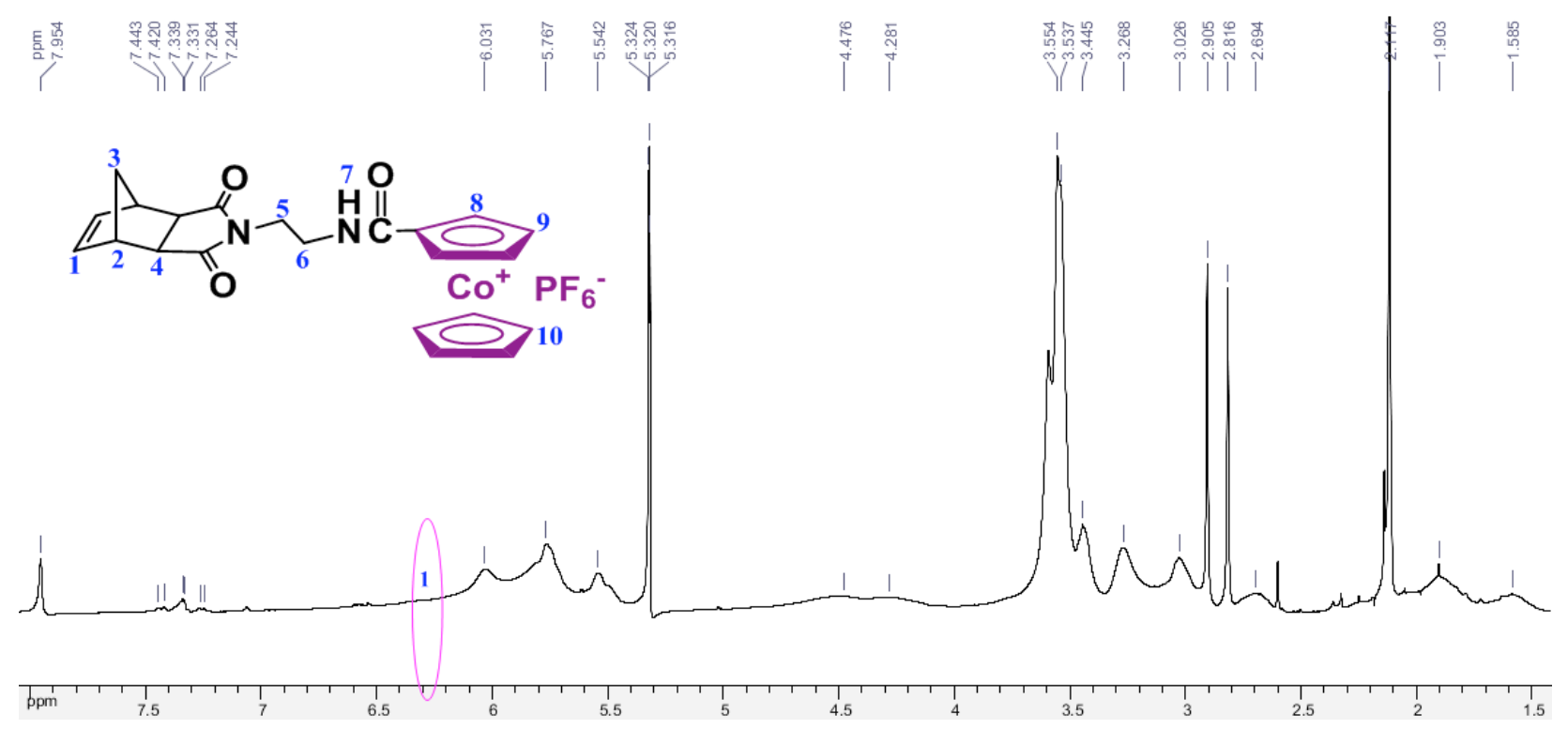

Figure $\mathbf{S 3 6}{ }^{1} \mathrm{H}$ NMR spectrum $(300 \mathrm{MHz})$ in $\mathrm{CD}_{2} \mathrm{Cl}_{2}$ of the precipitate from the ROMP reaction mixture for the synthesis of diblock copolymer $\mathbf{6}$ after the addition of monomer $\mathbf{4}$ with 20 minutes stirring. No peak is observed at $6.30 \mathrm{ppm}$ for the olefin protons of monomer 4 .

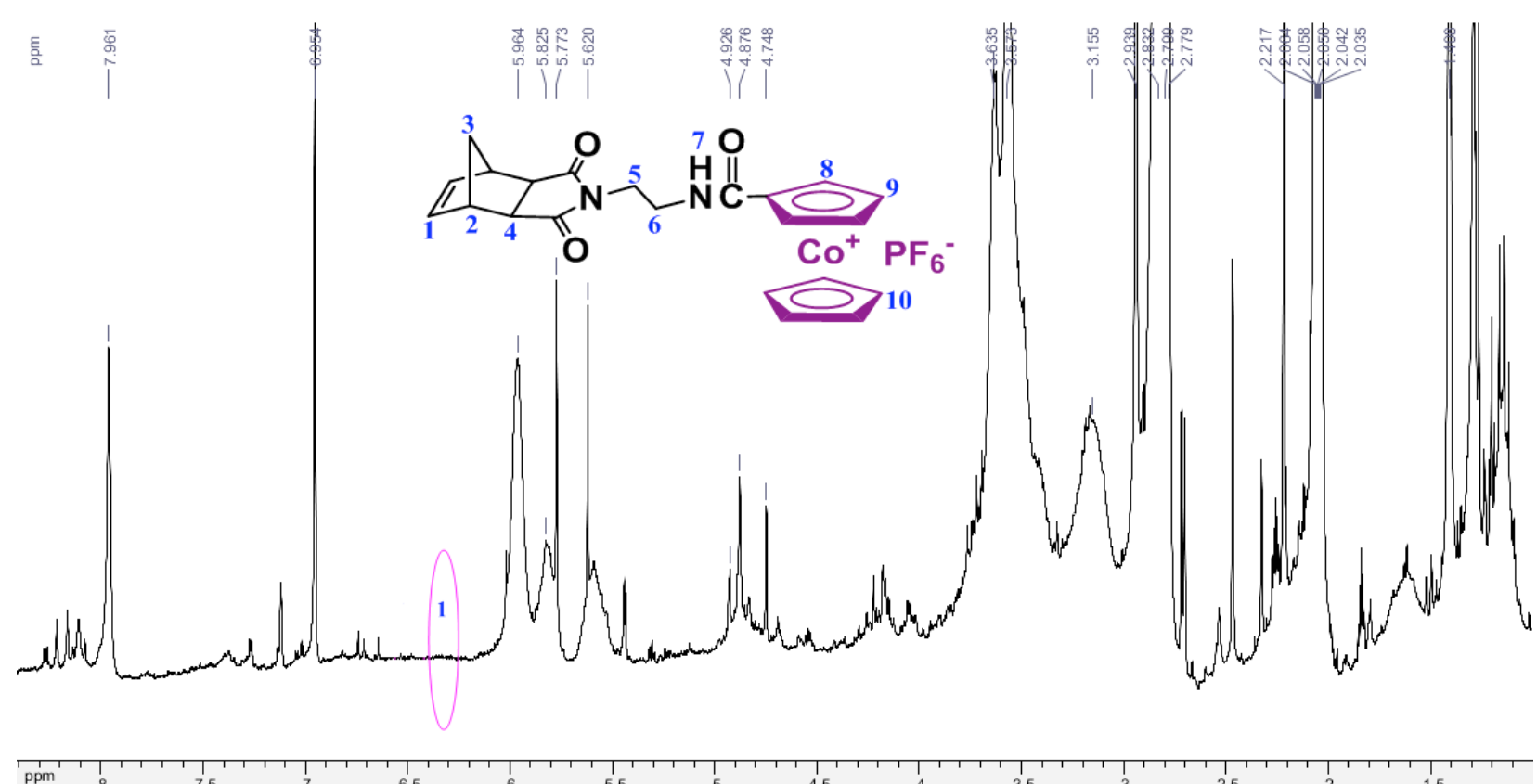

Figure S37 Enlarged ${ }^{1} \mathrm{H}$ NMR spectrum $(300 \mathrm{MHz})$ in acetone- $d_{6}$ of the products in washing liquors and filtrate from the ROMP reaction mixture for the synthesis of diblock copolymer 6 after the addition of monomer 4 with 20 minutes stirring. No peak is observed at $6.32 \mathrm{ppm}$ for the olefin protons of monomer 4 . Namely no monomer $\mathbf{4}$ was left and the ROMP of $\mathbf{4}$ is complete. 
Calculation of the polymer degrees of diblock copolymers 6 by ${ }^{1} \mathrm{H}$ NMR end-group analysis and errors

Table S1 Polymer degree of the first $\mathrm{Fc}^{*}$ block using the ${ }^{1} \mathrm{H} \mathrm{NMR}$ spectrum in $\mathrm{CD}_{2} \mathrm{Cl}_{2}$ of homopolymer of $\mathbf{2}^{\mathrm{a}}$

\begin{tabular}{|l|l|l|l|l|l|l|l|}
\hline $\begin{array}{l}\text { Proton } \\
\text { peak }\end{array}$ & $\begin{array}{l}\text { End- } \\
\text { phenyl }\end{array}$ & Amido & olefinic & Sub. Cp & Sub. Cp & $\begin{array}{l}\text { methylen } \\
\mathrm{e}\end{array}$ & $\begin{array}{l}\text { Methyl of } \\
\mathrm{C}_{5} \mathrm{Me}_{5}\end{array}$ \\
\hline$\delta p p m$ & $7.38-7.22$ & 6.16 & $5.72-5.50$ & 4.13 & 3.87 & $3.59-3.50$ & 1.74 \\
\hline Integr. & 0.197 & $0.96-1.0$ & $2.00-2.04$ & $1.93-2.00$ & $1.86-1.95$ & $15.7-16.3$ & $14.3-14.7$ \\
\hline $\mathrm{n}_{\mathrm{p} 2 \mathrm{a}} \mathrm{b}$ & - & $24-25$ & $25-26$ & $25-25$ & $24-25$ & $25-26$ & $24-25$ \\
\hline $\mathrm{n}_{\mathrm{p} 2 \mathrm{~b}}{ }^{\mathrm{c}}$ & \multicolumn{7}{|c|}{$25 \pm 1$} \\
\hline
\end{tabular}

${ }^{\mathrm{a}}$ Figure S5 is used for the calculation of polymer degree of the first $\mathrm{Fc}^{*}$ block. ${ }^{\mathrm{b}}$ Calculated polymer degrees based on integral of each peak. ${ }^{c}$ Average polymer degree according to $\mathrm{n}_{\mathrm{p} 2 \mathrm{a}}$ values.

As shown in Table $\mathrm{S} 1$, the ${ }^{1} \mathrm{H}$ NMR end-group analysis in $\mathrm{CD}_{2} \mathrm{Cl}_{2}$ provides the value of $25 \pm 1$ for the polymer degree of the first $\mathrm{Fc}^{*}$ block. These calculations were conducted by comparing the intensities of the signals of the five protons of the end-phenyl group with those of characteristic protons in the $\mathrm{Fc}^{*}$ block. Namely, the proton integration for end-phenyl group (7.39-7.22 ppm) was compared with those of the amide proton $(6.16 \mathrm{ppm})$, olefin protons (5.72-5.50 ppm), Cp protons (4.13 and $3.87 \mathrm{ppm}$ ), methylene protons (3.5-3.50 ppm) and methyl protons of $\mathrm{C}_{5} \mathrm{Me}_{5}$ (1.74 ppm), respectively. The obtained values are 24-25, 25-26, 25-25, 24-25, 25-26 and 24-25, respectively. Thus, the overage value of the polymer degree for the first block is $25 \pm 1$. The error is due to the integration error on each signal.

Table S2 Polymer degree of the second CcX block using the ${ }^{1} \mathrm{H}$ NMR spectrum in DMSO- $d_{6}$ of copolymer 6. ${ }^{\mathrm{a}, \mathrm{b}}$

\begin{tabular}{|l|c|c|c|c|}
\hline $\begin{array}{l}\text { Proton } \\
\text { peak }\end{array}$ & $\begin{array}{c}\text { End-phenyl and amido } \\
\text { in the first block }\end{array}$ & $\begin{array}{c}\text { Amido in the } \\
\text { second block }\end{array}$ & $\begin{array}{c}\text { Sub. Cp in the } \\
\text { second block }\end{array}$ & $\begin{array}{c}\text { Sub. and free Cp in } \\
\text { the second block }\end{array}$ \\
\hline$\delta_{\mathrm{ppm}}$ & $7.46-6.91$ & 9.08 & 6.21 & 5.90 and 5.85 \\
\hline Integration & $1.351-1.471$ & $0.978-1.019$ & $2.0-2.068$ & $6.818-7.012$ \\
\hline $\mathrm{n}_{\mathrm{p} 2 \mathrm{a}}$ & - & $17-20^{\mathrm{c}}$ & $17-21^{\mathrm{d}}$ & $17-20^{\mathrm{e}}$ \\
\hline $\mathrm{n}_{\mathrm{p} 2 \mathrm{~b}}{ }^{\mathrm{f}}$ & \multicolumn{4}{|c|}{$19 \pm 2$} \\
\hline
\end{tabular}

${ }^{a}$ Figure S30 is used for the calculation of the polymer degree of the second block. ${ }^{\mathrm{b}}$ The average polymer degree of $25 \pm 1$ for the first $\mathrm{Fc}^{*}$ block is used for the calculation of polymer degree of the second CcX block. ${ }^{c}$ Calculated by comparing the end-phenyl and amido proton integrations in the first block and the amido in the second block. ${ }^{\mathrm{d}}$ Calculated by comparing the end-phenyl and amido proton integrations in the first block and the substituted $\mathrm{Cp}$ proton integration in the 
second block. ${ }^{\mathrm{e}}$ Calculated by comparing the end-phenyl and amido proton integrations in the first block and the substituted and free Cp proton integration in the second block. ${ }^{\mathrm{f}}$ Average polymer degree for the second block according to the $\mathrm{n}_{\mathrm{p} 2 \mathrm{a}}$ values.

For the second CcX block, the polymer degree is $19 \pm 2$, as shown in Table S2. The higher error results from the following two sides. (1) This analysis is carried out by comparing the integration of end-phenyl and characteristic amido peak from the first $\mathrm{Fc}^{*}$ block and the integrations of characteristic amido, substituted and free $\mathrm{Cp}$ peaks in the second CcX block. The former is located at 7.46-6.91 ppm, and the latter is observed at 9.08, 6.21, 5.90 and 5.85, respectively. Obviously, integrations for each peak have errors that result in the corresponding error for the calculated polymer degree of the second block. (2) The above obtained polymer degree of $25 \pm 1$ for the first $\mathrm{Fc}^{*}$ block is used for the calculation of the polymer degree for the second CcX block, which also results in a larger error than for the first block. The obtained values are 17-20, 17-21 and 17-20, respectively, and then the average is $19 \pm 2$.

Table S3 Redox potentials, chemical $\left(i_{c} / i_{a}\right)$ and electrochemical $\left(E_{\mathrm{pa}}-E_{\mathrm{pc}}=\Delta \boldsymbol{E}\right)$ reversibility data for diblock copolymer $\mathbf{6}$.

\begin{tabular}{|l|c|c|c|}
\hline Redox centers & $E_{1 / 2}(\mathrm{~V})$ & $(\Delta E)(\mathrm{V})$ & $i_{c} / i_{a}$ \\
\hline $\mathrm{Fc}^{*}$ & 0.367 & 0.010 & 1.06 \\
\hline $\mathrm{CcX}\left(\mathrm{Co}^{\mathrm{III} / \mathrm{II}}\right)$ & -0.711 & 0.020 & 1.06 \\
\hline $\mathrm{CcX}\left(\mathrm{Co}^{\mathrm{II} / \mathrm{I}}\right)$ & -1.667 & 0.050 & 1.14 \\
\hline
\end{tabular}

\section{Calculation of polymerization degrees $\left(n_{\mathrm{p} 3}\right)$ for diblock copolymer 6 by Bard-Anson's method}

Bard-Anson's electrochemical equation: ${ }^{\mathrm{S} 6}$

$n_{p}=\frac{\left(i_{d p} / C_{p}\right)}{\left(i_{d m} / C_{m}\right)}\left(\frac{M_{p}}{M_{m}}\right)^{0.275}$

$\left(i_{\mathrm{dp}}\right.$ : intensity of polymer; $\mathrm{C}_{\mathrm{p}}$ : concentration of polymer; $i_{\mathrm{dm}}$ : intensity of monomer; $\mathrm{C}_{\mathrm{m}}$ : concentration of monomer; $\mathrm{M}_{\mathrm{p}}$ : molecular weight of polymer; $\mathrm{M}_{\mathrm{m}}$ : molecular weight of monomer).

In this part, the symbol of $n_{\mathrm{p} 3}$ is used to stand for the polymerization degree. So,

$n_{p 3}=\frac{\left(i_{d p} / C_{p}\right)}{\left(i_{d m} / C_{m}\right)}\left(\frac{M_{p}}{M_{m}}\right)^{0.275}$ 
$=\left(\frac{i_{d p} C_{m}}{i_{d m} C_{p}}\right)\left(\frac{M_{p}}{M_{m}}\right)^{0.275}$

$=\left(\frac{i_{d p}\left(n_{m} / v\right)}{i_{d m}\left(n_{p} / v\right)}\right)\left(\frac{M_{p}}{M_{m}}\right)^{0.275}\left(n_{\mathrm{m}}:\right.$ mole of monomer; $n_{\mathrm{p}}$ : mole of polymer; $v$ : volume of solution $)$

$=\left(\frac{i_{d p} n_{m}}{i_{d m} n_{p}}\right)\left(\frac{M_{p}}{M_{m}}\right)^{0.275}$

Here, we use decamethyferrocene $\left(\left[\mathrm{FeCp}_{2}^{*}\right]\right)$ as the monomer reference, because (i) it has the same number of electron transferred between its reduced and oxidized forms as that of the monomers 2 and 4, (ii) its redox potential is sufficiently far from that of $\mathrm{Fc}^{*}$ and $\mathrm{CcX}$ redox center in the polymers, which allows a clear distinction of the CV wave of the reference and that of the polymers 6 . This leads to calculate the polymerization degrees $\left(n_{\mathrm{p} 3}\right)$ of $\mathrm{Fc}^{*}$ block and the cationic CcX block for diblock copolymer $\mathbf{6}$ by the above equation, and the results are listed in Table S4.

Table S4 Polymerization degree $\left(n_{\mathrm{p} 1}\right)$ of diblock copolymer 6 calculated by the Bard-Anson's equation

\begin{tabular}{|c|c|c|}
\hline$\left[\mathrm{M}_{2}\right]:\left[\mathrm{M}_{4}\right]:[\mathrm{C}]^{\mathrm{a}}$ & \multicolumn{2}{|c|}{$25: 25: 1$} \\
\hline $\mathrm{M}_{\mathrm{m}}^{\mathrm{b}}$ & \multicolumn{2}{|c|}{326.3} \\
\hline $\mathrm{M}_{\mathrm{p}}^{\mathrm{c}}$ & \multicolumn{2}{|c|}{29754} \\
\hline$n_{\mathrm{m}}{ }^{\mathrm{d}}(\mathrm{mmol})$ & \multicolumn{2}{|c|}{$1.53 \times 10^{-3}$} \\
\hline$n_{\mathrm{p}}^{\mathrm{e}}(\mathrm{mmol})$ & \multicolumn{2}{|c|}{$2.03 \times 10^{-4}$} \\
\hline$i_{\mathrm{dm}}(\mathrm{cm})$ & \multicolumn{2}{|c|}{1.7} \\
\hline Redox centers & $\mathrm{Fc}^{*}$ & $\mathrm{CcX}$ \\
\hline$i_{\mathrm{dp}}(\mathrm{cm})$ & 1.4 & 1.7 \\
\hline$n_{\mathrm{p} 1}^{\mathrm{f}}$ & $22 \pm 2$ & $23 \pm 2$ \\
\hline
\end{tabular}

${ }^{\mathrm{a}}\left[\mathrm{M}_{2}\right]:\left[\mathrm{M}_{4}\right]$ : [C]: feed molar ratio of monomers 2 and $\mathbf{4}$ to $1 .{ }^{\mathrm{b}}$ Molecular weight of $\left[\mathrm{FeCp}{ }_{2}\right] .{ }^{\mathrm{c}}$ Molecular weight of polymer of 6 calculated by monomer conversion determined by ${ }^{1} \mathrm{H}$ NMR. ${ }^{\mathrm{d}}$ $n_{\mathrm{m}}$ : mole of [ $\mathrm{FeCp}_{2}{ }_{2}$ ] added in the DMF solution of polymer $6 .{ }^{\mathrm{e}} n_{\mathrm{p}}$ : mole of polymer $\mathbf{6}$ in DMF. ${ }^{\mathrm{f}}$ $n_{\mathrm{p} 3}$ : polymerization degree calculated by the above modified Bard-Anson's equation. 


\section{Triblock copolymer 7 Synthesis}

Monomers 2 (24.0 mg, $0.0387 \mathrm{mmol}), 3(21.3 \mathrm{mg}, 0.0387 \mathrm{mmol})$ and $4(21.9 \mathrm{mg}, 0.0387 \mathrm{mmol})$ were added into three separate small glass tubes, and dissolved in $0.25 \mathrm{~mL}$ dry $\mathrm{CH}_{2} \mathrm{Cl}_{2}, 0.20$ dry $\mathrm{CH}_{2} \mathrm{Cl}_{2} \mathrm{~mL}$ and $0.2 \mathrm{~mL}$ dry DMF, respectively. A desired amount of Grubbs catalyst $3^{\text {rd }} \mathbf{1}(1.37$ $\mathrm{mg}, 0.00155 \mathrm{mmol}$ ) was added into a small Schlenk flask, flushed with nitrogen, and dissolved in $0.03 \mathrm{~mL}$ of dry $\mathrm{CH}_{2} \mathrm{Cl}_{2}$. First, monomer 2 was transferred to the flask containing the catalyst via a small syringe, and the reaction mixture was stirred vigorously for 10 minutes at $r$. t.. Then, monomer 4 in DMF was added into the flask using a small syringe and stirred for another 20 minutes, after which monomer 3 in $\mathrm{CH}_{2} \mathrm{Cl}_{2}$ was added into the flask via a small syringe. The reaction mixture was stirred vigorously for 2 hours at r. t., quenched with $0.25 \mathrm{~mL}$ EVE, purified by precipitating from $\mathrm{CH}_{2} \mathrm{Cl}_{2}$ with $\mathrm{Et}_{2} \mathrm{O}$ three times and dried in vacuo until constant weight to get the polymer 7 as a yellow-brown solid. Yield: 95\%. ${ }^{1} \mathrm{H}$ NMR $\left(300 \mathrm{MHz}, \mathrm{DMSO}-d_{6}\right)$, $\delta_{\mathrm{ppm}}$ : 8.91 (broad, NHCO-CcX), 7.79 (broad, NHCO-Fc), 7.49-7.20 (m, NHCO-Fc* and phenyl), 6.17 (s, sub. Cp of CcX), 5.90 (s, sub. Cp of CcX), 5.84 (s, free $\mathrm{Cp}$ of CcX), 5.64 and 5.46 (double broad, $\mathrm{CH}=\mathrm{CH}$ ), 4.78 (s, sub. $\mathrm{Cp}$ of $\mathrm{Fc}$ ), 4.43 (broad, sub. $\mathrm{Cp}$ of Fc*), 4.31 (s, sub. Cp of Fc), 4.14 (s, free $\mathrm{Cp}$ of Fc), 4.02 (broad, sub. $\mathrm{Cp}$ of $\mathrm{Fc} *$ ), 3.55-3.22 (m, $\mathrm{CH}_{2}\left(\mathrm{CH}_{2} \mathrm{OCH}_{2}\right)_{3} \mathrm{CH}_{2}, \mathrm{H}_{2} \mathrm{O}$ and $\mathrm{NCH}_{2} \mathrm{CH}_{2} \mathrm{~N}$ ), 3.03 (broad, $=\mathrm{CH}-\mathrm{CH}$ ), 2.60 (broad, CO-CH), 1.97 (broad, $\mathrm{CH}_{3}$ of of $\left.\left.\eta^{5}-\mathrm{C}_{5} \mathrm{Me}_{5}\right)\right), 1.46\left(\right.$ broad, $\left.\mathrm{CH}=\mathrm{CHCHCH}_{2}\right)$.

\section{Kinetic Study}

In order to know when the polymerization of the third block can finish, the kinetic study was conducted as following: Monomer $2(0.367 \mathrm{~g}, 0.592 \mathrm{mmol})$ in $3.5 \mathrm{~mL}$ dry $\mathrm{CH}_{2} \mathrm{Cl}_{2}$ was added into the solution of Grubbs catalyst $3^{\text {rd }} \mathbf{1}(20.95 \mathrm{mg}, 0.0237 \mathrm{mmol})$ in $0.2 \mathrm{~mL}$ dry $\mathrm{CH}_{2} \mathrm{Cl}_{2}$. The reaction mixture was stirred vigorously for 10 minutes at r. t. under $\mathrm{N}_{2}$ atmosphere. Next, monomer $4(0.335 \mathrm{~g}, 0.592 \mathrm{mmol})$ in $3.0 \mathrm{~mL}$ dry DMF was added, and stirred for another 20 minutes. Then, monomer $3(0.326 \mathrm{~g}, 0.592 \mathrm{mmol})$ in $3.0 \mathrm{~mL}$ dry $\mathrm{CH}_{2} \mathrm{Cl}_{2}$ was added, and after 0.5 , 1, 2, 3 and $4 \mathrm{hrs}$, respectively, $0.5 \mathrm{~mL}$ of samples were taken out, quenched with $0.5 \mathrm{~mL}$ of EVE, and precipitated by adding $5.0 \mathrm{~mL}$ of $\mathrm{Et}_{2} \mathrm{O}$. The obtained precipitate was washed with $\mathrm{Et}_{2} \mathrm{O}(3 \times 5$ $\mathrm{mL}$ ), vacuumed and then checked for ${ }^{1} \mathrm{H}$ NMR spectrum in $\mathrm{CD}_{2} \mathrm{Cl}_{2}$. All the washing liquors and filtrate were collected, the solvent was removed in vacuo, and the ${ }^{1} \mathrm{H}$ NMR spectrum of the residue was recorded in $\mathrm{CDCl}_{3}$. The monomer conversion was deemed to be $100 \%$ when the signal of the olefin protons for monomer 3 at $6.28 \mathrm{ppm}$ in $\mathrm{CD}_{2} \mathrm{Cl}_{2}$ and $6.25 \mathrm{ppm}$ in $\mathrm{CDCl}_{3}$ disappeared. Actually, the polymerization for the second block can finish in $2 \mathrm{hrs}$ with $100 \%$ monomer conversion. 


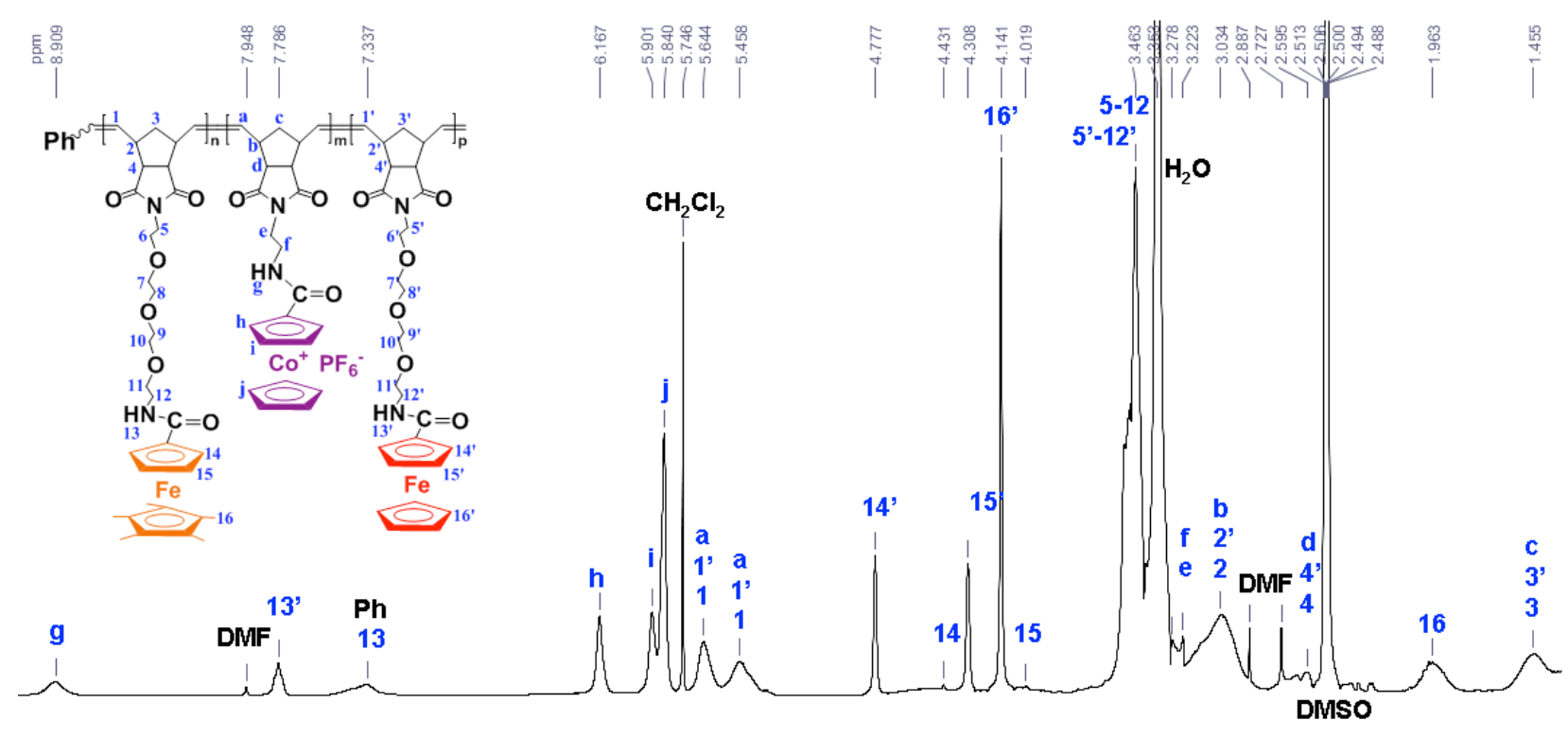

Figure S38 ${ }^{1} \mathrm{H}$ NMR spectrum of triblock copolymer 7 in DMSO- $d_{6}$.



Figure S39 ${ }^{1} \mathrm{H}$ NMR spectrum of triblock copolymer 7 in $\mathrm{CD}_{2} \mathrm{Cl}_{2}$.

${ }^{1} \mathrm{H}$ NMR (300 MHz, $\mathrm{CD}_{2} \mathrm{Cl}_{2}$ ), $\delta_{\mathrm{ppm}}$ : 7.47-7.22 (m, NHCO-CcX and phenyl), 6.53 (broad, NHCO-Fc), 5.96 (broad, NHCO-Fc* and sub. Cp of CcX), 5.83 (broad, sub. Cp of CcX), 5.74 (broad, $\mathrm{CH}=\mathrm{CH}$, free $\mathrm{Cp}$ of $\mathrm{CcX}$ ), 5.53 (broad, $\mathrm{CH}=\mathrm{CH}$ ), 4.71 (s, sub. $\mathrm{Cp}$ of Fc), 4.33 (s, sub. Cp of Fc), 4.20 (s, free $\mathrm{Cp}$ of $\mathrm{Fc}$ ), 3.62-3.53 (m, $\left.\mathrm{CH}_{2}\left(\mathrm{CH}_{2} \mathrm{OCH}_{2}\right)_{3} \mathrm{CH}_{2}\right), 3.39$ (broad, $\mathrm{NCH}_{2} \mathrm{CH}_{2} \mathrm{~N}$ ), 3.19 (broad, =CH-CH), 3.03 (broad, $\mathrm{CO}-\mathrm{CH}), 2.69$ and 2.05 (broad, $\mathrm{CH}=\mathrm{CHCHCH}$ ), 1.69 (broad, $\mathrm{CH}_{3}$ of of $\eta^{5}-\mathrm{C}_{5} \mathrm{Me}_{5}$ ). 

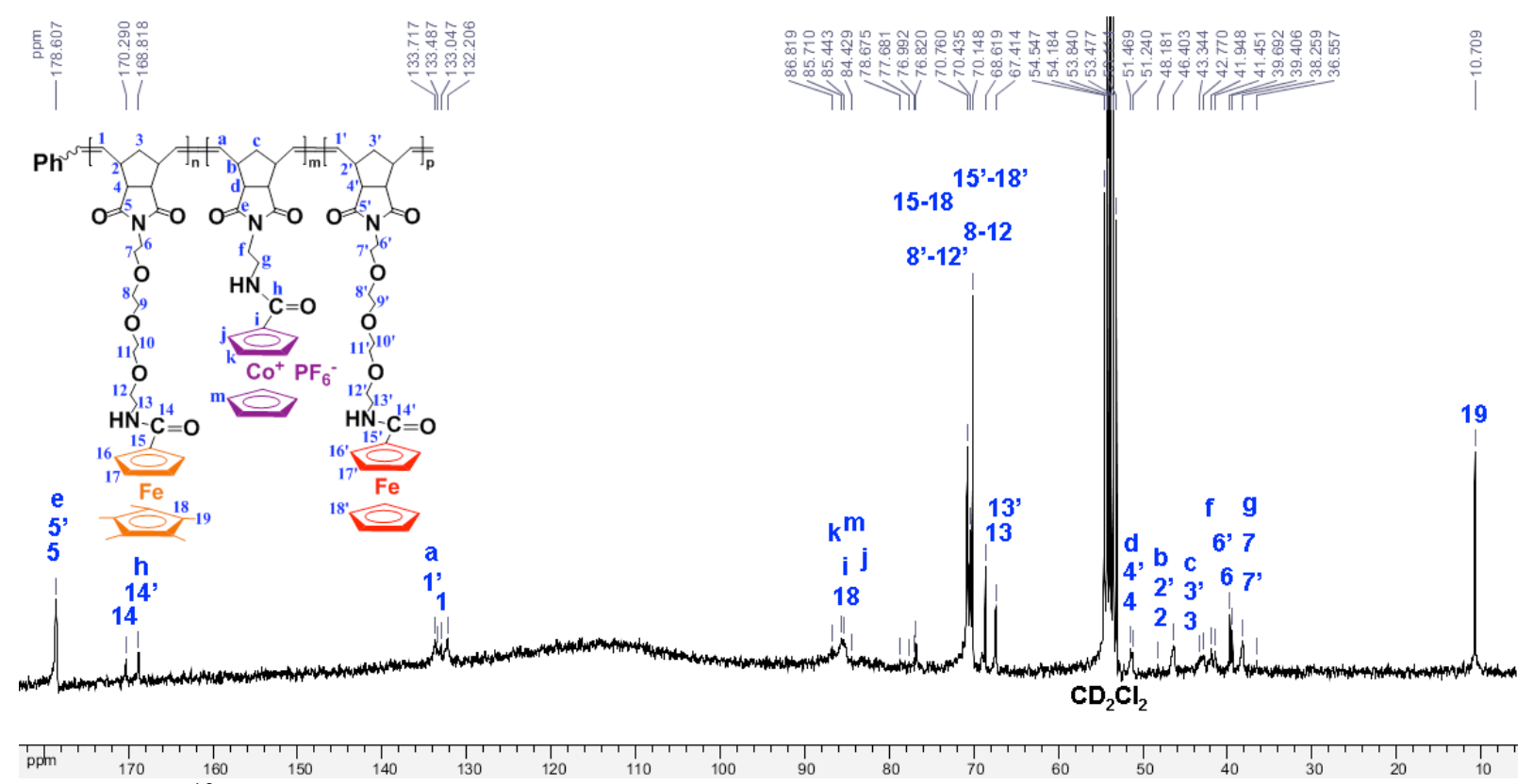

Figure $\mathbf{S 4 0}{ }^{13} \mathrm{C}$ NMR spectrum of triblock copolymer 7 in $\mathrm{CD}_{2} \mathrm{Cl}_{2}$.

${ }^{13} \mathrm{C}$ NMR $\left(50 \mathrm{MHz}, \mathrm{CD}_{2} \mathrm{Cl}_{2}\right), \delta_{\mathrm{ppm}}: 178.6(\boldsymbol{C O N}), 170.3,168.8(\boldsymbol{C O N H}), 133.7,133.5,133.047$, $132.2(\mathrm{C}=\mathrm{C}), 86.8,85.7,85.4,84.4\left(\eta^{5}-C_{5} \mathrm{Me}_{5}\right.$, free and sub. $\mathrm{Cp}$ of $\left.\mathrm{CcX}\right), 78.7,77.7,77.0,76.8$, 70.8, 70.4, 70.1, 68.6, $67.4\left(\mathrm{CH}_{2}\right.$ and sub. $\left.\mathrm{Cp}\right), 51.5,51.2(\mathrm{COCH}), 48.2,46.4(=\mathrm{CH}-\mathrm{CH}), 43.3$, 42.8, 41.9, $41.5\left(=\mathrm{CHCHCH}_{2}\right), 39.7,39.4,38.3\left(\mathrm{NCH}_{2} \mathrm{CH}_{2}\right), 10.7\left(\mathrm{CH}_{3}\right.$ of $\left.\eta^{5}-\mathrm{C}_{5} \mathrm{Me}_{5}\right)$.

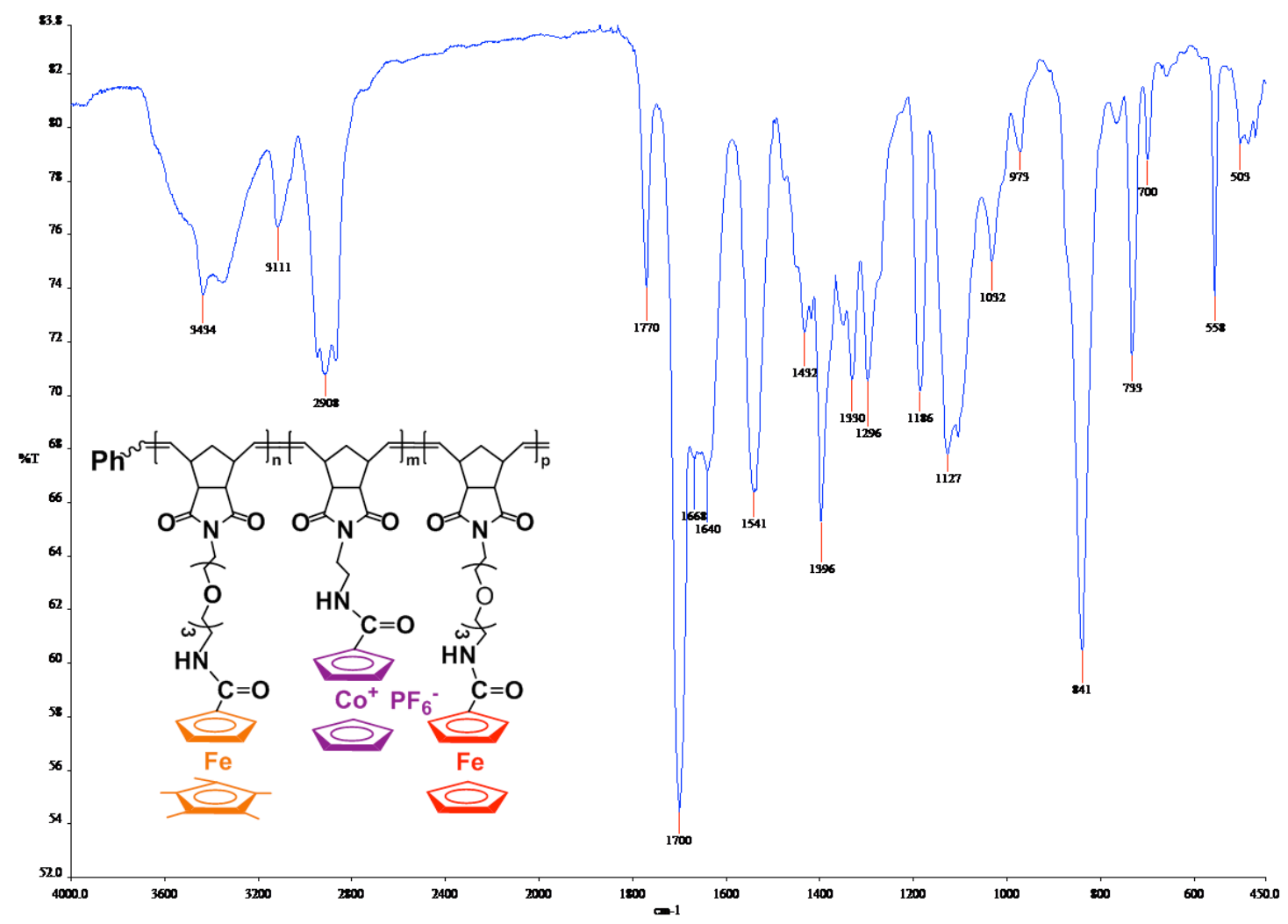

Figure S41 IR spectrum of triblock copolymer 7.

$3434 \mathrm{~cm}^{-1}(\mathrm{NH}), 2908 \mathrm{~cm}^{-1}\left(\mathrm{CH}_{3}\right), 1770 \mathrm{~cm}^{-1}(\mathrm{C}=\mathrm{C}), 1700 \mathrm{~cm}^{-1}(\mathrm{NC}=\mathrm{O}), 1668,1640 \mathrm{~cm}^{-1}$ $(\mathrm{NHC}=\mathrm{O}), 841 \mathrm{~cm}^{-1}\left(\mathrm{PF}_{6}\right)$. 

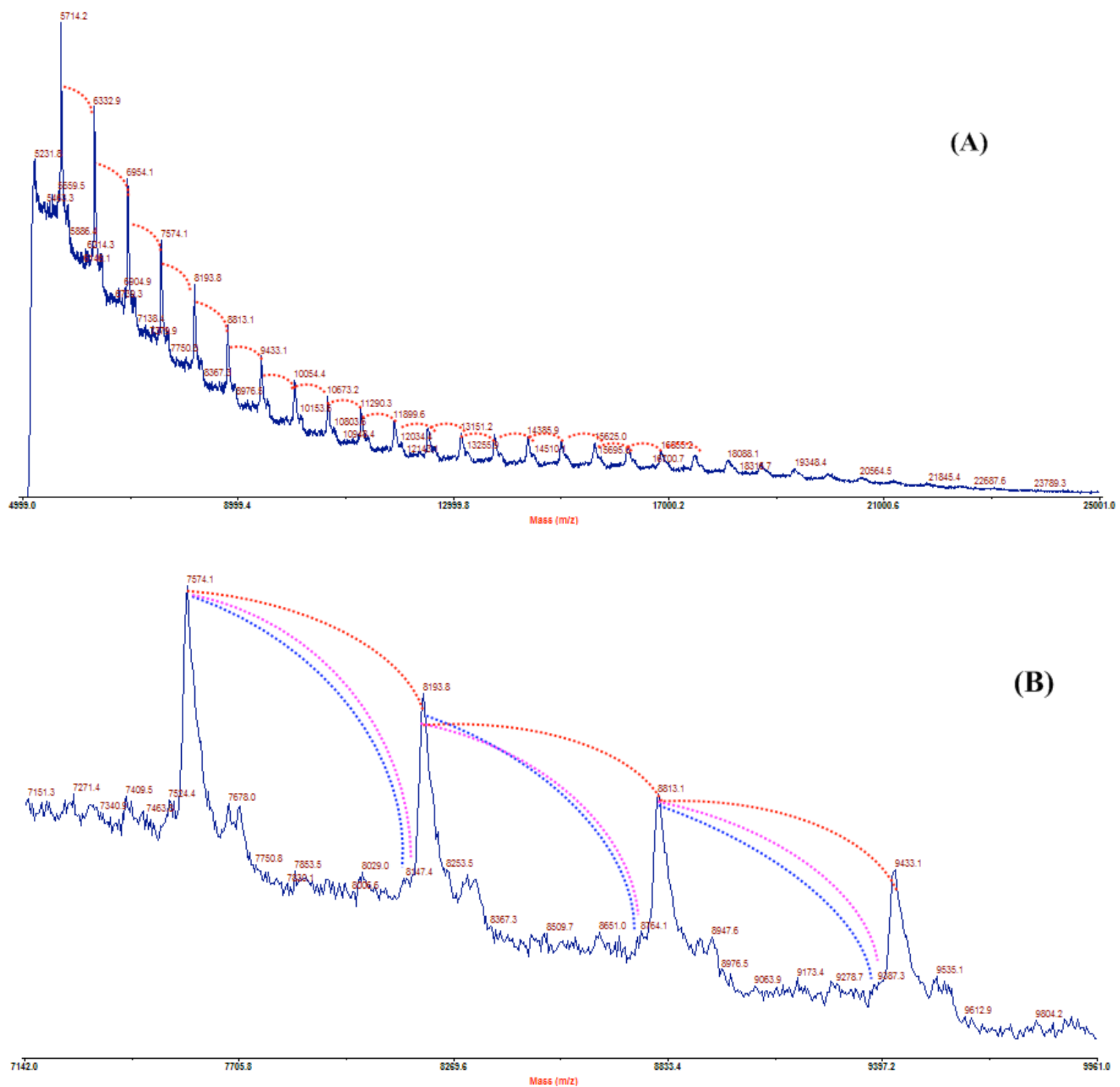

Figure S42 MALDI-TOF MS spectrum of triblock copolymer 7. The feed molar ratio of monomers $2, \mathbf{4}$ and $\mathbf{3}$ to $\mathbf{1}$ is $25: 25: 25: 1$. (A) is the region of 4999-25001 in the spectrum; and (B) is the enlarge region of the spectrum from 7142 to 9961 . The red dotted lines are corresponding to the difference between molecular peaks of a value of $620 \pm 1 \mathrm{Da}$ (MW of monomer 2). The blue dotted lines are corresponding to the difference between molecular peaks of a value of $550 \pm 1 \mathrm{Da}$ (MW of monomer 3). The pink dotted lines are corresponding to the difference between molecular peaks of a value of $566 \pm 1$ Da (MW of monomer 4). 


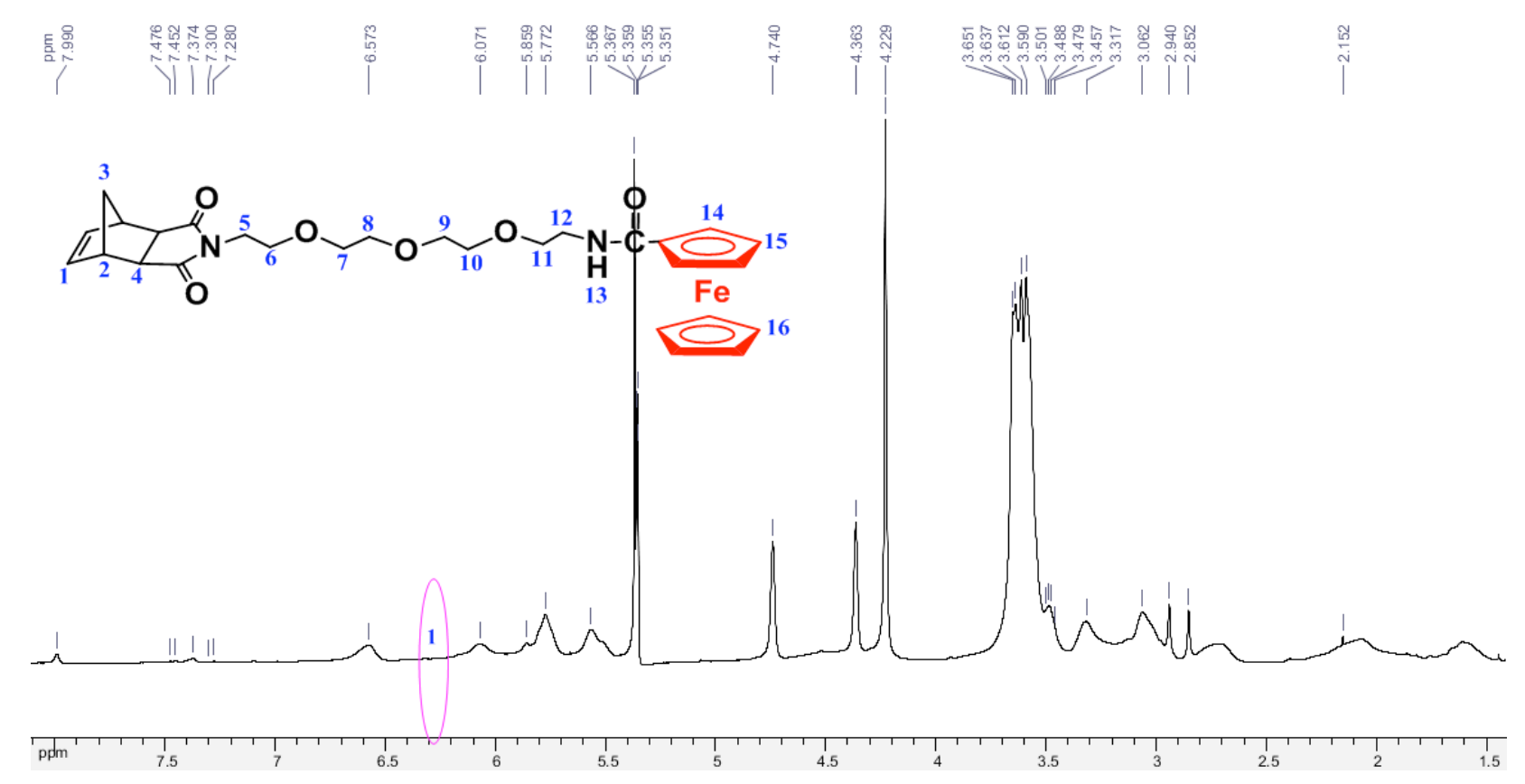

Figure $\mathbf{S 4 3}{ }^{1} \mathrm{H}$ NMR spectrum $(300 \mathrm{MHz})$ in $\mathrm{CD}_{2} \mathrm{Cl}_{2}$ of the precipitate from the ROMP reaction mixture for the synthesis of triblock copolymer 7 after the addition of monomer 3 with 2 hrs stirring. No peak is observed at $6.26 \mathrm{ppm}$ for the olefin protons of monomer 3 . The precipitate is purified triblock copolymer 7.

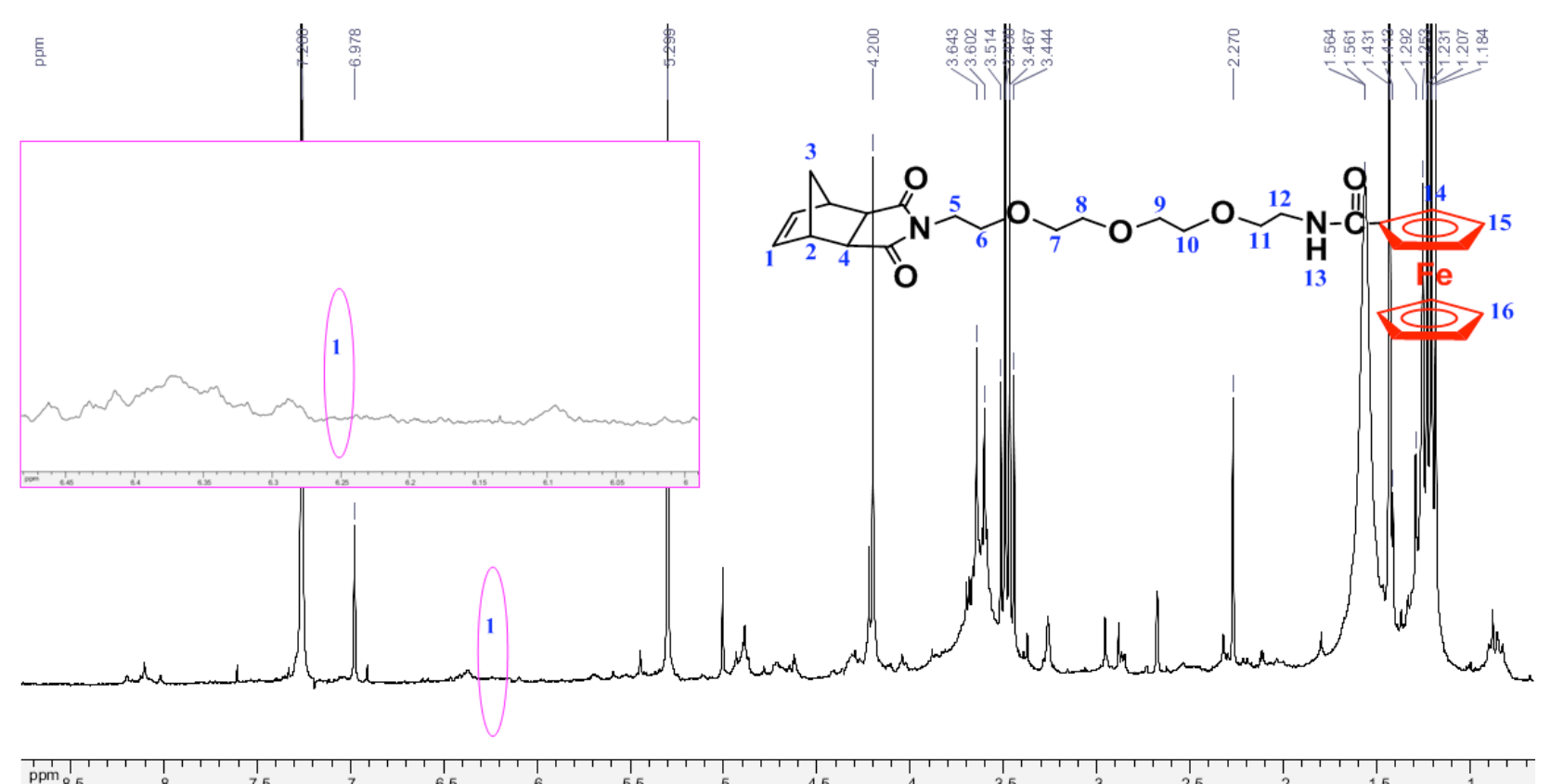

Figure S44 Enlarged ${ }^{1} \mathrm{H}$ NMR spectrum $(300 \mathrm{MHz})$ in $\mathrm{CDCl}_{3}$ of the products in washing liquors and filtrate from the ROMP reaction mixture for the synthesis of triblock copolymer 7 after the addition of monomer 3 with 2 hrs stirring. No peak is observed at $6.25 \mathrm{ppm}$ for the olefin protons of monomer 3. Namely no monomer $\mathbf{3}$ was left and the ROMP of $\mathbf{3}$ is complete. 
Calculation of the polymer degrees of triblock copolymers 7 by ${ }^{1} \mathrm{H}$ NMR end-group analysis and errors

Table S5 Polymer degree of the second CcX block using the ${ }^{1} \mathrm{H}$ NMR spectrum in DMSO- $d_{6}$ of copolymer 7. ${ }^{\mathrm{a}, \mathrm{b}}$

\begin{tabular}{|l|c|c|c|c|}
\hline $\begin{array}{l}\text { Proton } \\
\text { peak }\end{array}$ & $\begin{array}{c}\text { End-phenyl and amido } \\
\text { in the first block }\end{array}$ & $\begin{array}{c}\text { Amido in the } \\
\text { second block }\end{array}$ & $\begin{array}{c}\text { Sub. Cp in the } \\
\text { second block }\end{array}$ & $\begin{array}{c}\text { Sub. and free Cp in } \\
\text { the second block }\end{array}$ \\
\hline$\delta_{\text {ppm }}$ & $7.49-7.20$ & 8.91 & 6.17 & 5.90 and 5.84 \\
\hline Integration & $1.179-1.193$ & $1.009-1.040$ & $2.111-2.146$ & $6.922-7.035$ \\
\hline $\mathrm{n}_{\mathrm{p} 2 \mathrm{a}}$ & - & $21-24^{\mathrm{c}}$ & $22-25^{\mathrm{d}}$ & $21-23^{\mathrm{e}}$ \\
\hline $\mathrm{n}_{\mathrm{p} 2 \mathrm{~b}}{ }^{\mathrm{f}}$ & \multicolumn{4}{|c|}{$23 \pm 2$} \\
\hline
\end{tabular}

${ }^{a}$ Figure S38 is used for the calculation of the polymer degree of the second block. ${ }^{b}$ The average polymer degree of $25 \pm 1$ for the first $\mathrm{Fc}^{*}$ block is used for the calculation of polymer degree of the second CcX block. ${ }^{c}$ Calculated by comparing the end-phenyl and amido proton integrations in the first block and the amido in the second block. ${ }^{d}$ Calculated by comparing the end-phenyl and amido proton integrations in the first block and the substituted $\mathrm{Cp}$ proton integration in the second block. ${ }^{\mathrm{e}}$ Calculated by comparing the end-phenyl and amido proton integrations in the first block and the substituted and free Cp proton integration in the second block. ${ }^{\mathrm{f}}$ Average polymer degree for the second block according to the $\mathrm{n}_{\mathrm{p} 2 \mathrm{a}}$ values.

Table S6 Polymer degree of the third Fc block using the ${ }^{1} \mathrm{H}$ NMR spectrum in DMSO- $d_{6}$ of copolymer 7. ${ }^{\text {a,b }}$

\begin{tabular}{|l|c|c|c|c|c|}
\hline $\begin{array}{l}\text { Proton } \\
\text { peak }\end{array}$ & $\begin{array}{c}\text { End-phenyl } \\
\text { and amido in } \\
\text { the first block }\end{array}$ & $\begin{array}{c}\text { Amido in the } \\
\text { third block }\end{array}$ & $\begin{array}{c}\text { Sub. Cp in the } \\
\text { third block }\end{array}$ & $\begin{array}{c}\text { Sub. Cp in the } \\
\text { third block }\end{array}$ & $\begin{array}{c}\text { Free Cp in the } \\
\text { third block }\end{array}$ \\
\hline$\delta_{\text {ppm }}$ & $7.49-7.20$ & 7.79 & 4.78 & 4.31 & 4.14 \\
\hline Integration & $1.179-1.193$ & $0.934-0.944$ & $1.908-2.002$ & $2.022-2.088$ & $4.816-4.873$ \\
\hline $\mathrm{n}_{\mathrm{p} 2 \mathrm{a}}$ & - & $20-22^{\mathrm{c}}$ & $20-23^{\mathrm{d}}$ & $21-24^{\mathrm{d}}$ & $20-22^{\mathrm{e}}$ \\
\hline $\mathrm{n}_{\mathrm{p} 2 \mathrm{~b}}{ }^{\mathrm{f}}$ & \multicolumn{5}{|l}{$22 \pm 2$} \\
\hline
\end{tabular}

${ }^{a}$ Figure S38 is used for the calculation of the polymer degree of the second block. ${ }^{b}$ The average polymer degree of $25 \pm 1$ for the first $\mathrm{Fc}^{*}$ block is used for the calculation of polymer degree of the third Fc block. ${ }^{\mathrm{c}}$ Calculated by comparing the end-phenyl and amido proton integrations in the first block and the amido in the third block. ${ }^{\mathrm{d}}$ Calculated by comparing the end-phenyl and amido proton integrations in the first block and the substituted Cp proton integration in the third block. ${ }^{\mathrm{e}}$ Calculated by comparing the end-phenyl and amido proton integrations in the first block and the free $\mathrm{Cp}$ proton integration in the third block. ${ }^{\mathrm{f}}$ Average polymer degree for the second block according to the $\mathrm{n}_{\mathrm{p} 2 \mathrm{a}}$ values. 
As shown in Table S5 and S6, the polymer degrees are $23 \pm 2$ for the second CcX block and $22 \pm$ 2 for the third Fc block, respectively. The higher error results from the following two sides. (1) The above obtained polymer degree of $25 \pm 1$ for the first $\mathrm{Fc}^{*}$ block is used for the calculation of the polymer degrees for the second $\mathrm{CcX}$ and third Fc blocks, which can results in a larger error than for the first block. (2) This analysis is carried out by comparing the integration of end-phenyl and characteristic amido peak from the first Fc block and the integrations of characteristic amido, substituted and free $\mathrm{Cp}$ peaks in the second $\mathrm{CcX}$ block and the third Fc block. The amido peak in the first block is mixed with the end-phenyl peaks at 7.49-7.20 ppm. For the second CcX block, the amido and Cp protons are observed at 8.91, 6.17, 5.90 and 5.84 ppm, respectively, and the corresponding calculated polymerization degrees are 21-24, 22-25 and 21-23, respectively, and so, the average polymerization degree is $23 \pm 2$ for the second CcX block. For the third Fc block, the amido and Cp protons are observed at 7.79, 4.78, 4.31 and 4.14 ppm, respectively, and the corresponding calculated polymerization degrees are 20-22, 20-23, 21-24 and 20-22, respectively, and so, the average polymerization degree is $22 \pm 2$ for the second Fc block.

Table S7 Redox potentials, chemical $\left(i_{c} / i_{a}\right)$ and electrochemical $\left(E_{\mathrm{pa}}-E_{\mathrm{pc}}=\Delta E\right)$ reversibility data for triblock copolymer 7 .

\begin{tabular}{|l|c|c|c|}
\hline Redox centers & $E_{1 / 2}(\mathrm{~V})$ & $(\Delta E)(\mathrm{V})$ & $i_{c} / i_{a}$ \\
\hline $\mathrm{Fc}$ & 0.365 & 0.02 & 1.06 \\
\hline $\mathrm{Fc}$ & 0.633 & 0.06 & 1.24 \\
\hline $\mathrm{CcX}\left(\mathrm{Co}^{\mathrm{III/II}}\right)$ & -0.700 & 0.07 & 1.10 \\
\hline $\mathrm{CcX}\left(\mathrm{Co}^{\mathrm{II} / \mathrm{I}}\right)$ & -1.647 & 0.110 & 1.00 \\
\hline
\end{tabular}




\section{Calculation of polymerization degrees $\left(n_{\mathrm{p} 3}\right)$ for triblock copolymer 7 by Bard-Anson's} method

The following modified Bard-Anson's empirical electrochemical equation ${ }^{\mathrm{S} 7}$ was used:

$$
n_{p 3}=\left(\frac{i_{d p} n_{m}}{i_{d m} n_{p}}\right)\left(\frac{M_{p}}{M_{m}}\right)^{0.275}
$$

$\left(i_{\mathrm{dp}}\right.$ : intensity of polymer; $n_{\mathrm{p}}$ : mole of polymer; $i_{\mathrm{dm}}$ : intensity of monomer; $n_{\mathrm{m}}$ : mole of monomer; $\mathrm{M}_{\mathrm{p}}$ : molecular weight of polymer; $\mathrm{M}_{\mathrm{m}}$ : molecular weight of monomer).

$\left[\mathrm{FeCp}_{2}{ }_{2}\right]$ was used as the monomer reference. The results of calculated polymerization degrees $\left(n_{\mathrm{p} 3}\right)$ of $\mathrm{Fc}^{*}, \mathrm{CcX}$ and $\mathrm{Fc}$ blocks for triblock copolymer 7 are listed in Table S8.

Table S8 Polymerization degree $\left(n_{\mathrm{p} 3}\right)$ of triblock copolymer 7 calculated by the Bard-Anson's equation

\begin{tabular}{|c|c|c|c|}
\hline$\left[\mathrm{M}_{2}\right]:\left[\mathrm{M}_{4}\right]:\left[\mathrm{M}_{3}\right]:[\mathrm{C}]^{\mathrm{a}}$ & \multicolumn{3}{|c|}{$25: 25: 25: 1$} \\
\hline $\mathrm{M}_{\mathrm{m}}^{\mathrm{b}}$ & \multicolumn{3}{|c|}{326.3} \\
\hline $\mathrm{M}_{\mathrm{p}}^{\mathrm{c}}$ & \multicolumn{3}{|c|}{43504} \\
\hline$n_{\mathrm{m}}{ }^{\mathrm{d}}(\mathrm{mmol})$ & \multicolumn{3}{|c|}{$9.19 \times 10^{-4}$} \\
\hline$n_{\mathrm{p}}^{\mathrm{e}}(\mathrm{mmol})$ & \multicolumn{3}{|c|}{$2.07 \times 10^{-4}$} \\
\hline$i_{\mathrm{dm}}(\mathrm{cm})$ & \multicolumn{3}{|c|}{1.3} \\
\hline Redox center & $\mathrm{Fc}^{*}$ & $\mathrm{Fc}$ & $\mathrm{CcX}$ \\
\hline$i_{\mathrm{dp}}(\mathrm{cm})$ & 2.1 & 1.9 & 1.0 \\
\hline$n_{\mathrm{p} 3}{ }^{\mathrm{f}}$ & $28 \pm 3$ & $25 \pm 2$ & $13 \pm 2$ \\
\hline
\end{tabular}

${ }^{\mathrm{a}}\left[\mathrm{M}_{2}\right]:\left[\mathrm{M}_{4}\right]:\left[\mathrm{M}_{3}\right]:[\mathrm{C}]$ : feed molar ratio of monomers 2,4 and 8 to $1 .{ }^{\mathrm{b}}$ Molecular weight of [FeCp* ${ }_{2}$ ]. ${ }^{\mathrm{c}}$ Molecular weight of the triblock copolymer 7 calculated by monomer conversion determined by ${ }^{1} \mathrm{H}$ NMR. ${ }^{\mathrm{d}} n_{\mathrm{m}}$ : mole of $\left[\mathrm{FeCp}_{2}{ }_{2}\right]$ added in the DMF solution of the triblock copolymer $7 .{ }^{\mathrm{e}} n_{\mathrm{p}}$ : mole of the triblock copolymer 7 in DMF. ${ }^{\mathrm{f}} n_{\mathrm{p} 3}$ : polymerization degree determined by the Bard-Anson's method. 


\section{Diblock copolymer $8^{\text {s8 }}$ Synthesis}

Monomers 2 (44.4 mg, $0.0716 \mathrm{mmol})$ and $3(39.4 \mathrm{mg}, 0.0716 \mathrm{mmol})$ were added into two separate small glass tubes and dissolved in $0.4 \mathrm{~mL}$ and $0.3 \mathrm{~mL}$ of dry $\mathrm{CH}_{2} \mathrm{Cl}_{2}$, respectively. A desired amount of Grubbs catalyst $1(2.53 \mathrm{mg}, 0.00286 \mathrm{mmol})$ was added into a small Schlenk flask, flushed with nitrogen, and dissolved in $0.03 \mathrm{~mL}$ of dry $\mathrm{CH}_{2} \mathrm{Cl}_{2}$. First, monomer 2 was transferred to the flask containing the catalyst via a small syringe. The reaction mixture was stirred vigorously for 10 minutes at r. t., after which monomer $\mathbf{3}$ was added into the flask using a small syringe. The polymerization was allowed to continue for another 15 minutes, and then quenched with $0.2 \mathrm{~mL}$ of EVE. The yellow-brown solid polymer 8 was purified by precipitation from $\mathrm{CH}_{2} \mathrm{Cl}_{2}$ with methanol five times and dried in vacuo until constant weight. Yield: $94 \%$. ${ }^{1} \mathrm{H}$ NMR (300 MHz, $\mathrm{CDCl}_{3}$ ), $\delta_{\text {ppm }}$ : 7.34-7.14 (m, phenyl and $\mathrm{CDCl}_{3}$ ), 6.48 (broad, 1H, NHCO-Fc), 6.09 (broad, 1H, NHCO-Fc*), 5.68 and 5.46 (double broad, 4H, $2 \times \mathrm{CH}=\mathrm{CH}$ ), 4.68 (s, 2H, sub. Cp of Fc), 4.28 (s, 2H, sub. Cp of Fc), 4.15 (s, 7H, free $\mathrm{Cp}$ of $\mathrm{Fc}$ and sub. $\mathrm{Cp}$ of Fc*), 3.90 (s, 2H, sub. Cp of $\mathrm{Fc}^{*}$ ), 3.56 (broad, $32 \mathrm{H}, 2 \times \mathrm{CH}_{2}\left(\mathrm{CH}_{2} \mathrm{OCH}_{2}\right)_{3} \mathrm{CH}_{2}$ ), 3.21 (broad, =CH-CH), 2.98 (broad, $\mathrm{CO}-\mathrm{CH}$ ), 2.63 (broad, $\left.\mathrm{CH}=\mathrm{CHCHCH}_{2}\right), 2.03$ (broad, $\left.\mathrm{CH}=\mathrm{CHCHCH}_{2}\right), 1.59\left(\mathrm{~s}, 15 \mathrm{H}, 5 \times \mathrm{CH}_{3}\right)$.

\section{Kinetic Study}

In order to know when the polymerization of the second block finishes, the kinetic study was conducted as following: monomer $2(0.405 \mathrm{~g}, 0.653 \mathrm{mmol})$ in $4 \mathrm{~mL}$ dry $\mathrm{CH}_{2} \mathrm{Cl}_{2}$ was added into the solution of Grubbs catalyst $1(23.1 \mathrm{mg}, 0.026 \mathrm{mmol})$ in $0.3 \mathrm{~mL}$ dry $\mathrm{CH}_{2} \mathrm{Cl}_{2}$. The reaction mixture was stirred vigorously for 10 minutes at $r$. $t$. under $\mathrm{N}_{2}$ atmosphere. Then, monomer 3 (0.359 g, $0.653 \mathrm{mmol}$ ) in $3 \mathrm{~mL}$ dry $\mathrm{CH}_{2} \mathrm{Cl}_{2}$ was added, and after 5, 10, 15, 20, 30, 45 and 60 minutes, respectively, $0.5 \mathrm{~mL}$ of samples were taken out and quenched with $0.5 \mathrm{~mL}$ of EVE. The In situ ${ }^{1} \mathrm{H} \mathrm{NMR}$ analysis in $\mathrm{CDCl}_{3}$ was conducted, and the conversion of monomer 3 was deemed to be $100 \%$ when the peak at $6.26 \mathrm{ppm}$, the signal of olefinic protons for monomer $\mathbf{3}$, disappeared. Actually, the polymerization of the second block finishes in 15 minutes with $100 \%$ monomer conversion. 


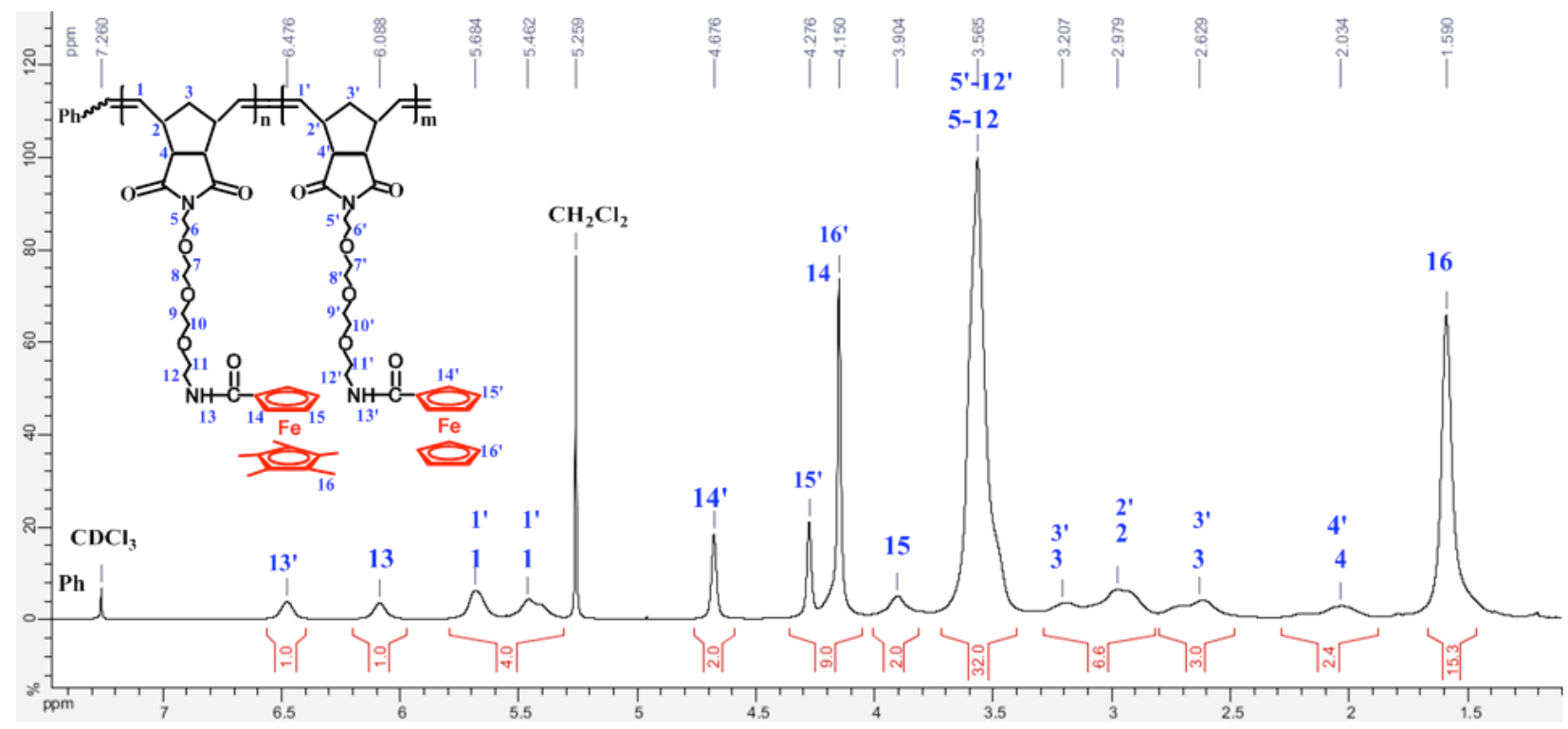

Figure $\mathbf{S 4 5}{ }^{1} \mathrm{H}$ NMR spectrum of diblock copolymer 8 in $\mathrm{CDCl}_{3}$.

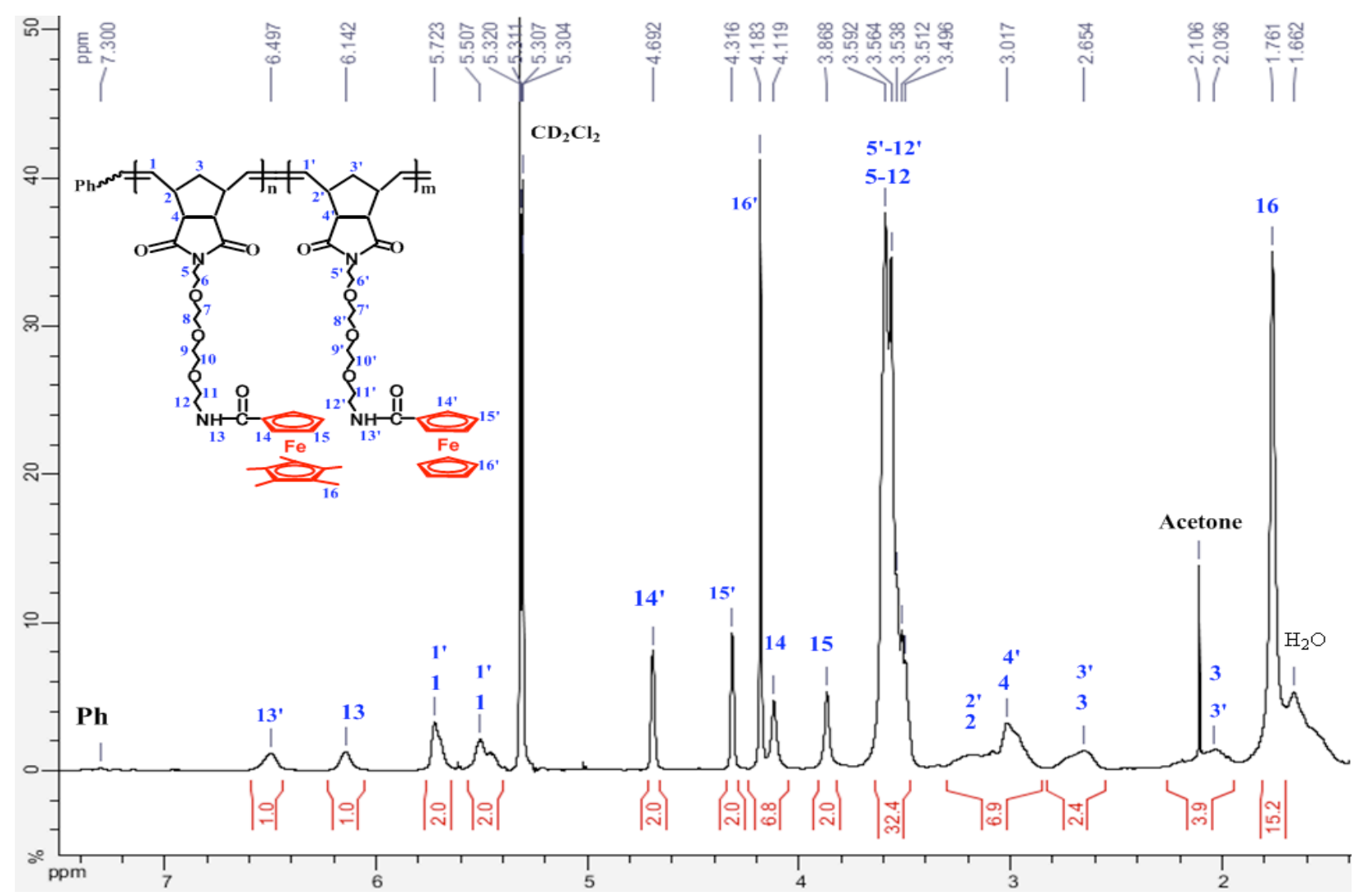

Figure S46 ${ }^{1} \mathrm{H}$ NMR spectrum of diblock copolymer 8 in $\mathrm{CD}_{2} \mathrm{Cl}_{2}$.

${ }^{1} \mathrm{H}$ NMR (300 MHz, $\mathrm{CD}_{2} \mathrm{Cl}_{2}$ ), $\delta_{\mathrm{ppm}}: 7.41-7.27$ (m, phenyl), 6.50 (broad, 1H, NHCO-Fc), 6.14 (broad, 1H, NHCO-Fc*), 5.72 and 5.51 (double broad, $4 \mathrm{H}, 2 \times \mathrm{CH}=\mathrm{CH}$ ), 4.69 (s, 2H, sub. Cp of Fc), 4.32 (s, 2H, sub. Cp of Fc), 4.18 (s, 7H, free Cp of Fc), 4.12 (s, 2H, sub. Cp of Fc*), 3.87 (s, $2 \mathrm{H}$, sub. $\mathrm{Cp}$ of $\mathrm{Fc}^{*}$ ), 3.59-3.50 (m and broad, $32 \mathrm{H}, 2 \times \mathrm{CH}_{2}\left(\mathrm{CH}_{2} \mathrm{OCH}_{2}\right)_{3} \mathrm{CH}_{2}$ ), 3.19 (broad, $=\mathrm{CH}-\mathrm{CH}), 3.02($ broad, $\mathrm{CO}-\mathrm{CH}), 2.65\left(\right.$ broad, $\left.\mathrm{CH}=\mathrm{CHCHCH}_{2}\right), 2.04(\text { broad, } \mathrm{CH}=\mathrm{CHCHCH})_{2}$, $1.76\left(\mathrm{~s}, 15 \mathrm{H}, 5 \times \mathrm{CH}_{3}\right)$. 




Figure $\mathbf{S 4 7}{ }^{13} \mathrm{C}$ NMR spectrum of diblock copolymer 8 in $\mathrm{CDCl}_{3}$.

${ }^{13} \mathrm{C}$ NMR (50 MHz, $\mathrm{CDCl}_{3}$ ), $\delta_{\mathrm{ppm}}: 178.2,178.1$ (CON), 170.2, $169.1(\mathrm{CONH}), 133.4,131.7$ $(\mathrm{C}=\mathrm{C}), 81.8$ (Cp*), 71.8, 70.5, 70.3, 70.2, 70.1, 69.8, 69.7, 68.2, $\left(\mathrm{CH}_{2}\right.$ and sub. Cp), 67.0 $\left(-\mathrm{CH}_{2} \mathrm{NH}\right), 53.5(\mathrm{COCH}), 51.0,50.8(=\mathrm{CHCH}), 45.7\left(\boldsymbol{C H}_{2}\right.$ of cyclopentane $), 41.3,39.3,39.1$ $\left(\boldsymbol{C} \mathrm{H}_{2} \mathrm{NCO}\right), 37.7\left(\mathrm{CH}_{2} \mathrm{CH}_{2} \mathrm{NCO}\right), 10.5\left(\mathrm{CH}_{3}\right)$.

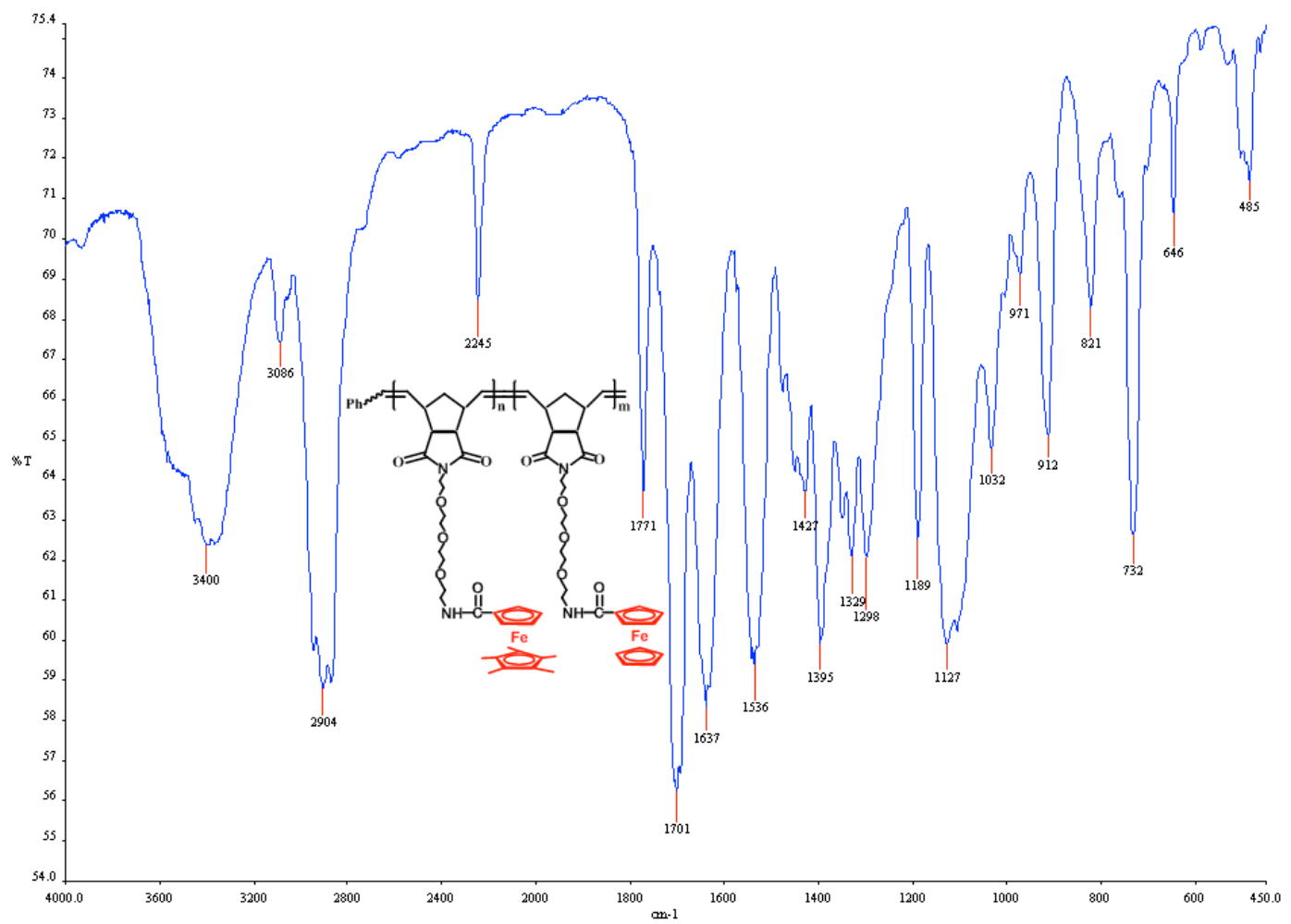

Figure S48 IR spectrum of diblock copolymer 8.

$3400 \mathrm{~cm}^{-1}\left(v_{\mathrm{N}-\mathrm{H}}\right), 2904 \mathrm{~cm}^{-1}\left(v_{\mathrm{CH} 3}\right), 1771 \mathrm{~cm}^{-1}\left(v_{\mathrm{C}=\mathrm{C}}\right), 1701 \mathrm{~cm}^{-1}\left(v_{\mathrm{C}=\mathrm{O}}\right), 1637 \mathrm{~cm}^{-1}\left(\delta_{\mathrm{N}-\mathrm{H}}\right), 821 \mathrm{~cm}^{-1}$ $\left(v_{\mathrm{FeII}}\right)$. 


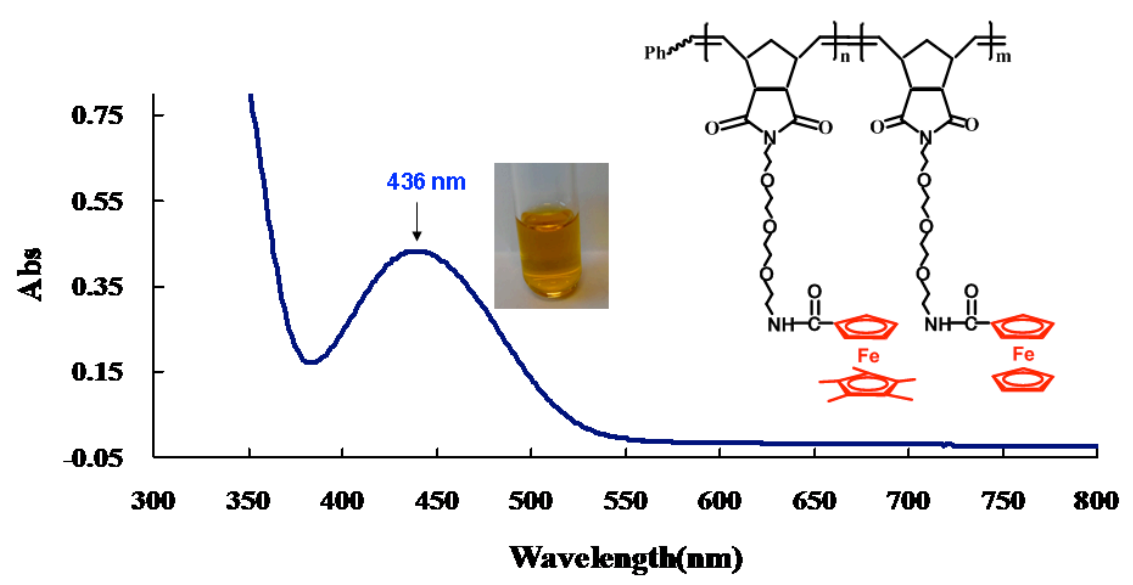

Figure S49 UV-Vis spectrum of diblock copolymer 8 in $\mathrm{CH}_{2} \mathrm{Cl}_{2}$

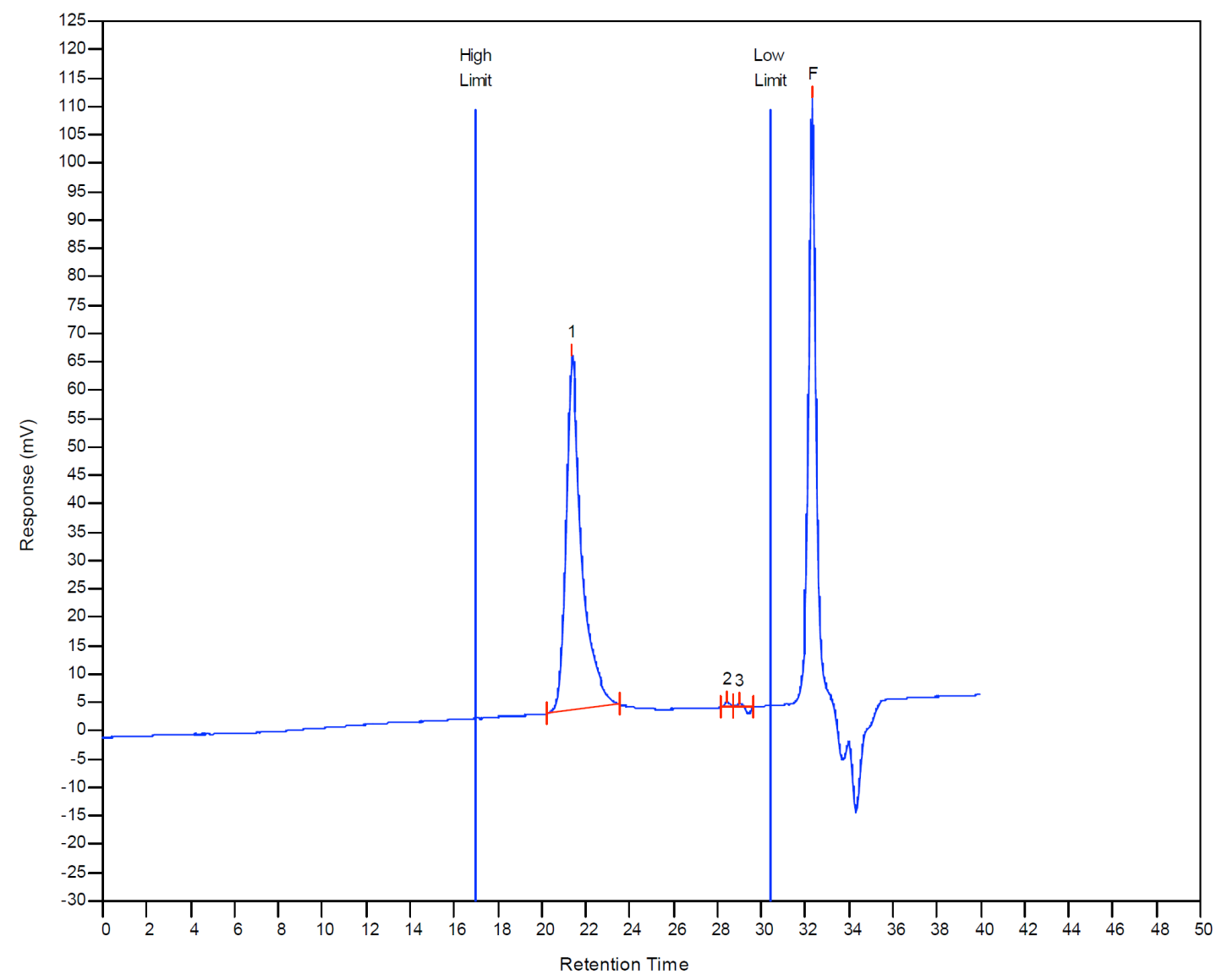

MW Averages

$\begin{array}{rrrrrrrr}\text { Peak No } & \text { Mp } & \text { Mn } & \text { Mw } & M z & M z+1 & M v & P D \\ 1 & 9616 & 8415 & 9005 & 9526 & 9996 & 8923 & 1.07011 \\ 2 & 416 & 419 & 401 & 412 & 413 & 397 & 0.957041 \\ 3 & 322 & 338 & 315 & 327 & 328 & 310 & 0.931953 \\ 4 & 0 & 0 & 0 & 0 & 0 & 0 & 0\end{array}$

Figure S50 SEC curve of diblock copolymer 8. 

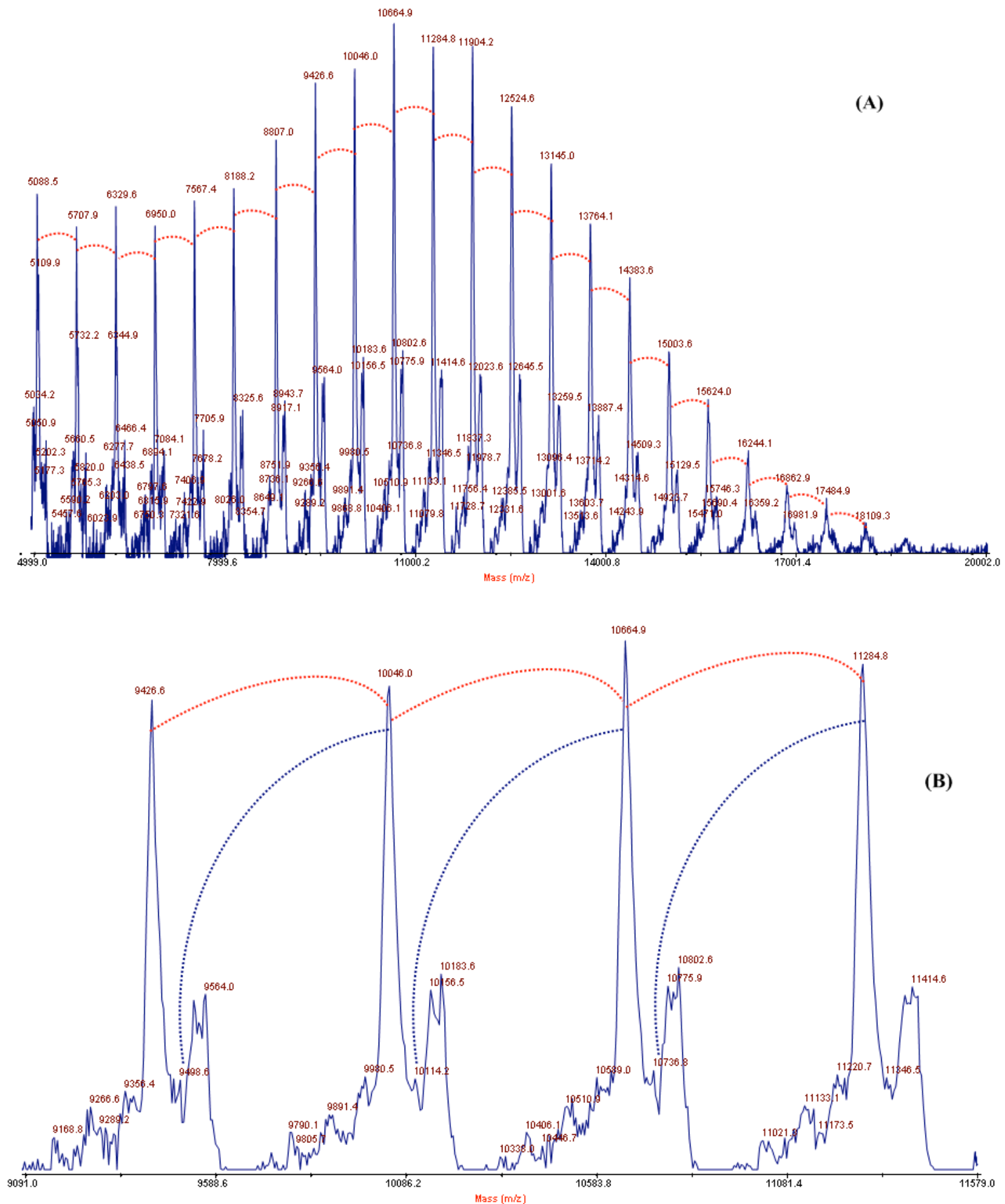

Figure S51 MALDI-TOF MS spectrum of diblock copolymer 8.

The feed molar ratio of monomers 2 and 3 to 1 is $25: 25: 1$. (A) is the region of 5000-20000 in the spectrum; and (B) is the enlarge region of the spectrum from 913 to 11560 . The red dotted lines are corresponding to the difference between molecular peaks of a value of $620 \pm 1 \mathrm{Da}$ (MW of monomer 2). The blue dotted lines are corresponding to the difference between molecular peaks of a value of $550 \pm 1 \mathrm{Da}$ (MW of monomer 3 ). 


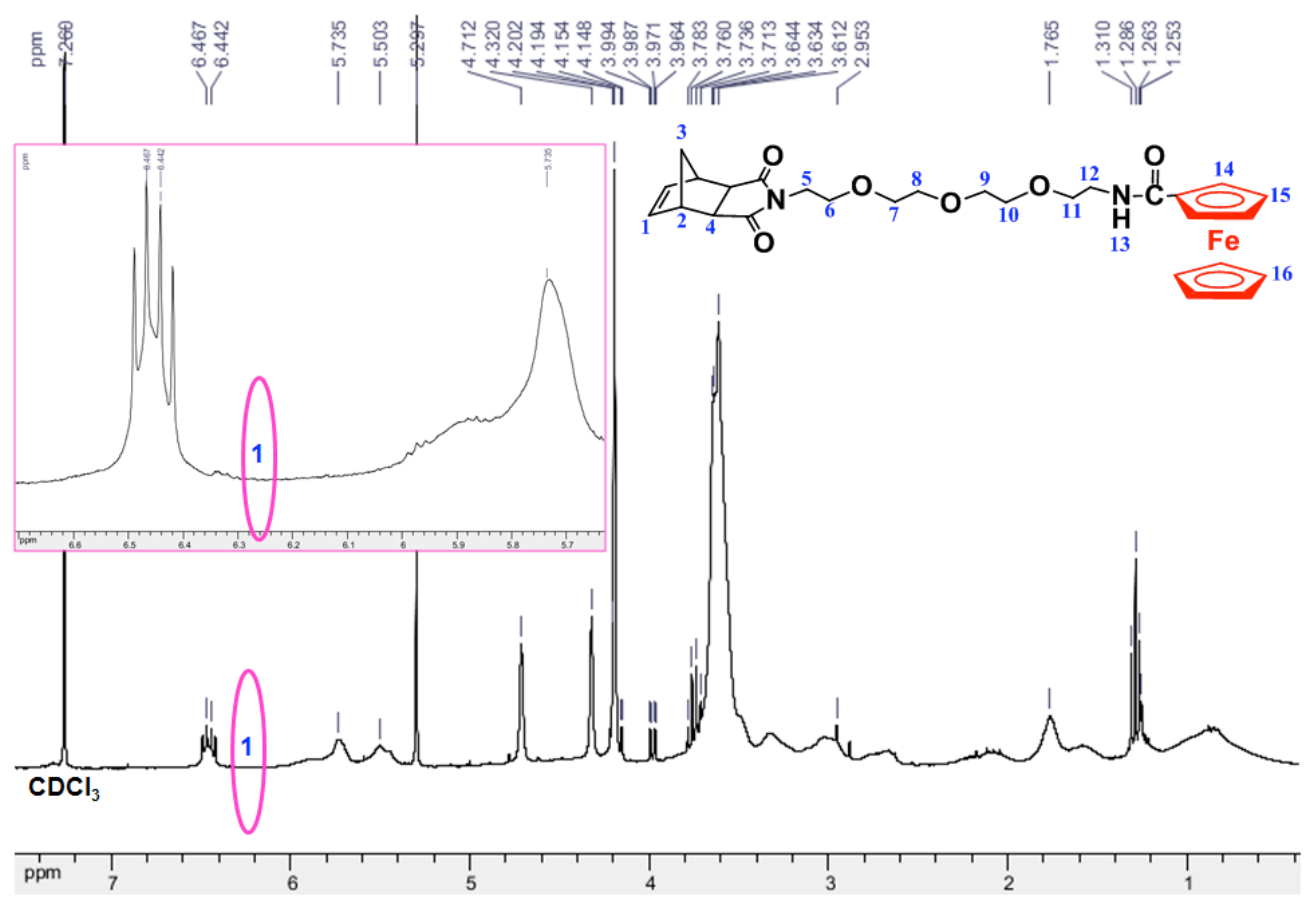

Figure S52 ${ }^{1} \mathrm{H}$ NMR spectrum in $\mathrm{CDCl}_{3}$ of the ROMP reaction mixture for the synthesis of diblock copolymer $\mathbf{8}$ after the addition of monomer $\mathbf{3}$ with 15 minutes stirring. No peak is observed at $6.26 \mathrm{ppm}$ or so for the olefin protons of monomer $\mathbf{3}$, namely no monomer $\mathbf{3}$ is left and the ROMP of $\mathbf{3}$ is complete.

\section{Calculation of the polymer degrees of diblock copolymers 8 by ${ }^{1} \mathrm{H}$ NMR end-group analysis} and errors

Table S9 Polymer degree of the second Fc block using the ${ }^{1} \mathrm{H}$ NMR spectrum in $\mathrm{CD}_{2} \mathrm{Cl}_{2}$ of



\begin{tabular}{|l|c|c|c|c|c|}
\hline $\begin{array}{l}\text { Proton } \\
\text { peak }\end{array}$ & $\begin{array}{c}\text { Amido in the } \\
\text { first block }\end{array}$ & $\begin{array}{c}\text { Sub. Cp in the } \\
\text { first block }\end{array}$ & $\begin{array}{c}\text { Amido in the } \\
\text { second block }\end{array}$ & $\begin{array}{c}\text { Sub. Cp in the } \\
\text { second block }\end{array}$ & $\begin{array}{c}\text { Sub. Cp in the } \\
\text { second block }\end{array}$ \\
\hline$\delta_{\mathrm{ppm}}$ & 6.139 & 3.868 & 6.498 & 4.692 & 4.316 \\
\hline Integration & $0.99-1.01$ & $1.99-2.01$ & $1.00-1.01$ & $1.99-2.00$ & $1.98-2.00$ \\
\hline $\mathrm{n}_{\mathrm{p} 2 \mathrm{a}}$ & - & - & $24-26^{\mathrm{c}}$ & $24-26^{\mathrm{d}}$ & $24-26^{\mathrm{d}}$ \\
\hline $\mathrm{n}_{\mathrm{p} 2 \mathrm{~b}}^{\mathrm{e}}$ & \multicolumn{5}{|c|}{$25 \pm 1$} \\
\hline
\end{tabular}

${ }^{\mathrm{a}}$ Figure S46 is used for the calculation of the polymer degree of the second block. ${ }^{\mathrm{b}}$ The average polymer degree of $25 \pm 1$ for the first $\mathrm{Fc}^{*}$ block is used for the calculation of polymer degree of the second Fc block. ${ }^{\mathrm{c}}$ Calculated by comparing the amido proton integrations in the first and second blocks. ${ }^{\mathrm{d}}$ Calculated by comparing the substituted $\mathrm{Cp}$ proton integrations in the first and second blocks. ${ }^{\mathrm{e}}$ Average polymer degree for the second block according to the $\mathrm{n}_{\mathrm{p} 2 \mathrm{a}}$ values.

As shown in Table S9, the polymer degree for the second Fc blcok is $25 \pm 1$, too, which is equal 
to that of the first $\mathrm{Fc}^{*}$ block. The analysis was carried out by using the above obtained polymer degree of $25 \pm 1$ for the first $\mathrm{Fc}^{*}$ block. The integrations of amido peaks in the first and second blocks, $6.14 \mathrm{ppm}$ with $0.99-1.01$ and $6.50 \mathrm{ppm}$ with 1.00-1.01, respectively, were compared, and the value of 24-26 was obtained. Similarly, the integrations of substituted Cp peaks in the first and second blocks were also compared. The former is $1.99-2.01$ at $3.87 \mathrm{ppm}$, and the latter is 1.99-2.00 at $4.69 \mathrm{ppm}$ and 1.98-2.0 at $4.32 \mathrm{ppm}$, respectively. The obtained corresponding polymer degrees for the second block are $24-26$, too. So, the average value is $25 \pm 1$. Obviously, the used analysis method resulted in a small error.

Table S10 Redox potentials, chemical $\left(i_{c} / i_{a}\right)$ and electrochemical $\left(E_{\mathrm{pa}}-E_{\mathrm{pc}}=\Delta E\right)$ reversibility data for the diblock copolymer $\mathbf{8}$.

\begin{tabular}{|l|l|l|l|l|l|}
\hline \multicolumn{3}{|c|}{ Fc center } & \multicolumn{3}{c|}{$\mathrm{Fc}^{*}$ center } \\
\hline$E_{1 / 2}(\mathrm{mV})$ & $\Delta E(\mathrm{mV})$ & $i_{c} / i_{a}$ & $E_{1 / 2}(\mathrm{mV})$ & $\Delta E(\mathrm{mV})$ & $i_{d} / i_{a}$ \\
\hline 0.640 & 0.020 & 1.10 & 0.380 & 0.020 & 1.08 \\
\hline
\end{tabular}

Calculation of the polymerization degrees $\left(n_{\mathrm{p} 3}\right)$ for the diblock copolymer 8 by Bard-Anson's method

The following modified Bard-Anson's empirical electrochemical equation ${ }^{\mathrm{S} 7}$ is used:

$$
n_{p 3}=\left(\frac{i_{d p} n_{m}}{i_{d m} n_{p}}\right)\left(\frac{M_{p}}{M_{m}}\right)^{0.275}
$$

$\left(i_{\mathrm{dp}}\right.$ : intensity of polymer; $n_{\mathrm{p}}$ : mole of polymer; $i_{\mathrm{dm}}$ : intensity of monomer; $n_{\mathrm{m}}$ : mole of monomer; $\mathrm{M}_{\mathrm{p}}$ : molecular weight of polymer; $\mathrm{M}_{\mathrm{m}}$ : molecular weight of monomer).

$\left[\mathrm{FeCp}_{2}{ }_{2}\right]$ was used as the monomer reference. The results of calculated polymerization degrees $\left(n_{\mathrm{p} 3}\right)$ of $\mathrm{Fc}^{*}$ and $\mathrm{Fc}$ blocks for diblock copolymer $\mathbf{8}$ are listed in Table S11.

Table S11 Polymerization degree $\left(n_{\mathrm{p} 3}\right)$ for each metalloblock in copolymer $\mathbf{8}$ calculated using the Bard-Anson electrochemical method. ${ }^{\mathrm{S} 7}$

\begin{tabular}{|c|c|c|}
\hline$\left[\mathrm{M}_{2}\right]:\left[\mathrm{M}_{3}\right]:[\mathrm{C}]^{\mathrm{a}}$ & \multicolumn{2}{|l|}{$25: 25: 1$} \\
\hline $\mathrm{M}_{\mathrm{m}}^{\mathrm{b}}$ & \multicolumn{2}{|l|}{326.3} \\
\hline $\mathrm{M}_{\mathrm{p}}^{\mathrm{c}}$ & \multicolumn{2}{|l|}{29354} \\
\hline$n_{\mathrm{m}}{ }^{\mathrm{d}}(\mathrm{mmol})$ & \multicolumn{2}{|l|}{$9.2 \times 10^{-4}$} \\
\hline$n_{\mathrm{p}}^{\mathrm{e}}(\mathrm{mmol})$ & \multicolumn{2}{|l|}{$1.7 \times 10^{-4}$} \\
\hline$i_{\mathrm{dm}}(\mathrm{cm})$ & \multicolumn{2}{|l|}{2.6} \\
\hline Redox centers & $\mathrm{Fc}^{*}$ & $\mathrm{Fc}$ \\
\hline$i_{\mathrm{dp}}(\mathrm{cm})$ & 2.6 & 2.7 \\
\hline$n_{\mathrm{p} 3}^{\mathrm{f}}$ & $19 \pm 2$ & $21 \pm 2$ \\
\hline
\end{tabular}

${ }^{\mathrm{a}}\left[\mathrm{M}_{2}\right]:\left[\mathrm{M}_{3}\right]:[\mathrm{C}]$ : feed molar ratio of monomers 2 and $\mathbf{3}$ to $\mathbf{1} .{ }^{\mathrm{b}}$ Molecular weight of [FeCp* $\left.{ }_{2}\right]$.

${ }^{\mathrm{c}}$ Molecular weight of copolymer $\mathbf{8}$ calculated by monomer conversion determined by ${ }^{1} \mathrm{H}$ NMR. ${ }^{\mathrm{d}}$ 
$n_{\mathrm{m}}$ : mole of [ $\mathrm{FeCp}_{2}{ }_{2}$ ] added in the $\mathrm{CH}_{2} \mathrm{Cl}_{2}$ solution of copolymer $\mathbf{8}$. ${ }^{\mathrm{e}} n_{\mathrm{p}}$ : mole of copolymer $\mathbf{8}$ in $\mathrm{CH}_{2} \mathrm{Cl}_{2} .{ }^{\mathrm{f}} n_{\mathrm{p} 3}$ : polymerization degree determined by the Bard-Anson's method.

\section{Triblock copolymer 9 Synthesis}

Monomers 2 (27.4 mg, $0.0442 \mathrm{mmol}), 3(24.3 \mathrm{mg}, 0.0442 \mathrm{mmol})$ and 4 (25.0 mg, $0.0442 \mathrm{mmol})$ were added into three separate small glass tubes, and dissolved in $0.25 \mathrm{~mL}$ dry $\mathrm{CH}_{2} \mathrm{Cl}_{2}, 0.25 \mathrm{~mL}$ dry $\mathrm{CH}_{2} \mathrm{Cl}_{2}$ and $0.2 \mathrm{~mL}$ dry DMF, respectively. A desired amount of Grubbs catalyst $3^{\text {rd }} \mathbf{1}(1.56$ $\mathrm{mg}, 0.00177 \mathrm{mmol}$ ) was added into a small Schlenk flask, flushed with nitrogen, and dissolved in $0.03 \mathrm{~mL}$ of dry $\mathrm{CH}_{2} \mathrm{Cl}_{2}$. First, monomer 2 was transferred to the flask containing the catalyst via a small syringe, and the reaction mixture was stirred vigorously for 10 minutes at $\mathrm{r}$. t.. Then, monomer 3 was added into the flask using a small syringe and stirred for another 15 minutes, after which monomer 4 in DMF was added into the flask via a small syringe. The reaction mixture was stirred vigorously overnight at $r$. t., and then quenched with $0.25 \mathrm{~mL} \mathrm{EVE.} \mathrm{The}$ product was purified by precipitating from $\mathrm{CH}_{2} \mathrm{Cl}_{2}$ with $\mathrm{Et}_{2} \mathrm{O}$ three times and dried in vacuo until constant weight to get the polymer 9 as a yellow-brown solid. Yield: $94 \%$. ${ }^{1} \mathrm{H}$ NMR $(600 \mathrm{MHz}$, DMSO- $d_{6}$ ), $\delta_{\mathrm{ppm}}: 8.92$ (broad, NHCO-CcX), 7.79 (broad, NHCO-Fc), 7.40 (broad, NHCO-Fc* and phenyl), 6.17 (s, sub. Cp of CcX), 5.90 (s, sub. Cp of CcX), 5.84 (s, free Cp of CcX), 5.64 and 5.46 (double broad, $\mathrm{CH}=\mathrm{CH}$ ), 4.78 (s, sub. $\mathrm{Cp}$ of $\mathrm{Fc}$ ), 4.43 (broad, sub. $\mathrm{Cp}$ of $\mathrm{Fc}^{*}$ ), 4.31 (s, sub. $\mathrm{Cp}$ of $\mathrm{Fc}$ ), 4.14 ( $\mathrm{s}$, free $\mathrm{Cp}$ of $\mathrm{Fc}$ ), 4.02 (broad, sub. $\mathrm{Cp}$ of $\mathrm{Fc}^{*}$ ), 3.52-3.35 (m, $\mathrm{CH}_{2}\left(\mathrm{CH}_{2} \mathrm{OCH}_{2}\right)_{3} \mathrm{CH}_{2}, \mathrm{NCH}_{2} \mathrm{CH}_{2} \mathrm{~N}$ and $\mathrm{H}_{2} \mathrm{O}$ ), 3.19 (broad, =CH-CH ), 3.03 (broad, CO-CH ), 2.60 (broad, $\left.\mathrm{CH}=\mathrm{CHCHCH}_{2}\right), 1.97\left(\right.$ broad, $\mathrm{CH}_{3}$ of of $\left.\eta^{5}-\mathrm{C}_{5} \mathrm{Me}_{5}\right)$ ), $1.45\left(\right.$ broad, $\left.\mathrm{CH}=\mathrm{CHCHCH} \boldsymbol{H}_{2}\right)$.

\section{Kinetic Study}

In order to know when the polymerization of the third block can finish, the kinetic study was conducted as following: Monomer $2(0.325 \mathrm{~g}, 0.524 \mathrm{mmol})$ in $3.0 \mathrm{~mL}$ dry $\mathrm{CH}_{2} \mathrm{Cl}_{2}$ was added into the solution of Grubbs catalyst $3^{\text {rd }} 1(18.56 \mathrm{mg}, 0.0210 \mathrm{mmol})$ in $0.2 \mathrm{~mL}$ dry $\mathrm{CH}_{2} \mathrm{Cl}_{2}$. The reaction mixture was stirred vigorously for 10 minutes at r. t. under $\mathrm{N}_{2}$ atmosphere. Next, monomer 3 ( $0.288 \mathrm{~g}, 0.524 \mathrm{mmol})$ in $2.5 \mathrm{~mL}$ dry $\mathrm{CH}_{2} \mathrm{Cl}_{2}$ was added, and stirred for another 15 minutes. Then, monomer $4(0.297 \mathrm{~g}, 0.524 \mathrm{mmol})$ in $2.5 \mathrm{~mL}$ dry DMF was added, and after $0.5,1$, 2, 4, $8 \mathrm{hrs}$ and overnight (12 hrs), respectively, $0.5 \mathrm{~mL}$ of samples were taken out, quenched with $0.5 \mathrm{~mL}$ of EVE and precipitated by adding $5.0 \mathrm{~mL}$ of $\mathrm{Et}_{2} \mathrm{O}$. The obtained precipitate was washed with $\mathrm{Et}_{2} \mathrm{O}(3 \times 5 \mathrm{~mL})$, vacuumed and then checked for ${ }^{1} \mathrm{H}$ NMR spectrum in $\mathrm{CD}_{2} \mathrm{Cl}_{2}$. All the washing liquors and filtrate were collected, the solvent was removed in vacuo, and the ${ }^{1} \mathrm{H}$ NMR spectrum of the residue was recorded in $\mathrm{CDCl}_{3}$. The monomer conversion was deemed to be $100 \%$ when the signal of the olefin protons for monomer 4 at $6.30 \mathrm{ppm}$ disappeared. Actually, only after overnight stirring, the polymerization of the third block can finish with $100 \%$ monomer conversion. 




Figure S53 ${ }^{1} \mathrm{H}$ NMR spectrum of triblock copolymer 9 in DMSO- $d_{6}$.

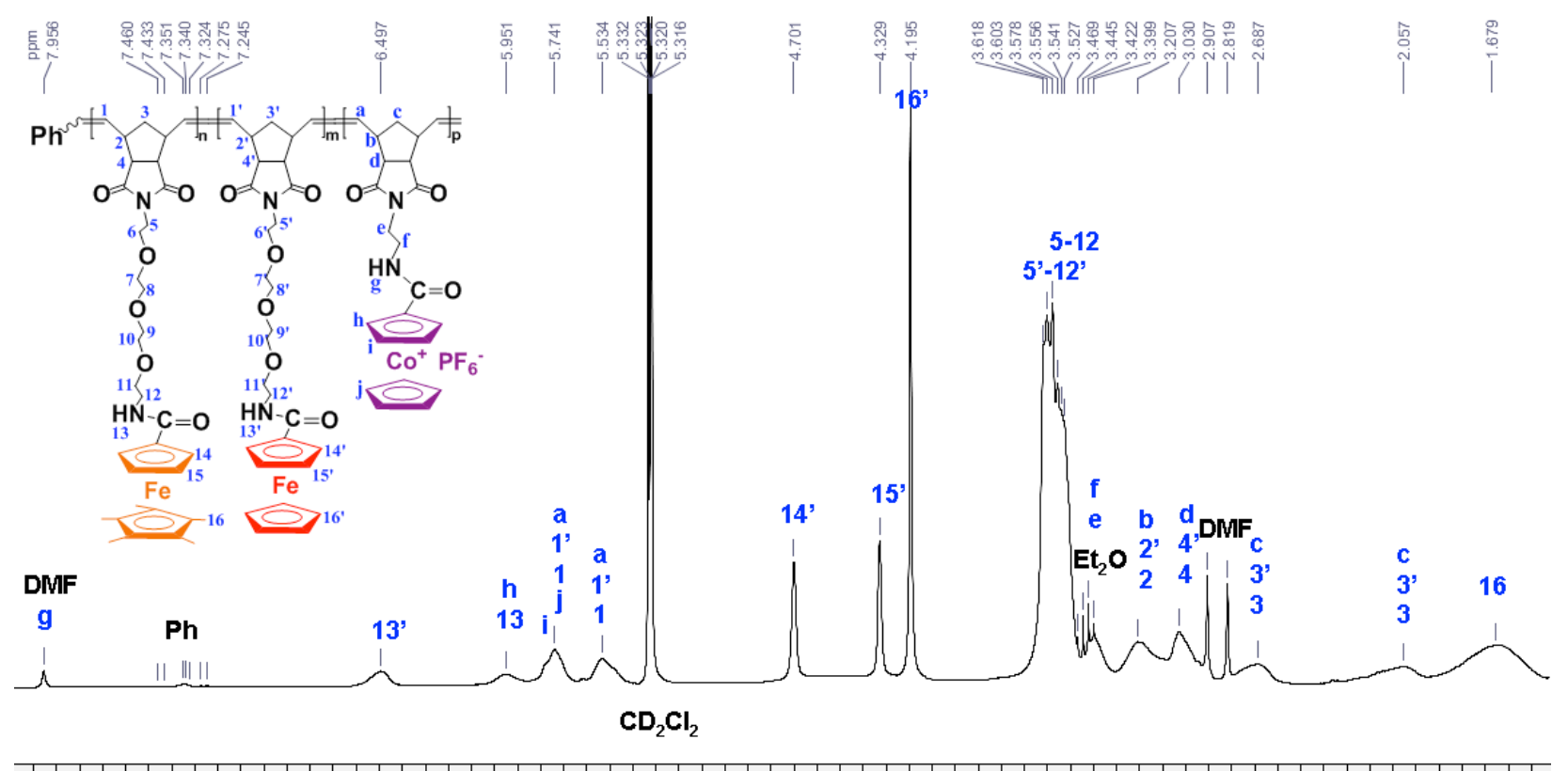

Figure S54 ${ }^{1} \mathrm{H}$ NMR spectrum of triblock copolymer 9 in $\mathrm{CD}_{2} \mathrm{Cl}_{2}$.

${ }^{1} \mathrm{H}$ NMR (300 MHz, $\mathrm{CD}_{2} \mathrm{Cl}_{2}$ ), $\delta_{\mathrm{ppm}}: 7.96$ (broad, NHCO-CcX and DMF), 7.46-7.25 (m, phenyl), 6.50 (broad, NHCO-Fc), 5.95 (broad, NHCO-Fc* and sub. $\mathrm{Cp}$ of $\mathrm{CcX}$ ), 5.74 (broad, $\mathrm{CH}=\mathrm{CH}$, free and sub. $\mathrm{Cp}$ of $\mathrm{CcX}$ ), 5.53 (broad, $\mathrm{CH}=\mathrm{CH}$ ), 4.70 (s, sub. $\mathrm{Cp}$ of Fc), 4.33 (s, sub. Cp of Fc), 4.19 (s, free $\mathrm{Cp}$ of $\mathrm{Fc}$ ), 3.62-3.53 (m, $\left.\mathrm{CH}_{2}\left(\mathrm{CH}_{2} \mathrm{OCH}_{2}\right)_{3} \mathrm{CH}_{2}\right), 3.47-3.40\left(\mathrm{~m}, \mathrm{NCH}_{2} \mathrm{CH}_{2} \mathrm{~N}\right.$ and ether), 3.21 (broad, =CH-CH), 3.03 (broad, $\mathrm{CO}-\mathrm{CH}$ ), 2.69 and 2.06 (broad, $\mathrm{CH}=\mathrm{CHCHCH}{ }_{2}$, 1.68 (broad, $\mathrm{CH}_{3}$ of of $\eta^{5}-\mathrm{C}_{5} \mathrm{Me}_{5}$ ). 


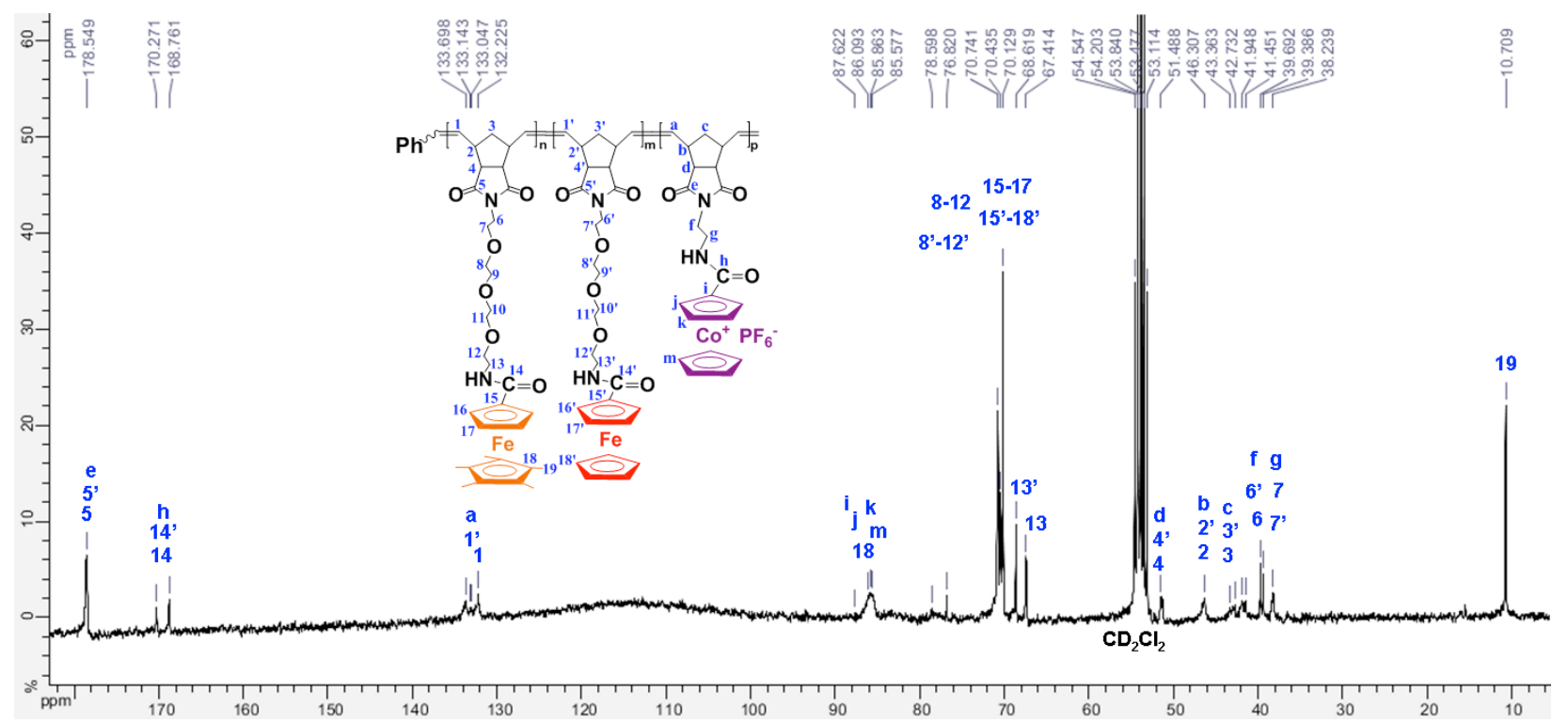

Figure $\mathbf{S 5 5}{ }^{13} \mathrm{C}$ NMR spectrum of triblock copolymer 9 in $\mathrm{CD}_{2} \mathrm{Cl}_{2}$.

${ }^{13} \mathrm{C}$ NMR $\left(50 \mathrm{MHz}, \mathrm{CD}_{2} \mathrm{Cl}_{2}\right.$ ), $\delta_{\mathrm{ppm}}: 178.5(\boldsymbol{C O N}), 170.27,168.8(\boldsymbol{C O N H}), 133.7,133.1,133.0$, $132.2(\mathrm{C}=\mathrm{C}), 87.7,86.1,85.9,85.6\left(\eta^{5}-C_{5} \mathrm{Me}_{5}\right.$, free and sub. $\mathrm{Cp}$ of $\left.\mathrm{CcX}\right), 78.6,76.8,70.7,70.4$, 70.3, 68.6, $67.4\left(\mathrm{CH}_{2}\right.$ and sub. $\left.\mathrm{Cp}\right), 51.5(\mathrm{COCH}), 46.3(=\mathrm{CH}-\mathrm{CH}), 43.4,42.7,41.9,41.5$ $\left(=\mathrm{CHCHCH}_{2}\right), 39.7,39.4,38.2\left(\mathrm{NCH}_{2} \mathrm{CH}_{2}\right), 10.7\left(\mathrm{CH}_{3}\right.$ of $\left.\eta^{5}-\mathrm{C}_{5} \mathrm{Me}_{5}\right)$.



Figure S56 ${ }^{13} \mathrm{C}$ NMR spectrum of triblock copolymer 9 in DMSO- $d_{6}$.

${ }^{13} \mathrm{C}$ NMR $\left(50 \mathrm{MHz}, \mathrm{DMSO}-d_{6}\right), \delta_{\mathrm{ppm}}: 177.9(\boldsymbol{C O N}), 168.9,168.0(\boldsymbol{C O N H}), 133.0,132.6,131.6$, $131.2(\mathrm{C}=\mathrm{C}), 85.9,85.6$ (sub. $\mathrm{Cp}$ of $\mathrm{CcX}$ ), $83.7\left(\eta^{5}-C_{5} \mathrm{Me}_{5}\right), 80.1$ (sub. Cp of CcX), 77.6, 76.4, 73.7 (free and sub. $\mathrm{Cp}$ of $\mathrm{Fc}$ ), 70.3, 69.7, 69.3, 68.1, 66.2, $66.1\left(\mathrm{CH}_{2}\right.$ and sub. $\mathrm{Cp}$ of $\left.\mathrm{Fc}^{*}\right), 50.3$ $(\mathrm{COCH}), 10.2\left(\mathrm{CH}_{3}\right.$ of $\left.\eta^{5}-\mathrm{C}_{5} \mathrm{Me}_{5}\right)$. 




Figure S57 IR spectrum of triblock copolymer 9.

$3432 \mathrm{~cm}^{-1}(\mathrm{NH}), 2904 \mathrm{~cm}^{-1}\left(\mathrm{CH}_{3}\right), 1770 \mathrm{~cm}^{-1}(\mathrm{C}=\mathrm{C}), 1700 \mathrm{~cm}^{-1}(\mathrm{NC}=\mathrm{O}), 1641 \mathrm{~cm}^{-1}(\mathrm{NHC}=\mathrm{O})$, $841 \mathrm{~cm}^{-1}\left(\mathrm{PF}_{6}\right)$.

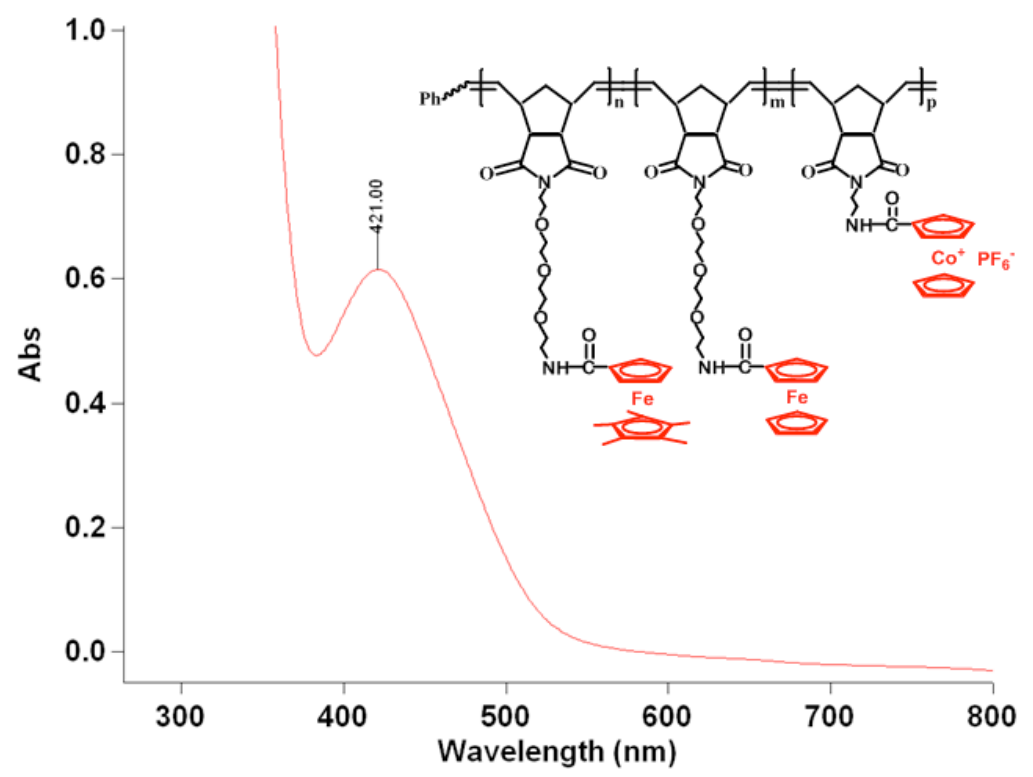

Figure $\mathbf{S 5 8} \mathrm{UV}$-Vis spectrum of triblock copolymer 9 in $\mathrm{CH}_{2} \mathrm{Cl}_{2}$. 



Figure S59 MALDI-TOF MS spectrum of triblock copolymer 9. The feed molar ratio of monomers 2,3 and 4 to 1 is $25: 25: 25: 1$. (A) is the region of 4999-25001 in the spectrum; and (B) is the enlarge region of the spectrum from 7830 to 10580 . The red dotted lines are corresponding to the difference between molecular peaks of a value of $620 \pm 1 \mathrm{Da}$ (MW of monomer 2). The blue dotted lines are corresponding to the difference between molecular peaks of a value of $550 \pm 1 \mathrm{Da}$ (MW of monomer 3). The pink dotted lines are corresponding to the difference between molecular peaks of a value of $566 \pm 1$ Da (MW of monomer 4). 




Figure $\mathbf{S 6 0}{ }^{1} \mathrm{H}$ NMR spectrum $(300 \mathrm{MHz})$ in $\mathrm{CD}_{2} \mathrm{Cl}_{2}$ of the precipitate from the ROMP reaction mixture for the synthesis of triblock copolymer $\mathbf{9}$ after the addition of monomer 4 with overnight (12 hrs) stirring. No peak is observed at $6.30 \mathrm{ppm}$ for the olefin protons of monomer 4 . The precipitate is purified triblock copolymer 9.

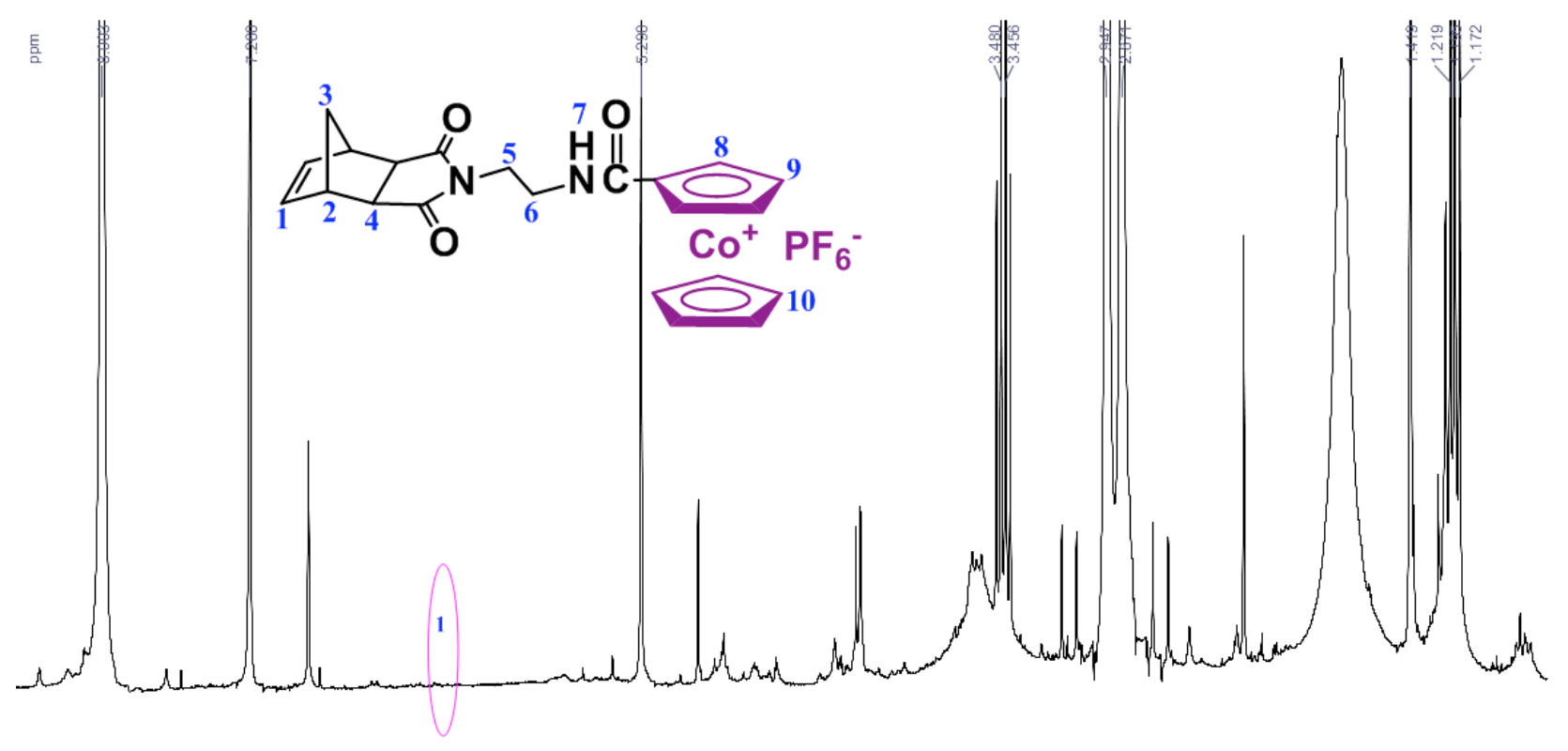

Figure S61 Enlarged ${ }^{1} \mathrm{H}$ NMR spectrum $(300 \mathrm{MHz})$ in $\mathrm{CDCl}_{3}$ of the products in washing liquors and filtrate from the ROMP reaction mixture for the synthesis of triblock copolymer 9 after the addition of monomer 4 with overnight (12 hrs) stirring. No peak is observed at $6.30 \mathrm{ppm}$ for the olefin protons of monomer $\mathbf{4}$. Namely no monomer $\mathbf{4}$ was left and the ROMP of $\mathbf{4}$ is complete. 
Calculation of the polymer degrees of triblock copolymer 9 by ${ }^{1} \mathrm{H}$ NMR end-group analysis and errors

Table S12 Polymer degree of the third CcX block using the ${ }^{1} \mathrm{H}$ NMR spectrum in DMSO- $d_{6}$ of copolymer 9. ${ }^{\mathrm{a}, \mathrm{b}}$

\begin{tabular}{|l|c|c|c|c|c|c|}
\hline $\begin{array}{l}\text { Proton } \\
\text { peak }\end{array}$ & $\begin{array}{c}\text { Amido in } \\
\text { the second } \\
\text { block }\end{array}$ & $\begin{array}{c}\text { Amido in } \\
\text { the third } \\
\text { block }\end{array}$ & $\begin{array}{c}\text { Sub. Cp in } \\
\text { the second } \\
\text { block }\end{array}$ & $\begin{array}{c}\text { Sub. Cp in } \\
\text { the third } \\
\text { block }\end{array}$ & $\begin{array}{c}\text { Sub. and } \\
\text { free Cp in } \\
\text { the second } \\
\text { block }\end{array}$ & $\begin{array}{c}\text { Sub. and } \\
\text { free Cp in } \\
\text { the third } \\
\text { block }\end{array}$ \\
\hline$\delta_{\text {ppm }}$ & 7.79 & 8.92 & 4.78 & 6.17 & $\begin{array}{c}4.31 \text { and } \\
4.14\end{array}$ & $\begin{array}{c}5.90 \text { and } \\
5.84\end{array}$ \\
\hline Integration & $\begin{array}{c}1.006-1.05 \\
5\end{array}$ & $\begin{array}{c}1.044-1.08 \\
7\end{array}$ & $\begin{array}{c}2.008-2.02 \\
3\end{array}$ & $\begin{array}{c}2.087-2.19 \\
9\end{array}$ & $\begin{array}{c}7.209-7.38 \\
6\end{array}$ & $\begin{array}{c}6.872-6.99 \\
4\end{array}$ \\
\hline $\mathrm{n}_{\mathrm{p} 2 \mathrm{a}}$ & - & $24-28^{\mathrm{c}}$ & - & $25-28^{\mathrm{d}}$ & - & $22-25^{\mathrm{e}}$ \\
\hline $\mathrm{n}_{\mathrm{p} 2 \mathrm{~b}}{ }^{\mathrm{f}}$ & \multicolumn{7}{|c|}{$25 \pm 3$} & \\
\hline
\end{tabular}

${ }^{a}$ Figure S53 is used for the calculation of the polymer degree of the second block. ${ }^{b}$ The average polymer degree of $25 \pm 1$ for the second Fc block is used for the calculation of polymer degree of the third CcX block. ${ }^{\mathrm{c}}$ Calculated by comparing the amido proton integrations in the second and third blocks. ${ }^{\mathrm{d}}$ Calculated by comparing the substituted $\mathrm{Cp}$ proton integrations in the second and third blocks. ${ }^{\mathrm{e}}$ Calculated by comparing the substituted and free $\mathrm{Cp}$ proton integrations in the second and third blocks. ${ }^{\mathrm{f}}$ Average polymer degree for the third block according to the $\mathrm{n}_{\mathrm{p} 2 \mathrm{a}}$ values.

As shown in Table S12, the polymer degree is $25 \pm 3$ for the third CcX block. The higher error results from the following two sides. (1) The above obtained polymer degree of $25 \pm 1$ for the second Fc block is used for the calculation of the polymer degree for the third CcX block, which can results in a larger error than for the first and second block. (2) This analysis is carried out by comparing the integrations of characteristic amido, substituted and free $\mathrm{Cp}$ peaks in the second $\mathrm{Fc}$ block and the third CcX block. For the second block, these peaks are located at 7.79, 4.78, 4.31 and $4.14 \mathrm{ppm}$; for the third block, the corresponding peaks are found at 8.92, 6.17, 5.90 and 5.84 ppm, respectively, and the calculated polymerization degrees are 24-28, 25-28 and 22-25, respectively. So, the average polymerization degree is $25 \pm 3$ for the third CcX block.

Table S13 Redox potentials, chemical $\left(i_{c} / i_{a}\right)$ and electrochemical $\left(E_{\mathrm{pa}}-E_{\mathrm{pc}}=\Delta E\right)$ reversibility data for triblock copolymer $\mathbf{9}$.

\begin{tabular}{|l|l|l|l|}
\hline Redox centers & $E_{1 / 2}(\mathrm{~V})$ & $(\Delta E)(\mathrm{V})$ & $i_{c} / i_{a}$ \\
\hline $\mathrm{Fc}$ & 0.670 & 0.050 & 1.23 \\
\hline $\mathrm{Fc}$ & 0.380 & 0.020 & 1.0 \\
\hline $\mathrm{CcX}\left(\mathrm{Co}^{\mathrm{III} / \mathrm{II}}\right)$ & -0.700 & 0.050 & 1.29 \\
\hline $\mathrm{CcX}\left(\mathrm{Co}^{\mathrm{II} / \mathrm{I}}\right)$ & -1.625 & 0.120 & 1.40 \\
\hline
\end{tabular}




\section{Calculation of polymerization degrees $\left(n_{\mathrm{p} 3}\right)$ for triblock copolymer 9 by Bard-Anson's method}

The following modified Bard-Anson's empirical electrochemical equation ${ }^{\mathrm{S} 7}$ was used:

$$
n_{p 3}=\left(\frac{i_{d p} n_{m}}{i_{d m} n_{p}}\right)\left(\frac{M_{p}}{M_{m}}\right)^{0.275}
$$

$\left(i_{\mathrm{dp}}\right.$ : intensity of polymer; $n_{\mathrm{p}}$ : mole of polymer; $i_{\mathrm{dm}}$ : intensity of monomer; $n_{\mathrm{m}}$ : mole of monomer; $\mathrm{M}_{\mathrm{p}}$ : molecular weight of polymer; $\mathrm{M}_{\mathrm{m}}$ : molecular weight of monomer).

$\left[\mathrm{FeCp}_{2}\right]$ was used as the monomer reference. The results of calculated polymerization degrees $\left(n_{\mathrm{p} 3}\right)$ of $\mathrm{Fc}^{*}, \mathrm{CcX}$ and $\mathrm{Fc}$ blocks for triblock copolymer 9 are listed in Table S14.

Table S14 Polymerization degree $\left(n_{\mathrm{p} 3}\right)$ of triblock copolymer 9 calculated by the Bard-Anson's equation

\begin{tabular}{|c|c|c|c|}
\hline$\left[\mathrm{M}_{2}\right]:\left[\mathrm{M}_{3}\right]:\left[\mathrm{M}_{4}\right]:[\mathrm{C}]^{\mathrm{a}}$ & \multicolumn{3}{|c|}{$25: 25: 25: 1$} \\
\hline $\mathrm{M}_{\mathrm{m}}^{\mathrm{b}}$ & \multicolumn{3}{|c|}{326.3} \\
\hline $\mathrm{M}_{\mathrm{p}}^{\mathrm{c}}$ & \multicolumn{3}{|c|}{43504} \\
\hline$n_{\mathrm{m}}{ }^{\mathrm{d}}(\mathrm{mmol})$ & \multicolumn{3}{|c|}{$1.22 \times 10^{-3}$} \\
\hline$n_{\mathrm{p}}{ }^{\mathrm{e}}(\mathrm{mmol})$ & \multicolumn{3}{|c|}{$1.84 \times 10^{-4}$} \\
\hline$i_{\mathrm{dm}}(\mathrm{cm})$ & \multicolumn{3}{|c|}{1.4} \\
\hline Redox center & $\mathrm{Fc}^{*}$ & $\mathrm{Fc}$ & $\mathrm{CcX}$ \\
\hline$i_{\mathrm{dp}}(\mathrm{cm})$ & 1.6 & 1.8 & 0.9 \\
\hline$n_{\mathrm{p} 3}{ }^{\mathrm{f}}$ & $29 \pm 3$ & $32 \pm 3$ & $16 \pm 2$ \\
\hline
\end{tabular}

${ }^{\mathrm{a}}\left[\mathrm{M}_{2}\right]:\left[\mathrm{M}_{3}\right]:\left[\mathrm{M}_{4}\right]:[\mathrm{C}]$ : feed molar ratio of monomers 2, 3 and 4 to $\mathbf{1} .{ }^{\mathrm{b}}$ Molecular weight of [FeCp* ${ }_{2}$ ]. ${ }^{\mathrm{c}}$ Molecular weight of the triblock copolymer 9 calculated by monomer conversion determined by ${ }^{1} \mathrm{H}$ NMR. ${ }^{\mathrm{d}} n_{\mathrm{m}}$ : mole of $\left[\mathrm{FeCp}_{2}{ }_{2}\right]$ added in the DMF solution of the triblock copolymer 9. ${ }^{\mathrm{e}} n_{\mathrm{p}}$ : mole of the triblock copolymer 9 in DMF. ${ }^{\mathrm{f}} n_{\mathrm{p} 3}$ : polymerization degree determined by the Bard-Anson's method.

\section{References}

s1. Love, J. A.; Morgan, J. P.; Trnka, T. M.; Grubbs, R. H. A practical and highly active ruthenium-based catalyst that effects the cross metathesis of acrylonitrile. Angew. Chem., Int. Ed., 2002, 41, 4035-4037.

s2. Gu, H.; Rapakousiou, A.; Castel, P.; Guidolin, N.; Pinaud, N.; Ruiz, J.; Astruc, D. Living Ring-Opening Metathesis Polymerization Synthesis and Redox-Sensing Properties of Norbornene Polymers and Copolymers Containing Ferrocenyl and Tetraethylene Glycol Groups. Organometallics, 2014, 33, 4323-4335.

s3. Gu, H.; Ciganda, R.; Castel, P.; Vax, A.; Gregurec, D.; Irigoyen, J.; Moya, S.; Salmon, L.; Zhao, P.; Ruiz, J.; Hernández, R.; Astruc, D. Redox-Robust Pentamethylferrocene Polymers and Supramolecular Polymers, and Controlled Self-Assembly of Pentamethylferricenium Polymer-Embedded Ag, Agl, and Au Nanoparticles. Chem. Eur. J., 2015, 21, 18177-18186. 
s4. Sheats, J. E.; Rausch, M. D. Synthesis and Properties of Cobalticinium Salts. I. Synthesis of Monosubstituted Cobalticinium Salts. J. Org. Chem. 1970, 35, 3245-3249.

s5. Schaefer, M.; Hanik, N.; Kilbinger, A. F. M. ROMP Copolymers for Orthogonal Click Functionalizations. Macromolecules 2012, 45, 6807-6818.

s6. Ciganda, R.; Gu, H.; Castel, P.; Zhao, P.; Ruiz, J.; Hernández, R.; Astruc, D. Living ROMP Synthesis and Redox Properties of Diblock Ferrocene/Cobalticenium Copolymers. Macromol. Rapid Commun. 2016, 37, 105-111.

s7. Flanagan, J. B.; Margel, S.; Bard, A. J.; Anson, F. C. Electron Transfer to and from Molecules Containing Multiple, Noninteracting Redox Centers. Electrochemical Oxidation of Poly(vinylferrocene). J. Am. Chem. Soc. 1978, 100, 4248-4253.

s8. Gu, H.; Ciganda, R.; Hernández, R.; Castel, P.; Vax, A.; Zhao, P.; Ruiz, J.; Astruc, D. Diblock Metallocopolymers Containing Various Iron Sandwich Complexes: Living ROMP Synthesis and Selective Reversible Oxidation. Polym. Chem. 2016, 7, 2358-2371. 